\title{
Potential of Nanomaterial Applications in Dietary Supplements and Foods for Special Medical Purposes
}

\author{
Josef Jampilek ${ }^{1,2, * \mathbb{C}}$, Jiri $\operatorname{Kos}^{3}$ and Katarina Kralova ${ }^{4}$ \\ 1 Division of Biologically Active Complexes and Molecular Magnets, Regional Centre of Advanced \\ Technologies and Materials, Faculty of Science, Palacky University, Slechtitelu 27, \\ 78371 Olomouc, Czech Republic \\ 2 Institute of Neuroimmunology, Slovak Academy of Sciences, Dubravska cesta 9, 84510 Bratislava, Slovakia \\ 3 Department of Pharmaceutical Chemistry, Faculty of Pharmacy, Comenius University, Odbojarov 10, \\ 83232 Bratislava, Slovakia; jirikos85@gmail.com \\ 4 Institute of Chemistry, Faculty of Natural Sciences, Comenius University, Ilkovicova 6, 84215 Bratislava, \\ Slovakia; kata.kralova@gmail.com \\ * Correspondence: josef.jampilek@gmail.com
}

Received: 8 January 2019; Accepted: 15 February 2019; Published: 19 February 2019

\begin{abstract}
Dietary supplements and foods for special medical purposes are special medical products classified according to the legal basis. They are regulated, for example, by the European Food Safety Authority and the U.S. Food and Drug Administration, as well as by various national regulations issued most frequently by the Ministry of Health and/or the Ministry of Agriculture of particular countries around the world. They constitute a concentrated source of vitamins, minerals, polyunsaturated fatty acids and antioxidants or other compounds with a nutritional or physiological effect contained in the food/feed, alone or in combination, intended for direct consumption in small measured amounts. As nanotechnology provides "a new dimension" accompanied with new or modified properties conferred to many current materials, it is widely used for the production of a new generation of drug formulations, and it is also used in the food industry and even in various types of nutritional supplements. These nanoformulations of supplements are being prepared especially with the purpose to improve bioavailability, protect active ingredients against degradation, or reduce side effects. This contribution comprehensively summarizes the current state of the research focused on nanoformulated human and veterinary dietary supplements, nutraceuticals, and functional foods for special medical purposes, their particular applications in various food products and drinks as well as the most important related guidelines, regulations and directives.
\end{abstract}

Keywords: bioactive agents; dietary supplements; foodstuffs; feed; nanoparticles; nanoformulations; nanoemulsions; nutraceuticals; encapsulation

\section{Introduction}

Fortification of edible products (e.g., food, food constituents, or supplements) with nutrients or non-nutrient bioactive components can help to balance the total nutrient profile of a diet and supplement nutrients lost in processing and thus to correct or prevent insufficient nutrient intake and associated deficiencies [1]. Compounds of natural origin, such as curcumin (CUR) occurring in turmeric, $\omega$-3-fatty acid in fish oil, vitamins from fruits, when encapsulated in an appropriate nanocarrier, will be released after consumption of the food in the target organ and utilized according to its nutritional property [2].

Basic types of preparations/materials influencing human health or condition can be classified as follows: (i) drug products, (ii) homeopathics, (iii) dietary supplements (DISs), (iv) medical devices, 
(v) cosmetics, and (vi) biocidal products. Dietary (food) supplements are products that look similar to medicines (can be sold in pharmacies) but are a special category of foods. They contain vitamins, minerals, amino acids, essential fatty acids, natural products, probiotics, etc., as active ingredients. The purpose of a DIS is to keep the human body functioning properly by delivering compounds that are needed by the human body but could not be received sufficiently from a regular diet. According to the manufacturers, DISs have beneficial effects on health conditions. They are manufactured in the form of pills, capsules, tablets, or liquids [3,4]. DISs are regulated by many guidelines, regulations and directives, for example, by the European Commission directives 2002/46/EC and 2006/37/EC, European regulations 1924/2006, 1137/2008, 1170/2009, 1161/2011, 119/2014, 2015/414, 2017/1203 [4], and by a number of documents published by the U.S. Food and Drug Administration (FDA) [5], to ensure the quality and safety of these products, to protect consumers against potential health risks from such products, and to ensure that they are not provided with misleading information. In addition, DISs are regulated by the European Food Safety Authority (EFSA), national legislation (e.g., on food) and regulations (e.g., requirements for food supplements and food enrichment), etc. For example, in the EU market, approx. 30 approved nutrition claims (meaning that specific requirements are to be met) can be found, and a product can be marketed as a DIS only if it meets the so-called health claims, which is any statement about a relationship between food and health. The European Commission approves various health claims, which have to be easily understood by consumers, based on scientific evidence. The EFSA is responsible for evaluating the scientific evidence supporting health claims, the types of which are as follows: (i) 'Function Health Claims' (relating to the growth, development and functions of the body, or referring to psychological and behavioral functions, or on slimming or weight-control), (ii) 'Risk Reduction Claims' (on reducing a risk factor in the development of a disease), and (iii) Health 'Claims referring to children's development' [6].

It is important to note that DISs are not food additives, which are special excipients added to foods for modifications of their flavor, color, or longevity [7].

Foods for special medical purposes (FSMPs), based on the definition of the EFSA, "are designed to feed patients who, because of a particular disease, disorder, or medical condition, have nutritional needs that cannot be met by consuming standard foodstuffs. Specifically, according to EU legislation, they are intended for patients with a limited, impaired, or disturbed capacity to take, digest, absorb, metabolize, or excrete ordinary foods, or certain nutrients or metabolites; or with other medically nutrient requirements whose dietary management cannot be achieved by modification of the normal diet alone" [8]. It means that FSMPs are foods that are intended for nourishment at: (i) certain groups of people whose digestive process or metabolism is impaired, (ii) certain groups of persons in a particular physiological state, which therefore, may have specific benefits from controlled consumption of certain substances in food, or (iii) healthy infants and young children. Therefore, the following categories of FSMPs can be distinguished: (i) food for infant and follow-on nourishment and nutrition of small children, (ii) food for cereal and other non-cereal food for infant and young children, (iii) low-energy foods designed to reduce body weight, (iv) food without phenylalanine, (v) gluten-free foods, (vi) foods for people with disorders of carbohydrate metabolism (diabetics), (vii) low lactose or lactose-free foods, (viii) foods with low protein content, (ix) foods intended for athletes and for persons with increased physical performance. FSMPs are advised to be used only under medical supervision and have to be provided with labels with information about their intended use. The European Commission also issued several documents for the regulation of FSMPs, e.g., Commission Directive 1999/21/EC, Commission Regulations No. 953/2009, 609/2013, 2016/128 [9], and so-called "medical foods" are regulated also by FDA [10].

A functional food or functional ingredient is any food or food component providing health benefits beyond basic nutrition, and natural bioactive compounds as functional ingredients showing beneficial effects for health become increasingly popular in the diet [11]. Therefore, functional foods are similar to traditional conventional foods but have more advantageous properties in relation to healthy physical condition. Nutraceuticals are based on both food and herbal or other natural products 
and are used in the form of pharmaceutical formulations, i.e., tablets, capsules, drops, or liquids, and have physiological benefits. The main focus of all these products is to improve health and reduce the risk of disease. In contrast to drugs, in all these cases, the active substance or a mixture of active compounds is present in low concentration [12].

Nanotechnology is a rapidly growing field that ensures the development of materials with new dimensions, novel properties, and a wider range of applications. U.S. National Nanotechnology Initiative defines nanoparticles (NPs) in the range of 1-100 nm [13]. According to the Recommendation on the definition of a nanomaterial adopted by the European Commission, the term "nanomaterial" means "a natural, incidental or manufactured material containing particles, in an unbound state or as an aggregate or as an agglomerate and where, for $50 \%$ or more of the particles in the number size distribution, one or more external dimensions is in the size range 1-100 nm. In specific cases and where warranted by concerns for the environment, health, safety or competitiveness the number size distribution threshold of 50\% may be replaced by a threshold between 1 and 50\%" [14]. However, in pharmacy, particles of 10-500 nm have been used, rarely up to $700 \mathrm{~nm}$. From the aspect of passage through vessels, the inside diameter of which is in the range from $25 \mathrm{~mm}$ (aorta) to $5 \mu \mathrm{m}$ (capillaries), the ideal size of NPs should be $<300 \mathrm{~nm}$ to ensure efficient transport for targeted distribution of drugs [15-20].

NPs can be prepared from both inorganic and organic materials [21-23], and currently, especially encapsulation to various biodegradable nature-based biopolymers is more and more frequently used $[19,20,24,25]$. NPs can be generated by either top-down methods (dispergation, fluidization, homogenization processes, or emulsifying technologies) or bottom-up methods (precipitation/condensation processes, evaporation techniques, various controlled sol-gel syntheses) [21,26]. NPs produced using mechanical approaches are usually, in the range 100-1000 nm; to produce NPs of size 10-100 nm, chemical and bottom-up methods are used [21,27]. "Green" synthesis of NPs or innovative biotechnological approaches related to the synthesis of NPs are summarized by Singh and Shukla et al. [22,23].

The physical, chemical, and biological properties of nanoscale materials are significantly, different from those of bulk materials and single atoms or molecules; therefore, different properties of active pharmaceutical ingredients have been modified in such a way [14,28-33]. In biomedical branches, NPs can be used for nanodiagnostics, as nanomaterials for tissue engineering, as drug carriers for specific delivery/targeted biodistribution or controlled release, and as agents/drugs for prevention/treatment of diseases. Therefore, application of nanotechnology can be considered as an excellent tool for modification of parameters of bioactive agents. Modification of properties using nanosystems /nanoformulations helps to enhance the bioavailability of active substances and change the route of administration when needed. Therefore, smaller amounts of substances can be used, which allows decreasing dose-dependent toxicity and various side effects. In addition, many formulations also protect bioactive molecules from degradation [19,20,24,25,28,29,31,34-42]. The enhancement of bioavailability could be achieved by the improved solubility of bioactive compounds under gastrointestinal (GI) conditions, their protection from the chemical conditions in the GI tract, and controlled release within the GI tract, or by an improved transfer through the intestinal wall, and the particle size, surface properties, and physical state of the nanomaterials used in food supplements are crucial characteristics affecting their final nutritional value [43]. Recent findings and advancements related to lipid nanoscale cargos for the protection and delivery of food bioactive ingredients and nutraceuticals were overviewed by Akhavan et al. [44]. Nanoemulsion (NE) compositions, types of active ingredients, applications in different types of food systems, toxicological and safety aspects, and future directions were summarized by Kumar and Sarkar [45]. For encapsulating drugs/nutraceuticals and fortification of food products, especially beverages with water insoluble nutraceuticals, nanostructured lipid carriers (NLCs) could be successfully applied [46]. Micro- and nano bio-based delivery systems (DESs) for food applications were discussed also by Simoes et al. [47]. 
The above-mentioned nanoformulations can be found in many drug classes, and so it is not surprising that supplements and FSMPs have also started being formulated in the nanoscale, especially with the aim to improve bioavailability, protect active ingredients against degradation, or reduce side effects. Therefore, this contribution summarizes the current state of the research focused on nanoformulated human and veterinary DISs and FSMPs.

\section{Types of Formulations and Used Materials}

Nutraceuticals' functionality in food products can be stabilized and enhanced using bio-based nanoscaled DESs that help to improve their bioavailability and protect valuable nutraceuticals at food processing or digestion, see Figure 1, where individual most frequently applied nanoformulations are mentioned. Selected nanoformulations are discussed below in the following subchapters. Advances in nutraceutical DESs with focus on the formulation design for the enhancement of nutraceuticals' bioavailability with the purpose to ensure effective preservation or maximization of their bioactivity and safety inside the human body were summarized by Goncalves et al. [48]. A review of recent research developments related to nanocarrier-based delivery of nutraceuticals for cancer prevention and treatment was presented by Arora and Jaglan [49]. Recent findings related to advances made in the nanoencapsulation of lipophilic and hydrophilic vitamins, safety issues, and health risks regarding the consumption of these products, which would result in widespread utilization of nanoencapsulated vitamins in the food and beverage products in the future, were summarized by Katouzian and Jafari [50]. The intelligent DESs for bioactive compounds in foods designed to improve their low solubility, poor stability, and low permeability in the GI tract and improving their oral bioavailability were discussed by Chai et al. [51] from the aspect of physicochemical and physiological conditions, absorption mechanisms, obstacles, and responsive strategies.

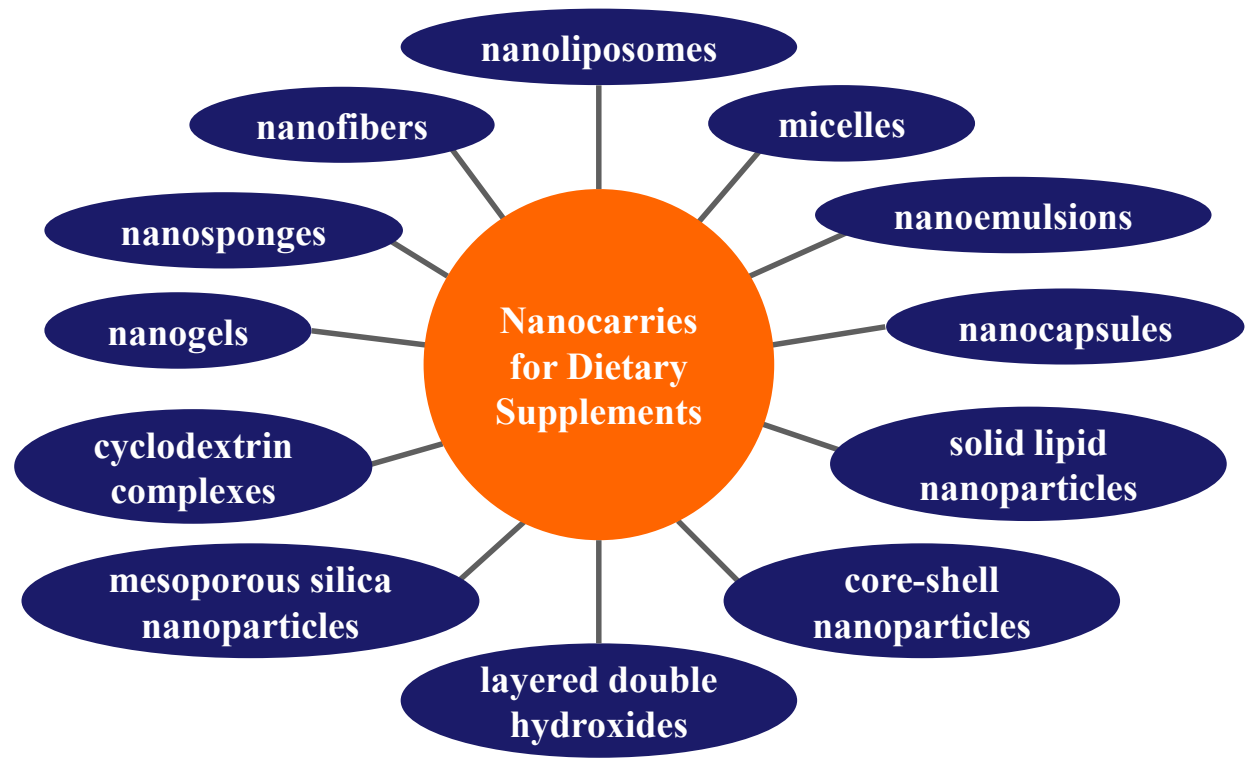

Figure 1. Most frequently used nanoformulation types of dietary supplements and foods for special medical purposes.

Gleeson et al. [52] looked into the potential of certain delivery strategies for the improvement of the oral bioavailability of different types of nutraceuticals, such as fatty acids, bioactive peptides, micronutrients, and phytochemicals, and emphasized that nutraceutical and pharmaceutical industries could leverage approaches to oral delivery formulations, which would result in synergies for nutraceutical and pharmaceutical molecules. For example, microfluidization could be considered as an efficient emulsification technique resulting in fish oil encapsulated powder producing emulsions at the nanoscale range $\left(d_{43}\right.$ of $\left.210-280 \mathrm{~nm}\right)$ with the lowest unencapsulated oil at the surface of 
particles [53]. At investigating the effect of excipient emulsions with different surface-weighted mean droplet diameters $d_{32}=0.15 \mu \mathrm{m}$ (small), $0.40 \mu \mathrm{m}$ (medium), and $22.3 \mu \mathrm{m}$ (large) on the bioaccessibility of carotenoids from tomatoes using a simulated GI tract, it was found that the bioaccessibility of carotenoids decreased with an increase of initial droplet size, which could be attributed to more efficient extraction of carotenoids from tomato tissues by smaller droplets that were digested faster. This caused faster mixed micelle formation and, consequently, enhanced solubilization of carotenoids in intestinal fluids. Moreover, when tomatoes were boiled with emulsions, the bioaccessibility of carotenoids was higher than when they were boiled alone and subsequently added to emulsions [54]. Electrospinning and electrospraying technologies constitute useful and modern techniques used for the encapsulation and controlled release of bioactive compounds, including drugs and health-promoting agents. Both electrospinning, mostly used for fibres, and electrospraying, mostly used for particles, are voltage-driven fabrication technologies enabling tight control of fibres and particles in the micro-, submicro- and nanoscale dimensions suitable for a wide range (polymers, proteins, inorganic) of materials. Both processes are able to replace traditional techniques, e.g., spray-drying or lyophilisation, as they propose several benefits such as (i) production of dry products in a single step, (ii) room temperature operation (suitable for labile components, e.g., antioxidants, omega-3 oils, living cells, etc.), (iii) enabling to produce single-phase or multi-component fibres and particles, and (iv) high effectivity of encapsulation [53,55-60], as mentioned below.

\subsection{Liposomes and Nanoscale Emulsions}

Nanoliposomes, or nanometric bilayer phospholipid vesicles, have a very promising potential for the nutraceutical industry, because they can encapsulate simultaneously lipophilic and hydrophilic materials, ensuring a synergistic effect, and can protect sensitive bioactive compounds, enhance their bioavailability, ensure sustained-release, and improve storage stability. The unique properties of nanoliposomes predestine them to be used in DISs for effective disease prevention and health promotion [61].

Nanophytosome is one of the newest lipid-based nanocarriers enabling the delivery of botanical based nutraceuticals, which could be potentially used in food products for designing novel functional foods and beverages [62]. Phytosomes-phosphatidylcholine (PC)—rutin complexes prepared by the encapsulation of rutin with PC using rutin:PC molar ratio 1:3 were found to provide the highest physical and chemical stability (during 30 days of storage) with fine particle sizes $(<100 \mathrm{~nm})$ and the encapsulation efficiency (EE) of $99 \%$, and due to the ability of masking undesirable features of rutin, they may be applied in fortification of food products with water insoluble nutraceuticals [63].

At the preparation of liposomes starting from multilamellar large vesicles with a diameter range 2.9-5.7 $\mu \mathrm{m}$ using an ultrasound-assisted approach based on the thin-film hydration method, unilamellar vesicles with diameter sizes ranging from $40 \mathrm{~nm}$ to $51 \mathrm{~nm}$ were achieved, showing the EE of $56 \%$ for cobalamin, $76 \%$ for $\alpha$-tocopherol, and $57 \%$ for ergocalciferol. The nanovesicles and their content were kept intact for $>10$ days when incubated at simulated conditions of extracellular environment thanks to the used lipid composition [64]. The investigation of the encapsulation and preservation of quercetin (Q) with cyclodextrins (CDs), conventional liposomes composed of three different types of phospholipids (unsaturated egg Lipoid E80, unsaturated soybean Lipoid S100, and saturated soybean Phospholipon 90H), and drug-in-CD-in-liposomes showed that the application of Lipoid E80-liposomes resulted in a better protection of $Q$ against $U V$ irradiation, and its photostability was additionally improved when encapsulated in drug-in-CD-in-liposomes (sulfobutylether $\beta-C D / Q$ inclusion complex in Lipoid E80 liposomes) [65].

Compared to CUR liposomes, the Pluronic ${ }^{\circledR}$ modified CUR liposomes showed a slower release rate and lower cumulative release percentage for CUR, enhanced $\mathrm{pH}$ stability and thermal stability, and pronouncedly improved absorption in simulated GI tract in vitro, suggesting that both types 
of liposomes could be used as carriers of CUR in nutraceuticals and functional foods. The best bioaccessibility was observed for CUR liposomes modified with Pluronic ${ }^{\circledR}$ F-127 [66].

Stimuli-sensitive (smart) nano DESs for nutraceuticals of both a nutritional and pharmaceutical value are of great importance for the formulation of novel functional foods. Because the best effect on the human health was observed when the weight ratio of $\omega-6 / \omega-3$ polyunsaturated fatty acids (PUFAs) is in the range between 1:1 and 5:1, Semenova et al. [67] focused their attention on the molecular design of DESs on the basis of nanoscale complexes formed between a covalent conjugate (sodium caseinate (SCas) + maltodextrin; dextrose equivalent $=2$ ) and combinations of polyunsaturated lipids that are mutually complementary in the content of $\omega-6$ and $\omega-3$ PUFAs: $\alpha$-linolenic acid ( $\alpha$-LNA) $+\alpha$-linoleic acid ( $\alpha$-LLA); liposomes of soy PC $+\alpha$-LNA, and micelles of soy lyso-PC $+\alpha$-LNA. The researchers concluded that thanks to the EE of all these lipid combinations by the conjugate, lipids were highly protected against oxidation, and their high solubility in an aqueous medium was reached. Dey et al. [68] designed $\omega-3$ PUFA enriched biocompatible NE with sesame protein isolate (SPI) as a natural surfactant. NE with $0.5 \%(w / v)$ SPI and Tween 20 and Span 80 used in 1:1 ratio having the hydrodynamic droplet size of $89.68 \pm 2.38 \mathrm{~nm}$ effectively enhanced the shelf-life stability of NEs, and the fatty acid release from NE droplets was $\geq 90 \%$ during 120 min of simulated two-step in vitro digestion.

The short-chain triglyceride-based NE encapsulating vitamin E did not physically withstand temperatures exceeding $25^{\circ} \mathrm{C}$, while with long-chain triglyceride-based NEs, good vitamin E retention even at $40{ }^{\circ} \mathrm{C}$ was observed, and the retention was increased when the NEs were stored in the dark [69]. Vitamin D NEs with small droplet diameters $(d<200 \mathrm{~nm})$ fabricated by spontaneous emulsification using medium chain triglycerides (MCT) and Tween 80 at surfactant-to-oil ratio $\geq 1$ at high stirring speeds $(800 \mathrm{rpm})$ were found to be relatively stable at ambient temperatures and unstable at heating ( $\mathrm{T}>80^{\circ} \mathrm{C}$ ), but the application of a cosurfactant (sodium dodecyl sulfate) could improve their thermal stability [70]. The investigation of the effect of excipient NEs formulated from long or medium chain triglycerides (LCT or MCT) on $\beta$-carotene ( $\beta$-Car) bioaccessibility from commercial DISs (tablets or soft gels) studied using an in vitro GI tract model showed that the application of LCT NEs enhanced $\beta$-Car bioaccessibility from tablets and soft gels by $20 \%$ and $5 \%$, respectively, while the effect of MCTs was minor. This could be connected with the fact that large carotenoid molecules could be incorporated only into large mixed micelles formed by LCT digestion, and thus, excipient NEs could be applied to improve nutraceutical bioavailability from DISs [71]. NEs prepared using three LCT oils (flaxseed, olive and corn oil) increased the bioaccessibility of astaxanthin (AST) compared to the control due to the formation of mixed micelles that solubilized the hydrophobic carotenoids. The final amount of free fatty acids released affected lipid digestion and AST bioaccessibility, which decreased in the following order: olive oil > flaxseed oil > corn oil, and free fatty acids unsaturation and chain length affected lipid digestion and micelle formation [72]. Saxena et al. [73] increased the bioavailability of the model bioactive compound $\alpha$-tocopherol as a food supplement using edible (coconut) oil NEs. The prepared NEs were found stable and biocompatible, and the contribution of kinetic-controlled release was found to be approx. $70 \%$, while that of diffusion-controlled release was approx. $30 \%$, suggesting the potential of the use of edible oil NEs in food and beverages.

A saponin coated NE with mean droplet diameter $277 \mathrm{~nm}$ encapsulating vitamin $\mathrm{E}$ was found to be more stable to droplet coalescence at thermal processing $\left(30-90^{\circ} \mathrm{C}\right)$, long-term storage, and mechanical stress than a conventional emulsion with mean droplet diameter $1.285 \mu \mathrm{m}$. At application of both emulsion formulations to male Wistar rats, droplet flocculation and coalescence during in vivo digestion was observed, however, the higher in vivo oral bioavailability of vitamin $\mathrm{E}$ encapsulated in the NE was reflected in a 3-fold increase in the area under the curve (AUC) compared to the conventional emulsion [74]. The lowest particle diameters $\left(d_{32}\right)$ of vitamin E NEs fabricated using natural surfactants, quillaja saponin, and lecithin and high-pressure homogenization were $0.13 \mu \mathrm{m}$ for lecithin and $0.12 \mu \mathrm{m}$ for quillaja saponin at vitamin $\mathrm{E}$ to orange oil ratio 50:50\%. At $\mathrm{pH}$ 7, both systems were stable in the temperature range $3-90{ }^{\circ} \mathrm{C}$ but unstable at $\mathrm{pH} 2$ or in the presence of $\mathrm{NaCl}$ 
( $>100 \mathrm{mM} \mathrm{NaCl}$ for lecithin and $\geq 400 \mathrm{mM} \mathrm{NaCl}$ for quillaja saponin) [75]. The encapsulation of CUR in saponin-coated CUR NEs fabricated using a simple pH-driven loading method improved CUR solubility and bioavailability, and its in vitro bioaccessibility was approx. 3.3-fold higher compared to free CUR. In an in vivo study, oral administration of these NPs to Sprague Dawley rats resulted in approx. 8.9-fold higher in vivo bioavailability than that estimated with free CUR [76].

Zheng et al. [77] subjected CUR loaded oil-in-water $(\mathrm{O} / \mathrm{W})$ NEs prepared using the conventional oil-loading method, the heat-driven method, and the $\mathrm{pH}$-driven method and three commercial CUR supplements (Nature Made, Full Spectrum, and CurcuWin) to a simulated GI tract model consisting of mouth, stomach, and small intestine phases and found that the three tested NEs showed similar CUR bioaccessibility (74-79\%) with the highest absolute amount of CUR in the mixed micelle phase of the NE fabricated by the $\mathrm{pH}$-driven method. The concentration of CUR in mixed micelles decreased as follows: CurcuWin $\approx \mathrm{pH}$-driven method $>$ heat-driven method $>$ conventional method $>>$ full spectrum $>$ nature made, and CUR encapsulated in small lipid particles had an improved absorption in GI tract.

Cholecalciferol (vitamin $\mathrm{D}_{3}$ ) minitablets and an optimized bile salt/lipase alginate-glycerin film provided unique oral components for inclusion in a bioactive association platform (BAP) capsule designed to deliver the active nutraceutical ingredient from the formulation framework resulting in the enhanced in vitro and in vivo performance of cholecalciferol. The in vivo experiment showed that cholecalciferol bioavailability from the BAP was 3.2-fold greater than that of the conventional product, and improved and maintained serum levels of 25-hydroxyvitamin $\mathrm{D}_{3}$ were observed as well, suggesting that BAP could be considered as an ideal oral vehicle for enhanced delivery of cholecalciferol [78].

$\beta$-Car enriched $\mathrm{O} / \mathrm{W}$ emulsions, in which chlorogenic acid-lactoferrin-polydextrose conjugate was used as an emulsifier to stabilize lipid droplets, showed improved stability to droplet aggregation under simulated GI tract conditions, resulting in increased $\beta$-Car bioaccessibility, suggesting that the ternary conjugate-stabilized emulsions could be used as protectors and carriers of hydrophobic drugs, supplements, and nutraceuticals [79]. On the other hand, excipient NEs had much less effect on the bioaccessibility of phenolic compounds, probably due to their smaller and more polar molecules, which could be more easily solubilized in aqueous intestinal fluids [80].

Among NEs prepared using soy protein isolate $(132 \mathrm{~nm})$, whey protein concentrate $(190 \mathrm{~nm})$, maltodextrin $(266 \mathrm{~nm})$, and gum arabic $(468 \mathrm{~nm})$, the soy protein isolate NE showing the smallest droplet size provided the highest protection of vitamin D (85\%) at $4 \mathrm{wt} \%$ concentration, $\mathrm{pH} 7$, and $25^{\circ} \mathrm{C}$ [81].

\subsection{Lipid-Based Carriers}

Nanocapsules based on lipid formulations having larger surface area than microsized carriers can more effectively enhance solubility, bioavailability, and controlled release of nanoencapsulated phenolic compounds and could be successfully applied in functional foods [82]. For example, the physical stability of $\beta$-Car nanocapsules $(>300 \mathrm{~nm}$ ) showed only minor changes during storage, suggesting that they could be used in functional beverages and foods as well as nutraceutical products [83]. At the investigation of the impact of solid domain properties on the rate of compound release from NLCs using Monte Carlo simulations, it was found that the release of encapsulated bioactive compounds by solid impenetrable domains at the particle/solution interface is hindered only when the domain size is much smaller than the size of NPs, even if a considerable proportion of the interface is covered by these domains, with the rate of release depending also on the geometry of the solid domains [84]. The preparation and characterization of vitamin A palmitate-loaded NLCs as DESs for food products was reported by Kong et al. [85].

Solid lipid microparticles (MPs) loaded with $0.1 \%$ of vitamin $\mathrm{D}_{3}$ by spray chilling with mean diameter $83.0-98.6 \mu \mathrm{m}$ that were fabricated using vegetable fat as a carrier and beeswax $(1 \%$ of the formulation) showed increased vitamin stability at $25^{\circ} \mathrm{C}$, and $86.3 \%$ of vitamin were detected after 
65 days of storage compared to $60.8 \%$ estimated with non-immobilized vitamin at same conditions, suggesting the potential of using such formulation in foods [86].

Prolonged physical stability at room and refrigerated temperature conditions as well as an increase in the bioavailability of encapsulated CUR compared to that of CUR suspensions was shown by chitosan (CS) coated solid lipid NPs incorporating this nutraceutical after oral administration [87].

In a systematic review, Nunes et al. [88] focused on the use of solid lipid NPs as oral DESs of phenolic compounds that allow overcoming the pharmacokinetic limitations of these compounds and ameliorate their nutraceutical potential.

\subsection{Polysaccharide Matrices}

Polysaccharides that have various enzymatic susceptibilities to ensure specific degradation in the small or large intestine when used as a NP coating can efficiently retard the nonspecific release of encapsulated bioactive compounds until the coating is exposed to its intended environment of release, and such coated NPs can be potentially targeted to different GI tract organs and taken up by the enterocytes, providing improved oral bioavailability [89].

High amylose corn and potato starches nanocarriers with granular structure and particle sizes ranging from 32.04 to $99.2 \mathrm{~nm}$ were used to encapsulate vitamin $\mathrm{D}_{3}$, and their EE ranged from 22.34 to $94.8 \%$. By using ultrasonic treatment, an increase of the hydrocarbon chain length was observed resulting in van der Waals and $H$-bonds of vitamin $\mathrm{D}_{3}$ with the potato starch and greater thermal stability [90]. Low-molecular-weight octenyl succinic anhydride modified starches were reported to be suitable to form stable vitamin E nanocapsules for potential application in beverages [91].

Recent findings concerning the use of cellulosic nanomaterials for food and nutraceutical needs were summarized by Khan et al. [92]. The addition of cellulose nanocrystals and lecithin into alginate microbeads improved the viability of encapsulated probiotic (Lactobacillus rhamnosus ATCC 9595) during gastric passage and storage, and at 25 and $4{ }^{\circ} \mathrm{C}$ storage conditions, a decrease in the viability of L. rhamnosus by 1.23 and $1.08 \mathrm{log}$, respectively, was estimated, while at encapsulation of the probiotic with alginate microbeads, a 3.17 and 1.93 log reduction, respectively, was observed [93]. The oligo-hyalurosomes nanoscale DES based on oligo-hyaluronic acid-CUR polymer co-loaded with both CUR and resveratrol (RES) showing the average particle size of $134.5 \pm 5.1 \mathrm{~nm}$, spherical shape, and zeta potential of $-29.4 \pm 1.2 \mathrm{mV}$ at $\mathrm{pH} 7.4$ phosphate buffer conditions exhibited excellent stability and sustained release character and higher radical scavenging activity compared to the single formulations and liposomes suggesting that this system could be considered as a promising nanofood DES applicable in juice, yoghourt and nutritional supplements [94].

CS/tripolyphosphate-nanoliposomes core-shell nanocomplexes as vitamin E carriers showed vitamin E retention rate $>80 \%$ during the 30-day storage and $92 \%$ and $97 \%$ after heating at $65{ }^{\circ} \mathrm{C}$ for $30 \mathrm{~min}$ and at $80^{\circ} \mathrm{C}$ for $16 \mathrm{~s}$, respectively, and based on the enhanced stability of liposomes against temperature stress reflected in reduced particle aggregation, zeta potential inversion, and membrane fluidity, this formulation could be considered as appropriate for commercial use in the food industry [95]. CS hydrochloride/carboxymethyl CS nanocomplexes loaded with anthocyanins with particle size $178.1 \mathrm{~nm}$, zeta potential $+25.6 \mathrm{mV}$, and polydispersity index 0.315 showed a higher stability when placed at different conventional storage temperatures, various L-ascorbic acid concentrations, varying $\mathrm{pH}$, or white fluorescent light, suggesting that such nanocomplexes could be applied in food ingredients associated with stable anthocyanins in functional foods and nutraceutical applications [96].

In food-grade alginate/CS nanolaminates obtained by the layer-by-layer technique, in which folic acid (FA) was incorporated by post-diffusion, a higher stability of FA under ultraviolet light exposure compared to free FA was estimated, and the higher rate and concentration of FA released from nanolaminates at $\mathrm{pH} 7$ in comparison with that at $\mathrm{pH} 3$ suggested that nanolaminates containing hydrophilic active compounds can be used for food applications [97]. 
Insulin encapsulated in antacid-loaded calcium alginate microgels (diameter $280 \mu \mathrm{m}$ ) had higher biological activity in simulated gastric conditions than free insulin, and considerably increased Akt phosphorylation at Thr308 and Ser473 in L6 myotubes was observed [98].

Papagiannopoulos and Vlassi [99] reported preparation of multi-functional stimuli-responsive NPs for food and biomedical applications by combining electrostatic complexation between proteins and polysaccharides with following thermal protein denaturation for the production of chondroitin sulfate/bovine serum albumin NPs. The irreversible protein-protein contacts upon temperature treatment provide the complexes with properties of nanogels, and the surface charge of the prepared NPs reversed at $\mathrm{pH} 5.3$, while their size depended on the solution ionic strength and $\mathrm{pH}$. Protein-polysaccharide-surfactant ternary complex particles prepared by anti-solvent co-precipitation using zein, propylene glycol alginate, and either rhamnolipid or lecithin pronouncedly improved the photostability and bioaccessibility of CUR suggesting that they could be used to deliver hydrophobic nutraceuticals for applications in foods, supplements, and pharmaceuticals [100].

\subsection{Protein-Based Carriers}

The state of the art of protein-based nanoencapsulation approaches as well as protein modification approaches in order to extend their functionality in nanocarrier systems to achieve an improvement in encapsulation, retention, protection, and release of bioactive agents was summarized by Fathi et al. [101]. A review paper discussing the latest findings concerning the nanoscale phenomena of whey protein denaturation and aggregation, which could contribute to the design of protein nanostructures with new or improved properties for the incorporation of nutraceuticals in food matrices and their release was presented by Ramos et al. [102]. Using whey protein isolate as an encapsulating agent, Parthasarathi and Anandharamakrishnan [103] presented a spray freeze-drying based microencapsulation technique as a promising strategy to enhance the oral bioavailability of poorly water-soluble bioactive compounds like vitamin E.

Significant aggregation and sedimentation of zein NPs encapsulating lutein (ZLNPs) with hydrodynamic radius approx. $75 \mathrm{~nm}$ were observed at gastric digestion conditions, and the ZLNPs that were not fully digested by gastric enzymes adhered to lipid droplets; however, the aggregation was reduced and digestion was stimulated when salt (i.e., high ion concentration) was left out. On the other hand, thanks to the encapsulation of lutein into NPs, its digestive stability was increased [104].

The size of egg albumin (Alb)-FA nanocomplexes prepared by mixing egg Alb NPs with FA did not change after adjusting the $\mathrm{pH}$ from 3 to 4 , but showed considerable increase after adjusting $\mathrm{pH}$ to 5,6, or 7; however, the bioavailability of FA in the form of digested nanocomplexes for Lactobacillus rhamnosus was improved [105].

The degree of FA binding to $\beta$-lactoglobulin $(\beta$-Lglb) and type A gelatin carriers was affected by their $\mathrm{pH}$-dependent zeta-potential, which indicated the occurrence of ionic bonds, and the binding of FA reached $100 \%$ at $\mathrm{pH} 3$. At $\mathrm{pH} 3$, particle size considerably increased at increasing the molar FA/protein ratio; however, shifting back the $\mathrm{pH}$ to 7 totally reversed it, which means that these formulations could protect $\mathrm{FA}$ at $\mathrm{pH} 3$ prevailing in the stomach, but they are strongly favorable for its delivery to the duodenum ( $\mathrm{pH}$ 7) [106]. $\beta$-Lglb nanostructures were reported to be suitable carriers for riboflavin and its controlled release in an in vitro GI system: approx. $11 \%$ was released during their passage through the stomach, while $35 \%, 38 \%$, and $5 \%$ of the total riboflavin were released during their passage through duodenum, jejunum, and ileum, respectively. At food simulant conditions (yoghurt simulant, 3\% acetic acid), $\beta$-Lglb nanostructures were stable for more than 14 days and had protective impact on riboflavin activity, releasing it in a 7-day period [107].

Isolated 7S and 11S globulins (Glbs) obtained from defeated soy flour, which were complexed with FA and included in culture media, showed higher bacterial growth of Lactobacillus casei BL23. Therefore, Glbs-FA based nanocomplexes have potential to be used in nutraceutical, pharmaceutical, and food industries [108]. Lactobacillus casei BL23 produces microvesicles carrying proteins that have been connected with its probiotic effect, and, using a proteomic approach, Rubio et al. [109] identified 
proteins described as mediators of Lactobacillus' probiotic effects, namely p40, p75, and the product of LCABL_31160, which was annotated as an adhesion protein. The expression and subsequent encapsulation of proteins into microvesicles of bacteria generally considered as safe could be also used in applications of foods and nutraceuticals.

Negatively charged $(-41 \mathrm{mV})$ sophorolipid-coated CUR NPs with the particle size of $61 \mathrm{~nm}$ showing relatively high EE and loading capacity for CUR that was present in an amorphous state exhibited 2.7-3.6-fold higher bioavailability than free CUR crystals, which was connected primarily with their higher bioaccessibility [110].

Protein-lipid composite NPs having a three-layered structure (barley protein layer, $\alpha$-tocopherol layer, and phospholipid layer) and an inner aqueous compartment to load the hydrophilic nutraceutical vitamin $B_{12}$ exhibited controlled release behavior in simulated GI media, and in an in vivo experiment, the NPs loaded with vitamin $B_{12}$ increased serum vitamin $B_{12}$ levels in rats upon their oral administration and reduced the level of methylmalonic acid more efficiently than the free vitamin $B_{12}$ form without any toxicity of the formulation observed during 14 days. These NPs could be used for increasing vitamin $\mathrm{B}_{12}$ absorption upon oral administration [111].

The enhanced physicochemical stability and in vitro bioaccessibility of vitamin $\mathrm{D}_{3}$ in corn protein hydrolysate-based vitamin $\mathrm{D}_{3}$ nanocomplexes showing spherical structure with sizes 102-121 nm was reported by Lin et al. [112]. In vitamin D-potato protein co-assemblies, the nanocomplexation provided pronounced protection and reduced vitamin $\mathrm{D}$ losses during pasteurization and also under several different sets of storage conditions, suggesting that potato protein could be used as a protective carrier for hydrophobic nutraceuticals suitable for enrichment of clear beverages and other food or drink products with beneficial impact on human health [113].

After drying and reconstitution, vitamin D-loaded re-assembled casein micelles (r-CMs) were found to improve the in vitro bioavailability of vitamin D in a Caco-2 cell model and showed strong protective effect against its gastric degradation, providing 4-fold higher bioavailability compared to free vitamin D [114]. Ghayour et al. [115] encapsulated CUR and Q using a hierarchical approach (binding of ligand to SCas with subsequent re-assembling of micellar nanostructures or formation of casein NPs). $\mathrm{r}$-CMs had smaller mean particle size than casein NPs, and the entrapment efficiency of both ligands was $>90 \%$. An incorporated phenolic compound showed notably improved chemical stability during an accelerated shelf-life test. The aqueous solubility of CUR and $Q$ after loading in r-CMs was higher than that of free polyphenol molecules, and the viability of treated MCF-7 human breast cancer cells decreased as follows: free polyphenol molecules $>>$ non-digested polyphenol-loaded carriers $>$ digested polyphenol-loaded r-CMs. Based on the investigation of the stability and bioavailability of CUR in mixed SCas and pea protein isolate NEs, Yerramilli et al. [116] reported that pea proteins could be used to partially replace SCas as an emulsion stabilizer for the protection and delivery of oil-soluble bioactive compounds. Based on in vitro proteolysis, it was found that in low-fat yogurt supplemented with the spray- and freeze-dried casein micelles loaded with vitamin $\mathrm{D}_{2}, 90 \%$ of the vitamin remained active compared to $67 \%$ estimated with free vitamin [117].

FA-loaded casein NPs of $150 \mathrm{~nm}$ fabricated with the use of a coacervation process, stabilized with lysine or arginine, and finally dried by spray-drying were administered to laboratory animals p.o. at dose $1 \mathrm{mg} \mathrm{FA} / \mathrm{kg}$ and ensured considerably higher serum levels of the vitamin than an aqueous solution of FA administered to animals, and the release profile and oral bioavailability of FA were not affected by the treatment of casein NPs by high hydrostatic pressure [118].

\subsection{Inorganic Matrices}

Inorganic porous materials, such as various silica- or aluminosilicate-based materials/composites, clays, calcium carbonate, calcium phosphate, layered double hydroxides (LDHs), etc., have become good candidates for the delivery of a range of drugs, providing some advantages in formulation and engineering. They have suitable architecture, large surface area, and stability in biological fluids; thus, they are used for high loading capacity, controllable release, and improved targeting [119-121]. 
Comparison of four different capped $\mathrm{SiO}_{2}$ mesoporous particles (MSPs) (i.e., hollow silica shells, MCM-41, SBA-15 and UVM-7) showed that they were able to hinder the delivery of FA at low $\mathrm{pH}$ (to stomach) and deliver large amounts of the vitamin at neutral $\mathrm{pH}$ (to intestine); nevertheless, the usage of supports with large pore entrance ensured an initial fast release, while the mesoporous material MCM-41 demonstrated a sustained release over the time [122]. The amine-capped MSPs also hindered the release of FA in gastric fluids $(\mathrm{pH} 2)$ and progressively delivered it in the presence of a simulated intestinal juice ( $\mathrm{pH}$ 7.5) [123]. Similarly, the in vitro digestion procedure showed that mesoporous silica support loaded with FA and functionalized with amines inhibited the release of FA in acidic solution at $\mathrm{pH} 2$ (stomach) and enabled its controlled release in neutral $\mathrm{pH}$ (intestine), thereby modulating the bioaccessibility [124]. Ruiz-Rico et al. [125] investigated controlled FA delivery and stability in fruit juices to reduce potential for over-fortification risks by using dated MSPs and observed that the encapsulation of FA into MSPs resulted in considerably improved vitamin stability and contributed to controlled release after consumption by modifying FA bioaccessibility.

RES encapsulated in mesoporous silica (MCM-48) NPs with the particle size of $90 \mathrm{~nm}$ did not alter its bioactivity and, at lower concentration, i.e., $5 \mu \mathrm{g} / \mathrm{mL}$, exhibited higher anti-inflammatory activity compared to RES suspension or its solution [126]. Similar findings concerning the enhancement of the biological activity of RES by colloidal mesoporous silica NPs were reported also by Summerlin et al. [127]. Singh et al. [128] reviewed causes and consequences of micronutrient deficiencies and the bioavailability of nutrients, vitamins, minerals, and silica for food and outlined that the release of nutrients from silica in simulated intestinal fluid is better than in simulated gastric fluid.

Simple powders and tablets of inorganic-organic nanostructured hybrids prepared by intercalating FA in the MgAl-LDH and ZnAl-LDH exhibited enhanced FA release compared to crystalline FA, suggesting that such hybrids could be used to enhance the active ingredient dissolution at low $\mathrm{pH}$ values in effective nutraceutical products [129].

The analysis and speciation of selenium in nutritional supplements based on next-generation Se ingredients, i.e., Se forms with lower toxicity, higher bioavailability, and controlled release, such as selenium NPs (SeNPs) and selenized polysaccharides, was presented by Constantinescu-Aruxandei et al. [130].

\section{Antioxidants}

Reactive oxygen species (ROS) is a term used for oxygen containing free radicals (such as $\mathrm{O}_{2}{ }^{\bullet}, \mathrm{HO}^{\bullet}, \mathrm{HO}_{2}{ }^{\bullet}, \mathrm{RO}^{\bullet}, \mathrm{ROO}^{\bullet}$ ) or reactive oxygen-containing compounds (such as $\mathrm{H}_{2} \mathrm{O}_{2}, \mathrm{O}_{3},{ }^{1} \mathrm{O}_{2}$ ), depending on their reactivity and oxidizing ability. ROS participate in diverse chemical reactions (oxidative stress) resulting in the decomposition of biologically active compounds or biomolecules. Antioxidants that are able to protect other molecules from the damaging effects of such ROS can be used as excipients in formulations or as biologically active compounds preventing oxidative stress [131]. Bioactive compounds like polyphenols, flavonoids, and vitamins showing antioxidant properties are suitable to be used for the fortification of food products to enhance their functionality, and therefore, encapsulation systems for the delivery of such nutraceuticals are necessary to overcome their low stability and bioavailability [132]. The choice of the appropriate encapsulation method is essential, because the modification of bioactivity (increase, preservation, or decrease) is affected by interactions established between the functional groups of the encapsulated compound and the encapsulating nanomaterial [133].

\subsection{Nanoformulations with Antioxidant Capacity}

A significant property of nanoformulations is the possibility to co-encapsulate antioxidants together with an active ingredient and thus increase the stability and extend expiration. As antioxidant excipients, PUFAs, carotenoids, antioxidant plant extracts, CUR, and catechins can be used, and as formulations, nano/micro emulsions, NLCs, NPs/MPs, and liposomes can be applied.

The antioxidant capacity of $\alpha$-LNA loaded microemulsion was strongly enhanced after the introduction of carbon dots, which were distributed mainly at the oil-water interface, suggesting a 
"turn off" effect of the interface [134]. Benzylisothiocyanate nutraceutical encapsulated in a stable $\alpha$-tocopherol-based O/W NE stabilized with a nontoxic, biodegradable surfactant, sodium stearoyl lactate, showed better antioxidant activity than pure and CUR encapsulated NEs, however CUR entrapped in the NE was effectively protected from UV light-induced degradation [135].

AST-loaded NLCs with the Z-average size of $94 \mathrm{~nm}$ containing $\alpha$-tocopherol and EDTA as antioxidants that were stabilized using Tween 80 and lecithin and mixed with non-pasteurized $\mathrm{CO}_{2}$-free beer at the volume ratio of 3:97 showed improved stability at low storage temperature of $6{ }^{\circ} \mathrm{C}$ [136].

Anionic sphere-shaped core-shell NPs with zein-epigallocatechin gallate (EGCG) conjugates as the hydrophobic core and a biosurfactant (rhamnolipid) as a shell with average diameters $<200 \mathrm{~nm}$ co-loaded with CUR and RES protected these nutraceuticals from degradation, simultaneously preserving their antioxidant activity, and by mixing these NPs with lipid droplets, the bioaccessibility of both encapsulated compounds pronouncedly increased [137]. The incorporation of polysaccharides as a second polymer matrix can provide stability in zein NPs used as DESs for antioxidants in the prevention of chronic degenerative diseases [138].

Ethyl cellulose MPs with encapsulated hydroxytyrosol, a constituent of olive oil showing antioxidant properties, produced by double emulsion solvent evaporation (average particle size ranging from $156.6 \pm 6.9 \mu \mathrm{m}$ to $304.0 \pm 16.0 \mu \mathrm{m}$ ) demonstrated the effectiveness of their gastro-resistance and the antioxidant capacity preservation of $>50 \%$, indicating possible applications of this formulation in foods, drugs, and nutraceuticals [139]. Citrus reticulata Blanco cv. unshiu peel extract (CPE) flavonoids encapsulated by pectin NPs with particle size $271.5 \pm 5.3 \mathrm{~nm}$ released only $28.78 \%$ of flavonoids in simulated gastric fluid within $2 \mathrm{~h}$ compared to naked CPE and showed higher antioxidant activity than blank pectin NPs and free CPE [140]. The replacement of 30\% of pectin (low charge density) with alginate (high charge density) forming shell around zein NPs significantly improved the aggregation stability at pH 5-7 and high ionic strengths $(2.0 \mu \mathrm{M} \mathrm{NaCl})$, and CUR encapsulated in these core-shell NPs was characterized by higher antioxidant and radical scavenging activities than CUR dissolved in ethanol solutions [141].

The comparison of liposomes and CS coated liposomes co-loaded with vitamin C and FA with the mean particle size of $138 \mathrm{~nm}$ and $249 \mathrm{~nm}$, respectively, showed the higher EEs of both drugs as well as the higher antioxidant activity of CS coated liposome nanoformulation, suggesting that it could be applied as a promising DES in the food industry [142]. The deposition of CS and alginate layers on CUR NEs improved CUR antioxidant capacity during in vitro digestion and showed a better control of the rate and extent of lipid digestibility by decreasing free fatty acids release compared to uncoated NEs [143].

\subsection{Supplements with Antioxidant Effect}

Oxidative stress is able to generate an imbalance between the production and accumulation of ROS in cells and tissues and thus modify the ability of a biological system to detoxify these reactive products. ROS have several physiological roles (i.e., cell signaling), and they are normally generated as by-products of oxygen metabolism; despite this, environmental stressors (i.e., UV, ionizing radiations, pollutants, and heavy metals) and xenobiotics (i.e., antiblastic drugs) contribute significantly to ROS production, thus causing an imbalance that leads to cell and tissue damage (oxidative stress) [144,145]. At present, various oral (flavonoids, carotenoids, vitamin C, and synthetic) antioxidants, see Figure 2, are available on the market and are generally recommended to be used. However, these supplements should be used in accordance with recommendations of a conscious physician or health care professional to avoid their adverse effect-pro-oxidant activity depending on the specific set of conditions (their dosage, redox conditions, the presence of free transition metals in cellular milieu) [144-148] 


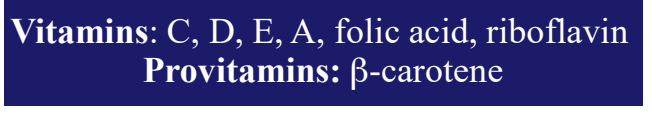
Provitamins: $\beta$-carotene
Probiotics: genera

Lactobacillus and Bifidobacterium

Most frequently used dietary supplements
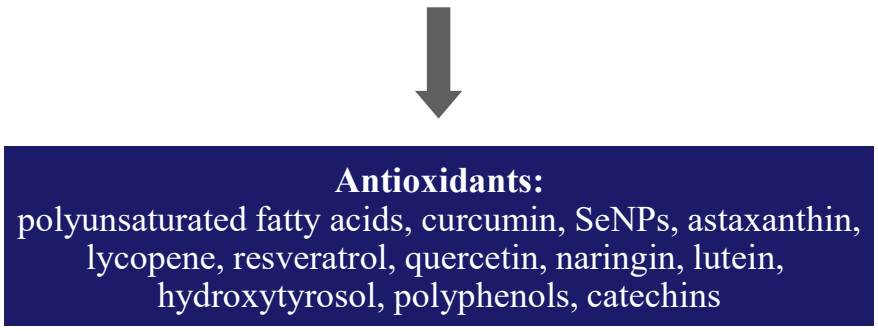

Figure 2. Most frequently used human dietary nanosupplements.

An improvement in aqueous solubility, antioxidant and other health-promoting properties, in vitro GI release profile, and protection against process and environment harsh conditions (e.g., light, oxygen, high temperatures, and humidity) of hydrophobic food bioactive compounds suitable as DISs could be achieved by nanoencapsulation using different nanoencapsulation DESs, including inclusion complexes of CDs, amylose, yeast cells, nanogels, NEs, nanofibers, nanosponges, nanoliposomes, and NPs made with lipids [149].

A CUR- $\beta$-CD inclusion complex and iron oxide NPs were co-encapsulated in liposomes, and these CUR-in- $\beta$-CD-in-nanomagnetoliposomes with mean particle size $67 \mathrm{~nm}$ and $71 \%$ CUR EE showed a radical scavenging property exceeding that of conventional CUR liposome and iron oxide NPs [150].

$\beta$-Car, the most important dietary source of provitamin $A$, is necessary for optimum human health. To increase its solubility and bioaccessibility, $0.1 \% \beta$-Car was dispersed in corn oil $(5$ or $10 \%)$ and homogenized with $2 \%$ SCas solution at $100 \mathrm{MPa}$, and the prepared NEs had particle sizes $<200 \mathrm{~nm}$. $\beta$-Car stability towards oxidation decreased with the decreasing droplet diameter, and the extent of lipolysis in an in vitro system was higher and linearly related to the inverse of the droplet diameter [151]. The updated understanding of emulsion-based DESs for $\beta$-Car was overviewed by Mao et al. [152] who focused their attention also on emulsion design enabling the delivery of $\beta$-Car in complex food systems and fulfilling its benefits in functional foods. Lipid droplets in $\beta$-Car enriched $\mathrm{O} / \mathrm{W}$ emulsions stabilized with surface-active chlorogenic acid-lactoferrin-polydextrose conjugate used as an emulsifier with the mean particle diameter of $<400 \mathrm{~nm}$ across the $\mathrm{pH}$ range 2-9 (except $\mathrm{pH}$ value around 6.0) exhibited better stability against droplet aggregation under simulated GI tract conditions (mouth, stomach, and small intestine) than other systems, which resulted in improved $\beta$-Car bioaccessibility, and such formulations could be potentially applied as protectors and carriers of hydrophobic drugs, supplements, and nutraceuticals [79]. Encapsulation of $\beta$-Car into solid lipid MPs of palm stearin stabilized with hydrolyzed soy protein isolate and containing $\alpha$-tocopherol with the mean diameter of about $1.2 \mu \mathrm{m}$ preserved approx. $75 \%$ of the encapsulated $\beta$-Car after $45 \mathrm{~d}$ of storage, and the formulation withstand treatments with higher temperatures $\left(>60^{\circ} \mathrm{C}\right)$, while showing low stability after different ionic strength stresses [153].

DESs of $Q$, one of the most well-known flavonoids that was included in human diet long ago due to health benefits associated with its antioxidant, anti-inflammatory, antiviral, and anticancer activities as well as $Q$ biological activities themselves, its chemical stability, metabolism, and positive impact on some cardiovascular diseases (CVD) (i.e., heart disease, hypertension, and high blood cholesterol) were overviewed by Wang et al. [154]. An extract of tartary buckwheat rich in flavonoids (TBFs) incorporated in spherical biocompatible lipid-polymer hybrid NPs of $61.25 \pm 1.83 \mathrm{~nm}$ showed higher antioxidant activity and significant suppression of the pro-inflammatory cytokine secretion 
in RAW 264.7 macrophage compared to free TBFs and exhibited immune-enhancing efficacy in immunosuppressed mice, suggesting that such nanosystem loaded with TBFs is suitable for nutraceutical applications [155]. Nanoliposomes incorporating olive leaf extract containing high levels of phenolic compounds and oleuropein, showing antioxidant and antimicrobial activities, with average particle size $25-158 \mathrm{~nm}$, negative charge, and EE 70.7-88.2\%, which were supplemented to yogurt, improved its antioxidant activity, and no significant changes in color and sensorial attributes were observed, suggesting that olive leaf phenolics can be entrapped in nanoliposomes and could increase the nutritional value of products like yogurt [156].

RES encapsulated in zein/pectin core-shell NPs with mean diameter approx. $235 \mathrm{~nm}$ and polydispersity index 0.24 showed improved in vitro antioxidant activity as well as lower $\mathrm{IC}_{50}$ values (by $32 \%$ ) related to antiproliferative activity tested using human hepatocarcinoma Bel-7402 cells compared to free RES, suggesting that such nanoformulation of RES could be used in functional foods and beverages as well as in DISs and pharmaceutical products [157]. The aqueous solubility of RES from $\alpha$-lactalbumin ( $\alpha$-Lalb)-RES nanocomplexes was 32-fold higher than that of free RES, and the nanocomplexes considerably improved the antioxidant chemical stability under storage, especially at $\mathrm{pH} 8.0$ and high temperature, and showed superb in vitro antioxidant activity compared to free RES, suggesting that $\alpha$-Lalb as a nanoscale carrier could effectively deliver lipophilic nutraceuticals in the functional food, biomedical, and pharmaceutical products [158]. The protection of light-sensitive AST, a carotenoid with the most potent antioxidant activity, from photodegradation achieved by its inclusion in different hierarchically assembled nano- and microstructures in order to produce model foods for humans and fishes decreased as follows: NEs > carrageenan-coated NEs > CS coated NEs, and CS beads provided higher protection to AST than alginate beads. These hierarchically assembled materials represent ideal platforms to create foods for humans and animal species, because their flexibility enables also the incorporation of other active molecules such as proteins, PUFAs, antibiotics, antiparasitics, etc. [159]. The average size $(94 \mathrm{~nm})$ of AST-loaded NLCs containing $\alpha$-tocopherol and ethylenediaminetetraacetic acid as antioxidants and stabilized with Tween 80 and lecithin increased at $\mathrm{pH} \leq 5$, high $\mathrm{NaCl}$ concentrations $(\geq 50 \mathrm{mM})$, and slightly at simulated gastric juice, which was connected mainly with decreasing zeta-potential, while increasing at treatment at $80 / 90{ }^{\circ} \mathrm{C}$. On the other hand, cryoprotectant glycerol prevented the aggregation of AST-NLCs during freeze-thawing. Therefore, this nanoformulation could be used as a DIS [160].

Nanoscale thymoquinone [161], which was found to improve the anticancer roles of doxorubicin by upregulation of P53 and downregulation of Bcl2 and potentiate paclitaxel's apoptosis in MCF-7 breast cancer cells, could protect also against diabetes, inflammation, central nervous system, and hepatotoxicity primarily by enhancing the antioxidant status of organs and could be considered as a promising nutraceutical for human health [162].

It should be noted that microencapsulation of riboflavin, a water-soluble vitamin acting as cofactor in various processes of oxidation-reduction in a cellular system, with galactomannan biopolymer and Pluronic ${ }^{\circledR}$ F127 resulted in its slower release in both acidic and basic media compared to free vitamin [163].

Digested kenaf (Hibiscus cannabinus L.) seed O/W NEs stabilized by a SCas, Tween 20, and $\beta$-CD complex demonstrated good lipid digestion, significant bioaccessibility of antioxidants (tocopherols and total phenolic contents), and lower phytosterol degradation rate compared to digested bulk oil, which indicates the possibility of their future application in food and nutraceutical industries [164].

\section{Other Functional Applications of Human Supplements}

This chapter is focused on all other applications of DISs and FSMPs except antioxidants, i.e., supplements affecting intestine, various nutraceuticals with beneficial effect against tumor cells or constituting nutritional support therapy in the treatment of cancer, supplements supporting mental and psychomotor development, supplements for prophylaxis of metabolic syndrome, supplements for osteoporosis management, and supplements against iron deficiency. 


\subsection{Supplements Affecting Intestine and Absorption}

It is indisputable that for proper functioning of the intestines, nutrient absorption and prevention of malnutrition, it is necessary to have a suitable composition of the "good" intestinal microflora. Different diseases and subsequent treatments may change the composition of the intestinal microflora, which may result in various, initially intestinal problems. These problems can be avoided by using different products. Prebiotics are compounds in food that induce the growth or the activity of beneficial microorganisms. Probiotics are live microorganisms (in general, bacteria of the genera Lactobacillus and Bifidobacterium) intended to provide health benefits when consumed, generally by improving or restoring the gut flora. Synbiotics refer to food ingredients or DISs combining probiotics and prebiotics in the form of synergism [165,166].

Probiotics, prebiotics, and synbiotics could suppress enteric pathogens, because they can compete with pathogenic microbiota for adhesion sites, inhibit the growth of pathogens, or stimulate, modulate, and regulate the immune response of the host by initiating the activation of specific genes in and outside the intestinal tract. Moreover, it was also shown that probiotics regulate fat storage and stimulate intestinal angiogenesis [167]. Probiotic encapsulation technology was developed rapidly in the past decade. Based on this technology, a wide range of microorganisms have been immobilized within semipermeable and biocompatible materials that modulate the delivery of cells [168].

Co-encapsulation of probiotic strains Staphylococcus succinus (MAbB4) and Enterococcus fecium (FIdM3) in alginate $(2 \mathrm{~g} / 100 \mathrm{~mL})$ resulted in a significant improvement $(P<0.05)$ in the survival of co-encapsulated cells when exposed to acidic ( $\mathrm{pH} 2.0-3.0)$ and bile $(0.3,0.6$ and $0.8 \mathrm{~g} / 100 \mathrm{~mL})$ conditions. Viability was maintained throughout the storage period and ranged from $8.1 \log \mathrm{cfu} / \mathrm{mL}$ (Colony Forming Unit) to $7.9 \log \mathrm{cfu} / \mathrm{mL}$ for about a period of 30 days at $4{ }^{\circ} \mathrm{C}[169]$.

Dietary factors such as prebiotics (e.g., inulin) play important roles in the growth of intestinal microbiota and may impact the intestinal health [170]. The encapsulation of the probiotic Pediococcus pentosaceus Li05 in alginate-gelatin microgels loaded with MgO NPs enhanced its viability by filling pores inside the microgels and thus, the ability of $\mathrm{O}_{2}$ and $\mathrm{H}^{+}$ions to access the probiotic could be inhibited due to the neutralization of $\mathrm{H}^{+}$ions in the gastric fluids by MgO NPs, thereby suppressing its acid-induced degradation. Such formulation could be considered as an appropriate DES for improving the efficacy of orally administered probiotics [171]. The effect of a prebiotic matrix consisting of inulin in concentrations $0 \%, 5 \%, 10 \%, 15 \%$ and $20 \%(w / v)$ in alginate beads on the viability of encapsulated probiotic strains Pediocucus acidilactici, Lactobacillus reuteri, and Lactobacillus salivarius was investigated by Atia et al., and the researchers found that the beads with $5 \% w / v$ inulin were the most effective in bacterial protection against bile-salts and acidity [172].

Probiotics are also affected by prebiotics apart from other things. Therefore, Peredo et al. [173] investigated the influence of natural prebiotics potato starch, Plantago psyllium, and inulin co-encapsulated with alginate on the viability of Lactobacillus casei Shirota and two strains of Lactobacillus plantarum Lp33 and Lp17. The results showed a higher encapsulation yield when P. psyllium (94\% for Lp17) and inulin (78\% in Lp33) were used; P. psyllium ensured a higher viability of the bacteria during storage at $4{ }^{\circ} \mathrm{C}$ and the best protection in GI conditions.

Recent findings related to the production of probiotics, prebiotics, and nutraceuticals using a nanotechnology approach with respect to the functional foods was presented by Mishra et al. [174].

\subsection{Anticancer Nutraceuticals}

Nutraceuticals, such as soya bean, garlic, ginger, green tea, propolis, honey, RES, Q, EGCG, etc., may have chemopreventive effects. They are able to induce the apoptosis of cancer cells. These special foods can be used for chemoprevention or as a supportive therapy at treatment of tumor by standard anticancer chemotherapeutics [175-180].

In a review paper, McClements and Xiao [181] focused their attention on some most important anticancer nutraceuticals found in foods, the main factors affecting their bioaccessibility, absorption, 
and transformation, and different types of DESs and excipient systems improving the overall bioavailability of anticancer nutraceuticals.

(-)-Epigallocatechin-3-gallate is the most abundant catechin and also the most effective cancer chemopreventive polyphenol in green tea. This EGCG pronouncedly inhibited $\beta$-Car degradation in both MCT and corn $\mathrm{O} / \mathrm{W}$ emulsions in a dose dependent manner and did not adversely affect lipid oxidation, while $\alpha$-Lalb was not able to protect $\beta$-Car in MCT emulsions; their combination had a similar effect as EGCG alone [182]. A comprehensive review related to findings concerning the encapsulation of EGCG by means of nanocarriers was presented by Granja et al. [183].

Biopolymer core-shell NPs consisting of hydrophobic protein (zein) as the core and a hydrophilic polysaccharide (pectin) as the shell fortified with CUR showing strong anticancer activity with the diameter of $250 \mathrm{~nm}$, which were converted into a powdered form resulting in good water dispersibility, were reported to be suitable for incorporating CUR into functional foods and beverages as DISs, and pharmaceuticals [184]. Bioavailable NEs loaded with nutraceuticals (CUR and fresh and dry tomato extracts rich in lycopene) with the hydrodynamic size of NEs approx. $100 \mathrm{~nm}$ applied in combination with doxorubicin enhanced cell viability in cardiomyoblasts (H9C2 cells) by $35-40 \%$ compared to that observed in cardiomyoblasts treated with doxorubicin alone, provided protection against oxidative stress, inhibited the release of IL-6, IL-8, IL-1, TNF- $\alpha$, and nitric oxide by approx. $35-40 \%$, and increased IL-10 production by $25-27 \%$ compared to cells without NE treatment. The best cardioprotective profile was showed by a lycopene-rich NE capable to effectively protect against doxorubicin-induced cardiotoxicity by reducing inflammation and lipid oxidative stress [185].

Both a cinnamon oil NE and a vitamin D encapsulated cinnamon oil NE with particle sizes 40.52 and $48.96 \mathrm{~nm}$, respectively, arrested the cell cycle progression in the $\mathrm{G}_{0} / \mathrm{G}_{1}$ phase, showed an increased expression of Bax, capase3, and caspase-9, and decreased the expression of BcL2 proteins along with a considerable increase of apoptotic cell population and loss of mitochondrial membrane potential. The NE with cinnamon oil as a carrier for a lipophilic nutraceutical like vitamin D showing potential anticancer activity in human alveolar carcinoma cells could be also used in the food industry [186].

A nanonutraceutical formulation of $\omega-3$ PUFAs (fish oil) could effectively inhibit the release of ROS and reactive nitrogen species from human neutrophils and murine macrophages, the production of the proinflammatory cytokines TNF- $\alpha$ and MCP1, and tumor-cell proliferation in FaDu head and neck squamous carcinoma and 4T1 breast cancer cells in in vitro cultures. The $\omega$-liposomes, in which docosahexaenoic acid (DHA) was formulated, could be used for intravenous delivery of fish oil fatty acids resulting in beneficial effects in the treatment of inflammatory disorders and cancer [187]. It is known that DHA ( $\omega-3$ PUFA), a component of fish oil, suppresses rat mammary carcinogenesis, reduces cell growth, and induces apoptosis in human breast cancer cell lines. An acid stable liposome formulation of DHA with the use of ether and phytanyl lipids similar in structure to those found in Archaea having the mean particle size of $137 \pm 12 \mathrm{~nm}$ and a slightly negative charge was resistant to oxidation and stable over the $\mathrm{pH}$ range of $1.0-7.4$ at $37^{\circ} \mathrm{C}$ for two hours. Cell viability in MCF-7 cells and apoptosis in both MCF-7 and MDA-MB-231 cells were reduced more effectively by this liposomal formulation than by free DHA, suggesting that it could be potentially used in breast cancer prevention [188].

The investigation of nanosized complexes prepared using high amylose corn starch and flax seed oil processed to powder of MPs by spray-drying and subsequently incorporated into bread formulation showed a considerable reduction of lipid oxidation in breads during baking due to the encapsulation as well as a decreased formation of carcinogen acrylamide, suggesting a beneficial effect of this nanoformulation on the final product quality and safety [189].

\subsection{Supplements Supporting Mental and Psychomotor Development}

Fermented soybean nanonutraceuticals administered to rats intoxicated with colchicine and showing impairment in learning and memory and decreased activity of acetylcholinesterase (AChE) caused an increase of AChE activity (42\%), a reduced activity of GSH (42\%), SOD (43\%), and catalase 
$(41 \%)$, and decreased lipid peroxidation (28\%) and protein carbonyl contents $(30 \%)$, which suggests a possible neuroprotective efficiency of the nanonutraceuticals, and in addition, a significant amyloid- $\beta$ and BACE-1 inhibition activity was demonstrated in an in silico study. The beneficial effect of the discussed nanonutraceuticals is associated with their strong antioxidant activity, and it could be assumed that they could also positively influence cognitive defects associated with Alzheimer's disease [190].

Encapsulation in bovine-milk exosomes could protect cargos against enzymatic and nonenzymatic degradation. RNAs encapsulated in exosomes could be delivered to circulating immune cells in humans, and some microRNAs and mRNAs in bovine-milk exosomes could regulate human gene expression and be translated into protein. Gene expression can be altered by low concentrations of dietary microRNAs through noncanonical pathways, such as the accumulation of exosomes in the immune cell microenvironment and microRNA binding to Toll-like receptors. In mice, the proliferation of intestinal cells was promoted by porcine-milk exosomes, suggesting that milk exosomes and their cargos could be used in human nutrition. Therefore, it was suggested that milk modified in this way could contribute to better mental, psychomotor, and functional development of infants [191].

Natural compounds that are commonly present in foods and beverages are regarded as promising molecules in a nutraceutical approach associated with life-long healthy diets. An increased attention is devoted to food molecules that are candidates to enter clinical trials as such or after targeted molecular engineering and could have a beneficial effect on amyloid neurodegenerative diseases. Natural phenols abundant in healthy food products, such as green tea, red berries, extra virgin olive oil, red wine, and spices, could be considered particularly promising [192]. Biodegradable poly(lactic-co-glycolic acid) NPs encapsulating ginsenoside Rg3 (an important constituent of ginseng, playing a significant role in memory and improving cognition) and thioflavin $\mathrm{T}$, which showed neuroprotective effects, were reported to be a theranostic material for the detection and treatment of Alzheimer's disease [193].

\subsection{Supplements for Metabolic Syndrome Prophylaxis}

Sodium alginates could be used for the management of GI tract disorders and the attenuation of components of the metabolic syndrome such as obesity, type 2 diabetes, hypertension, non-alcoholic fatty liver disease, and dyslipidemia. They could also protect cells during transplantation from immune responses of the host, and, in combination with antacid alginates, be applied in the treatment of gastric reflux disease. Moreover, alginates decrease food intake by inducing satiety, increase weight loss in patients on a calorie-restricted diet, and reduce both glucose and fatty acid uptake, and a decrease in blood pressure by alginates in rat models of hypertension was reported as well [194].

Using advanced proteomic and bioinformatic approaches, Kar et al. [195] characterized the protein components of six different protein sources (casein, partially delactosed whey powder, spray-dried porcine plasma, soybean meal, wheat gluten meal, and yellow meal worm) and predicted the bioactive properties of these protein sources after in silico digestion with monogastric proteolytic enzymes. The tested protein sources were potentially rich in bioactive peptides, in particular, angiotensin-converting enzyme inhibitors and peptides with antioxidant properties, and could be used as alternative sources of protein in animal feeds for monogastrics.

Temporal improvements in vitamin D status by vitamin D supplementation resulted in an increase in serum 25-hydroxyvitamin D concentrations and reduction of serum homocysteine concentrations suggesting that such treatment could reduce risk factors for CVD and may potentially contribute to the primary prevention of CVD [196]. Liposome-in-alginate beads were used to encapsulate the oyster hydrolysates showing antihypertensive effect to improve their bioavailability, protect them from degradation, and obtain sustained release; the release time of the oyster hydrolysate in the simulated GI fluid was up to $16 \mathrm{~h}$ [197]. Encapsulation of naringin, a flavonoid that occurs naturally in citrus fruits and possesses strong health benefits (recommended for the prevention of CVD and diabetes), in ternary NPs consisting of amylose, $\alpha$-LLA, and $\beta$-Lglb resulted in a gradual release of naringin from 
the ternary NP-naringin inclusion complex in simulated gastric and intestinal fluids, and ternary NPs effectively improved the bioavailability of bioflavonoid [198].

Mahmoud et al. [199] studied the impact of dietary camel whey protein administered as a supplement to streptozotocin (STZ)-induced diabetic pregnant mice on the efficiency of the immune system of the offspring and verified its protective role in decreasing the tendency of the offspring to develop diabetes and related complications. A comparison of prophylactic effects of $\alpha$-eleostearic acid rich nano and conventional bitter gourd seed oil emulsions in induced diabetic rats showed that the maximum efficiency in suppressing oxidative stress was achieved with a diet supplementation of $0.5 \%$ $(w / v)$ NE with bioactive lipid-conjugated $\alpha$-LNA, suggesting that such nanoformulation could be used as an appropriate nutraceutical against diabetes mellitus strongly attenuating an adverse impact of excessive ROS [200].

Although natural nanosized clinoptilolite and/or metformin did not affect pronouncedly the levels of serum glucose, minerals, and lipid profile in rats with high-fat-diet/STZ induced diabetes, the co-treatment of clinoptilolite with the drug notably increased high-density lipoprotein (HDL) cholesterol, while $\mathrm{Cu}$ and $\mathrm{Ca}$ levels increased only in the metformin group [201]. In STZ induced diabetic rats treated with nanosized clinoptilolite, blood glucose was found to decrease to near normal levels (12.4 vs. $27.5 \mathrm{mmol} / \mathrm{L}$ ), but no significant impact on oxidative stress markers was estimated [202]. Nanosized clinoptilolite injected to STZ induced diabetic rats caused a partial improvement in their weight status and lack of undesirable effects, although beneficial changes in lipid profile were not detected, which could be connected with short study duration [203].

CS NPs loaded with Stevia rebaudiana leaf extract caused a considerable decrease of the mean fasting blood glucose level of treated diabetic rats in comparison with the diabetic control group, and serum levels of different enzymes and some antioxidants, e.g., catalase, reduced glutathione (GSH), and superoxide dismutase (SOD), were closer to normal levels in the group treated with NPs than in the control group [204].

By adding Catathelasma ventricosum polysaccharides (CVPs) to the redox system of selenite and ascorbic acid, spherical CVPs-selenite NPs with particle size approx. $50 \mathrm{~nm}$ were prepared, and based on serum profiles and antioxidant enzyme levels, it could be concluded that CVPs-selenite NPs showed a notably higher antidiabetic activity $(p<0.05)$ than other SeNPs, selenocysteine, and $\mathrm{Na}_{2} \mathrm{SO}_{3}$ [205].

To control the release of the anti-hyperglycemic agent fisetin for nutraceutical and/or therapeutic applications, an oral controlled release system consisting of polymeric NPs (140-200 nm) based on poly-( $\varepsilon$-caprolactone) and poly(lactic-co-glycolic acid)-polyethylene glycol-COOH encapsulating fisetin was designed, which protected and preserved the release of the active compound in gastric simulated conditions, controlled the release in the intestinal medium, and showed an improved $\alpha$-glucosidase inhibiting activity of fisetin compared to that of the commercial formulation acarbose [206].

NLCs loaded with betasitosterol, a phytosterol showing beneficial effects on reducing total cholesterol and low-density lipoprotein (LDL), with particle size $165 \mathrm{~nm}$, zeta potential $-13.5 \mathrm{mV}$, and EE 99.96\%, which were incorporated in butter, showed good stability during three months' storage period and increased the antioxidant property of enriched butter during the storage period, suggesting the suitability of such nanoformulation for functional dairy products [207]. Multilayer CS-alginate-CUR NEs could be important for functional food development for combating obesity, because they increase satiety by retarding lipid digestion [143].

\subsection{Supplements for Osteoporosis Management}

Many supplements in pharmacies serve to prevent or mitigate the effects of osteoporosis. Calcium (Ca) has clearly been shown to have some positive effect on osteoporosis, although the bioavailability of Ca from classical preparations is approximately 10-15\% [208-210]. Recently, a number of scientific teams investigated Ca supplementation by nano-Ca either as solid peroral DISs or as nano-Ca from the fortified milk. Experiments performed in vivo on ovariectomized (OVX) rats demonstrated much greater absorption (up to $89 \%$ ) and overall bioavailability (up to $42 \%$ ) of preparations with nano- $\mathrm{CaCO}_{3}$, 
citrate, or organically bound in shell oyster. Therefore, by in vivo studies it was confirmed that the application of nanosized Ca could improve $\mathrm{Ca}$ and even phosphorous content in bones [211-215].

Ca alginate NPs (200-500 nm in diameter) loaded with collagen peptide chelated Ca with the average diameter of approximately $150 \mathrm{~nm}$ and the Ca content of up to $130.4 \mathrm{~g} / \mathrm{kg}$ notably enhanced Ca absorption and significantly increased femur bone mineral density and femur Ca content in rats, suggesting that they could prevent Ca deficiency and could be used as a new Ca supplement in the food industry [216]. A nanocomposite of whey protein hydrolysate chelated with Ca showed superb stability and absorbability under both acidic and basic conditions, which was beneficial for Ca absorption in the GI tract of the human body. Its pronouncedly higher Ca absorption on Caco-2 cells compared with $\mathrm{Ca}$ gluconate and $\mathrm{CaCl}_{2}$ in vitro suggested a possible increase in Ca bioavailability and thus its potential to be used as DIS for improving bone health of humans [217].

It is also important to remember that oral administration of Ca hydroxyapatite microcrystals can accelerate fracture healing and repair and even prevent osteoporosis [218]. Moreover, Zhang et al. [219] described the benefit of nanohydroxyapatite/CS composite for bone regeneration when it was administered by injection. In addition, these nanocomposites showed antistaphylococcal activity [220].

Additionally, $\mathrm{CaCO}_{3}$ from eggshell can be used as a Ca supplement [221]. Chicken eggshell powder became an attractive source of $\mathrm{Ca}$ for human nutrition. It can be added to food or drinks. For example, chocolate cakes were fortified by $3 \%, 6 \%$, and $9 \%$ of them, and the results indicated that with respect to the Ca content, texture and sensory properties of the cakes, $6 \%$ eggshell supplementation (i.e., increased Ca content to $816.8 \mathrm{mg} / 100 \mathrm{~g}$ ) was the best [222]. The preventive effects of nanopowdered eggshell (NPES) on postmenopausal osteoporosis in OVX rats was also studied, and the results were surprising. NPES fed rats showed an increase in bone mineral densities (BMD) by about 7\% compared to OVX rats. Only powdered eggshell led to an increase of BMD by $2 \%$. Serum analysis showed that NPES fed rats had a $22.4 \%$ higher osteocalcin level than OVX rats. Therefore, NPES attenuated the bone loss induced by ovariectomy in rats [223]. High-calcium yogurt as food for combat with osteoporosis was prepared using its fortification with 10-nm crystals of NPES. The addition of NPES up to $0.3 \%$ gave cow and buffalo's milk yogurts with acceptable composition, textural properties and sensory attributes, and this additive increased the Ca content of yogurt by about $15 \%$ [224].

\subsection{Supplements against Iron Deficiency}

Iron-deficiency anemia is the most common nutritional disorder worldwide with impact on health and economy. In spite of a number of commercially available supplements, this deficiency is a global public health problem due to the poor tolerability of the standard care soluble iron salts (such as ferrous sulfate), which results in non-compliance and ineffective correction of iron-deficiency anemia. On the other hand, poorly water-soluble compounds cause less sensory changes, but are not well absorbed [225]. Nanoformulations of iron were proposed to fortify food and feed to address these issues due to enhanced bioavailability, good product stability, limited side effects and the absence of changes of taste and color of the fortified foods [226]. In addition, in vitro and in vivo experiments have shown that iron NPs can be considered safe [227]. Ferritin, which is well absorbed [228] is itself composed of an iron oxide nanocore surrounded by a protein shell. Recently, Powell et al. [229] synthesized tartrate-modified, nano-disperse ferrihydrite having small primary particle size and enlarged or strained lattice structure (about $2.7 \AA$ for the main Bragg peak versus $2.6 \AA$ for synthetic ferrihydrite) that was able to efficiently provide GI delivery of soluble Fe(III) without the risk of free radical generation in murine models, where GI delivery did not depend on luminal Fe(III) reduction to Fe(II), and absorption was similar to that of $\mathrm{FeSO}_{4}$. This nanoformulation could be considered as a potentially side effect-free form of Fe supplementation to human suffering from anemia.

The most promising preparation (iron hydroxide adipate tartrate: IHAT) showed $\sim 80 \%$ relative bioavailability to $\mathrm{FeSO}_{4}$ in humans and, in a rodent model, IHAT was equivalent to $\mathrm{FeSO}_{4}$ at repleting hemoglobin. Moreover, IHAT did not accumulate in the intestinal mucosa and, unlike 
$\mathrm{FeSO}_{4}$, promoted a beneficial microbiota. In an in vitro study, IHAT was 14-fold less toxic than Fe(II) sulfate/ascorbate. The results of IHAT NPs observed from three-arm, double-blind, randomized, placebo-controlled trial conducted in Gambian children 6-35 months of age in relation to ferrous sulfate and non-inferiority in relation to placebo in terms of diarrhea incidence and prevalence confirmed the hypothesis that supplementation with IHAT eliminates iron deficiency and improves hemoglobin levels without inducing GI adverse effects [230,231].

Poorly water-soluble nanosized $\mathrm{FePO}_{4}$ with specific surface area approx. $190 \mathrm{~m}^{2} / \mathrm{g}$ made by scalable flame aerosol technology possesses in vivo iron bioavailability in rats comparable to $\mathrm{FeSO}_{4}$ and causes less color change in reactive food matrices than conventional iron fortificants. The addition of $\mathrm{Zn}$ or $\mathrm{Mg}$ oxides to nano $\mathrm{FePO}_{4}$ increases Fe absorption and also improves their color [232]. Additionally, Srinivasu et al. prepared nano ferric pyrophosphate (particle size 10-30 nm) as a potential food fortificant in iron-deficiency anemia and found that the peroral bioavailability of ferric pyrophosphate NPs in rats, calculated using hemoglobin regeneration efficiency, was $103.02 \%$ with respect to the reference salt, ferrous sulfate, while the NPs did not show any significant toxicity [233].

Salaheldin and Regheb biosynthesized biocompatible $\mathrm{Fe}_{3} \mathrm{O}_{4}$ NPs capped with vitamin $\mathrm{C}$, and thus intestinal villi absorbed the NPs as vitamin $C$ and not as an iron, because iron was coated with vitamin C. Clinical and histopathological studies on rats recommended the use of fortified biscuits with concentrations of $10 \mathrm{ppm}$ and $30 \mathrm{ppm}$ of nano iron; hemoglobin concentration increased from $9.9 \pm 1.2 \mathrm{~g} / \mathrm{dL}$ to $14.6 \pm 1.1$ and $16.7 \pm 1.6 \mathrm{~g} / \mathrm{dL}$, respectively [234].

\section{Veterinary Nanoscale Nutraceuticals and Dietary Supplements}

As mentioned above for humans, nanoformulated DISs can also be applied for animals. In general, these veterinary DISs are regulated by the FDA's Center for Veterinary Medicine [235,236]. Nutraceuticals have become popular with the veterinary community; worldwide estimates of sales approach $\$ 100$ billion [237]. Therefore, many different products can be found for veterinary applications. For example, the use of clinoptilolite (natural zeolite comprising a microporous arrangement of silica and alumina tetrahedra) showing unique antibacterial properties as a DIS in food and unifying properties of an immunomodulator and nutraceutical could represent an alternative to antibiotic growth promoters in animals of veterinary importance. Valpotic et al. [238] focused their attention mainly on clinoptilolite potentials and limitations in cattle related to metabolic and endocrine status, oxidative stress, and systemic local inflammatory responses involved in reproductive and metabolic disorders of dairy cows.

Zinc $(\mathrm{Zn})$, copper $(\mathrm{Cu})$ and selenium $(\mathrm{Se})$ are essential nutrients for animals and humans, because these metals occur in various metaloenzymes as co-factors [239]. $\mathrm{Zn}$ is a nutritionally indispensable trace element that is required for normal growth, bone development, feathering, appetite regulation, metabolic functioning of nearly 300 biochemical enzymes, hormone production, cell division, protein and DNA synthesis for all avian species $[239,240]$; so, it can affect animals production and reproduction performance [241]. Zinc deficiency in animals caused a decrease in feed intake, growth, serum insulin-like growth factor-I, and growth hormone $(\mathrm{GH})$ and lowered the hepatic production of insulin-like growth factor-I, GH receptor, and GH binding protein [241-244]. In addition, Zn is used to decrease fermentation of digestible nutrients in intestines and improve nutrients digestibility and appetite. Dietary Zn supplementation stimulates feed intake probably caused by increased ghrelin secretion [245]. It was observed that it caused an increase in insulin-like growth factor expression in the small intestine mucosa [246]. Increased $\mathrm{Zn}$ concentration in the intestines influences their structure and function. The growth-stimulating properties of dietary $\mathrm{Cu}$ have been attributed to its antimicrobial action, however, it was shown that also intravenous injection of $\mathrm{Cu}$ to weanling piglets stimulated their growth [247]. It seems that the growth-promoting properties of high dietary concentrations of $\mathrm{Cu}$ complement its antimicrobial action [248].

Se is very important in animal nutrition, because it functions as an anti-oxidant assisted by vitamin E; e.g., Se is a cofactor of glutathione peroxidase (GSHpx), deiodinases, thioredoxin reductases, 
selenophosphate synthatase, selenoprotein $\mathrm{P}$, selenoprotein $\mathrm{W}$, etc. Se deficiency can be a major problem that can be reduced or prevented by supplementation with inorganic or organic sources of Se. On the other hand, Se in high concentration is toxic to human and animal [249]. Recent knowledge related to beneficial biological effects of SeNPs in the organism, absorption mechanisms, and nanotechnological applications for peroral administration were summarized by Hosnedlova et al. [250]. The applications of the above-mentioned nutrients $(\mathrm{Zn}, \mathrm{Cu}, \mathrm{Se})$ in nanoscale formulations allow increased efficacy, enhanced absorption, lower overall doses, etc. [251,252]. In the following subchapters, an attention is mainly focused on the beneficial effect of some inorganic NPs ( $\mathrm{Zn}, \mathrm{ZnO}, \mathrm{Cu}, \mathrm{CuO}, \mathrm{Se}, \mathrm{Ag}$ ) and nanoscale formulations containing organic active compounds (e.g., essential oils, vitamins) on growth performance and some important biochemical parameters of aquatic animals, poultry, pigs and other domestic animals like cattle, sheep, and rabbits. Nanoformulations have also found their way into the fortification of animal feeds [253,254].

\subsection{Aquatic Animals}

The major challenge facing fish farming is the availability of relatively cheap but high-quality feed. Regular fish diet blended with nanosized mineral nutrients has beneficial impact on growth and overall health of fish, because they can pass across the gut tissue into cells more readily than bulk nutrients, and thus their assimilation processes in the fish are accelerated, resulting in improved growth [255].

Thyme essential oil at doses 400 and $800 \mathrm{mg} / \mathrm{kg}$ used as a DIS was found to reduce oxidative stress of gibel carp (Carassius auratus gibelio; average weight of $8.73 \pm 2.1 \mathrm{~g}$ ), and exposure to a sub-acute toxicity level of AgNPs for a period of $96 \mathrm{~h}$ after six weeks of a feeding trial confirmed the resistance of the carp to non-fatal effects of AgNPs [256]. A fish diet containing 1\% Aloe vera NPs improved the growth factors (weight gain, initial body weight, condition factor, feed conversion ratio, specific growth rate) of Siberian sturgeon [257]. CS NPs showing spherical shape, particle size $185 \mathrm{~nm}$, and positive zeta potential used to carry vitamin C through the GI tract of rainbow trout (Oncorhynchus mykiss) exhibited in vivo controlled release until $48 \mathrm{~h}$ and increased lysozyme and complement contents in the fish serum [258].

Shrimps (Litopenaeus vannamei) reared in clear water and in a biofloc system and receiving feed supplemented with nanocapsules containing lipoic acid showed increased final weight, higher GSH levels in the hepatopancreas and decreased percentage of hyaline hemocytes, while increased levels of granular hemocytes. Increased glutathione $S$-transferase activity in the gills and hepatopancreas was estimated only in shrimps reared in the biofloc system and fed with encapsulated antioxidant, while decreased levels of thiobarbituric acid reactive substances were estimated in the gills and muscles of the shrimps maintained in clear water [259].

A 60-day feeding of red sea bream (Pagrus major) with CuNPs ( $2 \mathrm{mg} / \mathrm{kg}$ ) or/and vitamin C (800-1200 mg/kg) improved its growth and health, and higher final weight, weight gain, specific growth rate, protein gain, protein retention, feed intake, protease and bactericidal activities, and higher tolerance against stress than in controls was estimated as well. The feed and protein efficiency ratios and the body lipid content were considerably higher at treatment with 0/1200, 2/800, 2/1000 and 2/1200 mg CuNPs/vitamin C per kg, while the application of 2/800, 2/1000 and 2/1200 mg CuNPs/vitamin C per $\mathrm{kg}$ resulted in considerably enhanced body protein and higher tolerance against stress compared to the control was estimated as well [260]. Wang et al. [261] reported that for the dietary $\mathrm{Cu}$ requirements of Russian sturgeon $(9.82 \pm 0.08 \mathrm{~g})$ fed with diets containing different forms of $\mathrm{Cu}$ for 8 weeks, $\mathrm{Cu}$-methionine (Met) and $\mathrm{CuO}$ NPs were 1.5-2-fold more bioavailable than $\mathrm{CuSO}_{4}$, optimal doses being approx. $5 \mathrm{mg} / \mathrm{kg}$ for $\mathrm{Cu}-\mathrm{Met}$ or $\mathrm{CuO} \mathrm{NPs}$ and $8 \mathrm{mg} / \mathrm{kg}$ for $\mathrm{CuSO}_{4}$.

In Pangasius hypophthalmus fed with a diet incorporating 10 and $20 \mathrm{mg} / \mathrm{kg} \mathrm{ZnNPs}$ and exposed to abiotic stress (sublethal dose of $\mathrm{Pb} 4 \mathrm{ppm}$ and temperature $34^{\circ} \mathrm{C}$ ), a considerably enhanced growth performance and improved immunological parameters (total protein, Alb, Glb, and Alb/Glb ratio) were observed, and reduced oxidative stress reflected in lower levels of blood glucose, cortisol, and HSP 70 suggested that the supplementation of dietary ZnNPs could alleviate abiotic stress in 
P. hypophthalmus [262]. In Mozambique tilapia (Oreochromis mossambicus) receiving a diet supplemented with $0.004 \%$ of Portunus pelagicus $\beta$-1,3-glucan binding protein based ZnO NPs, considerable increases in growth performance and in cellular and humoral immune responses were estimated. Moreover, when after 30 days of a feeding trial, the fish was challenged with aquatic fish pathogen Aeromonas hydrophila $\left(1 \times 10^{7}\right.$ cells $\left./ \mathrm{mL}\right)$ through intraperitoneal injection, a reduced mortality rate was observed in fish fed with the diet containing such ZnO NPs, suggesting a potential beneficial impact of the NPs on the immune system and survival of O. mossambicus [263]. Beneficial effects of $\mathrm{Zn}$-proteinate, $\mathrm{ZnSO}_{4}$, and $\mathrm{ZnO} N P s$ applied at dose $50 \mathrm{mg} / \mathrm{g}$ of $\mathrm{Zn}$ sources in an early diet of rainbow trout larvae with average weight of $82.3 \pm 11.6 \mathrm{mg}$ for 70 days enhanced the growth performance of the larvae [264].

Common carp (Cyprinus carpio) juveniles $(9.7 \pm 0.1 \mathrm{~g})$, the diet of which was supplemented with SeNPs $(0.7 \mathrm{mg} \mathrm{Se} / \mathrm{kg})$, showed the highest weight gain of $97.2 \pm 10.8 \%$ and feed efficiency ratio $42.4 \pm 0.8 \%$, the highest serum hemolytic activity, total immunoglobulin, and total protein and Alb contents as well as the lowest serum total cholesterol and LDL levels after 8 weeks of feeding compared to the carp fed with $\mathrm{Na}_{2} \mathrm{SeO}_{3}$, Se-Met, and the control. Carps fed with SeNPs or Se-Met showed also pronouncedly higher activities of serum glutathione peroxidase (GPx) and SOD and an increase in white blood cell counts, neutrophil percentage, and serum lysozyme activity compared to the control group and the $\mathrm{Na}_{2} \mathrm{SeO}_{3}$ group [265]. Dietary treatments of crucian carp, Carassius auratus gibelio, with SeNPs and Se-Met showed higher Se levels in muscle $(16.42 \pm 1.07 \mu \mathrm{g} / \mathrm{g}$ and $13.52 \pm 1.31 \mu \mathrm{g} / \mathrm{g}$, respectively) compared to carps fed with basal feed $(6.10 \pm 0.78 \mu \mathrm{g} / \mathrm{g})$. Although the survival rate and the feed conversion ratio were not affected by the dietary treatments, GPx activities in Se-treated carp plasma and liver differed significantly from those of the control [266]. Dietary SeNPs supplementation at the dose of $0.68 \mathrm{mg} / \mathrm{kg}$ to juvenile mahseer (Tor putitora) considerably increased red blood cell count, hemoglobin level, hematocrit values, and lysozyme activity as well as serum GH levels, tissue total protein content, and GPx activity in liver and muscle tissues of T. putitora [267]. Chinese mitten crabs (Eriocheir sinensis) fed with a diet containing $0.2 \mathrm{mg} / \mathrm{kg}$ SeNPs in a $60 \mathrm{~d}$ feeding trial had a considerably higher weight gain rate and a reduced feed coefficient. When juvenile Chinese mitten crabs were kept under the condition of hypoxia, the up-regulative effects of SeNPs on antioxidant capacity, hemocyte counts, and hemocyanin expression were further amplified. Hypoxia exposure increasing mortality in crabs infected with A. hydrophila bacteria was also alleviated when crabs received a diet containing $0.2 \mathrm{mg} / \mathrm{kg}$ SeNPs, suggesting the importance of dietary SeNPs in regulating the immunity and disease resistance in crabs kept under hypoxia stress [268]. Naderi et al. [269] who investigated the impact of dietary SeNPs $(1 \mathrm{mg} / \mathrm{kg})$, vitamin E (500 mg/ $\mathrm{kg})$, and their combination on the humoral immune status and serum parameters of rainbow trout under high-density condition $\left(80 \mathrm{~kg} / \mathrm{m}^{3}\right)$ reported that the positive effects observed in the performance following the combine treatment may be due to vitamin $\mathrm{E}$ alone, because supplementation with SeNPs did not markedly affect the performance in rainbow trout under high-density conditions. In addition, the immuno-protective role of biologically synthesized dietary SeNPs applied at the dose of $1 \mathrm{mg} / \mathrm{kg}$ against multiple stressors ( $\mathrm{Pb}$ level of $4 \mathrm{ppm}$, high temperature of $34^{\circ} \mathrm{C}$ ) in Pangasinodon hypophthalmus was reported by Kumar et al. [270].

\subsection{Poultry}

Typical poultry diets are commonly enriched by feed additives containing vitamins and minerals to support rapid growth and a favorable feed conversion ratio, and nanosized feed additives characterized by a high surface area to volume ratio and high absorption in the body could be incorporated in vaccines and nutrient supplements and directly transported to targeted organs or systems without degradation resulting in health benefits. Current state of NPs use as poultry feed supplements was reviewed by Gangadoo et al. [271].

AgNPs received in drinking water containing $1000 \mathrm{mg}$ AgNPs $/ \mathrm{kg}$ significantly reduced the body weights of the broilers after 42 days of administration, and this adverse effect could not be 
mitigated with a basal diet supplemented with $\mathrm{Zn}(60$ and $120 \mathrm{mg} / \mathrm{kg}$ ) and vitamin $\mathrm{E}$ ( $\alpha$-tocopherol acetate; 100 and $200 \mathrm{mg} / \mathrm{kg}$ ). On the other hand, the increased activity of CuZn-SOD observed in AgNPs-treated broilers was not recorded in birds fed with the basal diet supplemented with $200 \mathrm{mg} / \mathrm{kg}$ vitamin E, suggesting its antioxidant effect. Moreover, $\mathrm{Zn}$ supplementing enhanced catalase and GPx activities in the jejunal mucosa resulting in increased malondialdehyde (MDA) levels in the animals. Therefore, it could be concluded that the dietary $\mathrm{Zn}$ and vitamin E supplementation was able to attenuate intestinal oxidative stress in AgNPs-treated broiler chickens, although it did not mitigate the growth reduction caused by AgNPs [272]. In ovo feeding was found to reduce post-hatch mortality and skeletal disorders and increase muscle growth and breast meat yield. Sawosz et al. [273] used AgNPs as a protective carrier for adenosine triphosphate (ATP) as well as an active agent, which may penetrate tissues and cells and localize inside cells. They injected AgNPs, ATP, or a complex of AgNPs + ATP (AgNPs/ATP) in broiler eggs, and on day 20 of incubation, the embryos were evaluated. An increased expression of fibroblast growth factor 2, vascular endothelial growth factor, and $\mathrm{Na}^{+} / \mathrm{K}^{+}$transporting ATPase were estimated at the application of ATP or AgNPs to chicken embryos. Moreover, AgNPs also upregulated the expression of myogenic differentiation 1, affecting cell differentiation. Based on the above-mentioned findings, it could be concluded that an extra energy source in the form of ATP addition enhanced molecular mechanisms of muscle cell proliferation, and ATP and AgNPs could accelerate the growth and maturation of muscle cells [273].

The in ovo injection of CuNPs using the dose of $50 \mathrm{mg} / \mathrm{kg}$ CuNPs improved broiler performance more efficiently than the injection of $50 \mathrm{mg} / \mathrm{kg} \mathrm{CuSO}_{4}$ or the provision of $\mathrm{CuNPs}_{\text {or }} \mathrm{CuSO}_{4}$ in drinking water containing $20 \mathrm{mg} / \mathrm{kg}$ CuNPs or $\mathrm{CuSO}_{4}$ to growing chickens. In another experiment, which was carried out with 126 one-day-old broiler chickens from day 1 to 35 post-hatching, the in ovo application of $\mathrm{Cu}$ enhanced the final body weight, average daily gain, and feed conversion ratio compared to control animals and resulted in a considerable improvement in energy and nitrogen utilization, mainly for CuNPs application. The CuNPs treatment also reduced cholesterol, urea, and glucose levels in the blood [274]. The supplementation of a $\mathrm{Cu}$ deficient basal diet of chickens with CuNPs in drinking water to the level of $\mathrm{Cu}$ exceeding the National Research Council (NRC) recommendation by $54 \%$ resulted in the increased antioxidant potential of the organism and the inhibition of lipid peroxidation. Antioxidant and immune defenses of chickens were simultaneously increased in chickens receiving diet supplemented with CuNPs up to $12 \mathrm{mg}$ per bird during 6 weeks of feeding, i.e., up to a level exceeding the NRC recommendation for growing broiler chickens at the most by $7 \%$. It could be mentioned that at a higher CuNPs supplementation, a deterioration in red blood cell parameters and the stimulation of the immune system reflected in an increase in interleukin- 6 , immunoglobulin $\mathrm{A}$ (IgA), IgM, and IgY was observed [275].

The in ovo administration of NPs could be considered as a new method of nano-nutrition to supply an additional quantity of nutrients to embryos. ZnNPs, CuNPs and SeNPs supplemented in ovo at doses 20, 40, 60, and $80 \mu \mathrm{g}$ ZnNPs/egg, 4, 8, 12, and $16 \mu \mathrm{g}$ CuNPs/egg, and 0.075, 0.15, 0.225, and $0.3 \mu \mathrm{g}$ SeNPs / egg (18th day incubation, amniotic route) did not show any adverse effect on the developing embryo and did not influence the hatchability, best feed efficiency being observed with $40 \mu \mathrm{g} Z n N P s / e g g, 4 \mu \mathrm{g}$ CuNPs/egg and $0.225 \mu \mathrm{g}$ SeNPs/egg. Moreover, the application of $12 \mu \mathrm{g}$ CuNPs/egg resulted in considerably higher breast muscle percentage [276].

In white Leghorn laying hens (68-week old) receiving a diet supplemented with Zn-Met, bulk $\mathrm{ZnO}$, and $\mathrm{ZnO}$ NPs reaching the level of $60 \mathrm{mg} \mathrm{Zn/} \mathrm{kg}$ in the diet, pronouncedly higher $\mathrm{Zn}$ retention, serum GH concentration, and carbonic anhydrase activity were observed at the application of the $\mathrm{ZnO}$ NPs and Zn-Met compared to the control, and the ZnO NPs enhanced eggshell thickness as well [241]. Laying hens at 64 weeks of age fed with a basal diet supplemented with $80 \mathrm{mg} / \mathrm{kg}$ of bulk $\mathrm{ZnO}, \mathrm{ZnO}$ NPs, and $\mathrm{Zn}-$ Met showed considerably higher egg production and egg mass as well as SOD activity in the liver, pancreas, and plasma when Zn-Met and the ZnO NPs were applied, while the greatest increase in eggshell thickness and shell strength was observed at the ZnO NPs application. The $\mathrm{Zn}$ supplementation resulted in reduced egg loss and lower MDA content and had a beneficial 
effect on serum total protein, Alb, glucose, alkaline phosphatase activity, carbonic anhydrase activity, and $\mathrm{Zn}$ level, which was reflected in an improved performance of laying hens. Due to the enhanced $\mathrm{Zn}$ absorption in the intestine of aged layers at the application of ZnO NPs, they could be considered as a more suitable source of $\mathrm{Zn}$ in diets than bulk $\mathrm{ZnO}$ [277]. At the dietary supplementation of Zn-Met, $\mathrm{ZnO}, \mathrm{ZnO}$ NPs or polyglutamic acid (PGA)-ZnO NPs reaching the level of $80 \mathrm{mg} \mathrm{Zn/} \mathrm{kg}$ in the diet, increased Zn content in eggshells, serum Zn concentration, ghrelin and IgG levels of 64-week old brown layers were observed at the application of the ZnO NPs and the PGA-ZnO NPs, exceeding that observed at the application of bulk $\mathrm{ZnO}$, and serum carbonic anhydrase activity and ghrelin levels were also increased compared to $\mathrm{Zn}$-Met, suggesting that the $\mathrm{ZnO} N P s$ alone or in combination with PGA show beneficial impact on the $\mathrm{Zn}$ status of aged layers [278].

Investigation of the effects of SeNPs on performance, meat quality, immune function, oxidation resistance, and tissue Se content in broilers performed with 1-day old male Arbor Acres broilers showed that the supplementation of corn-soybean meal-based diets with $0.3-0.5 \mathrm{mg}$ SeNPs $/ \mathrm{kg}$ was found to be the best, and the maximum supplementation of SeNPs could not exceed $1.0 \mathrm{mg}$ SeNPs $/ \mathrm{kg}$ [279]. The adverse effects of oxidative stress in broiler chickens induced by tert-butyl hydroperoxide were attenuated when the animals received a diet supplemented with $0.3 \mathrm{mg}$ SeNPs $/ \mathrm{kg}$. In stressed chicks fed with SeNPs, the heterophil:lymphocyte ratio was lower than in the groups, the diet of which was supplemented with bulk inorganic or organic Se, suggesting a higher effectiveness of SeNPs in the mitigation of oxidative stress [280]. Supplementation of SeNPs $(0.1-0.5 \mathrm{mg} / \mathrm{kg})$ in broiler diets could improve growth performance, carcass components, and immune function of the animals, and no adverse effects on internal organs, other carcass parameters, and GI parts were observed. SeNPs dietary supplementation resulted in significantly improved weight gain and feed conversion ratio during the whole period of experiment (42 days) and more efficient energy and protein utilization compared to the control group [281].

Rahmatollah et al. [282] reported that $1.2 \mathrm{mg} / \mathrm{kg}$ cysteine-coated $\mathrm{Fe}_{3} \mathrm{O}_{4} \mathrm{NPs}$ were found to be required and sufficient for quails' optimal maintenance and growth suggesting that cysteine- $\mathrm{Fe}_{3} \mathrm{O}_{4}$ NPs can be used as a Fe source in the quail diet.

Cr utilization in 32 three-week-old broilers fed with a diet supplemented with $\mathrm{Cr}$ at the $1200 \mathrm{~g} / \mathrm{kg}$ level using $\mathrm{CrCl}_{3}$, chromium picolinate (CrPic), and $\mathrm{CrPic}$ NPs decreased as follows: $\mathrm{CrPic}$ NPs > $\mathrm{CrPic}>\mathrm{CrCl}_{3}>$ control groups, and significant differences between individual groups were estimated. When one-day-old broilers were fed with diet supplemented with the above-mentioned Cr compounds, the feed intake of 4-5 weeks showed better results in the $\mathrm{CrCl}_{3}$ group compared to the CrPic group, while the LDL-cholesterol in the CrPic NPs groups was lower than in the CrPic group, and CrPic NPs and CrPic groups showed considerably enhanced serum $\mathrm{Cr}$ concentration compared to the control and $\mathrm{CrCl}_{3}$ groups. Based on the above results, it could be concluded that the CrPic NPs supplementation has advantages compared to the bulk CrPic supplementation, because it not only increases Cr utilization but also results in a lower serum LDL-cholesterol level in broilers [283].

\subsection{Pigs}

$\mathrm{ZnO}$ and $\mathrm{Cu}$ salts, traditionally used in high doses as supplements to piglet's diet, stimulate piglet's daily gain and decrease feed conversion factor. However, the application of high concentrations of these metal additives could result in increased environmental pollution of soil and tap water; on the other hand, Zn applied at doses $2500-3000 \mathrm{mg} / \mathrm{kg}$ feed can contribute to the development of antimicrobial resistance and may regulate the expression of genes that modify piglets' immune response. Consequently, higher bioavailability which could be achieved by applying nanosized $\mathrm{ZnO} / \mathrm{Cu}$ particles could notably reduce the dietary inclusion rate and environmental pollution with preserving beneficial impact on pig's health [244].

The degree of the reduction of piglet diarrhea incidence observed with a low dose of $\mathrm{ZnO}$ NPs (600 mg Zn/kg) supplemented to the basal diet of weaning piglets was comparable with that observed with the dose of $2000 \mathrm{mg} \mathrm{Zn/kg}$ when bulk $\mathrm{ZnO}$ was used, which could be connected with 
improved intestinal microbiota and inflammation response in piglets at the ZnO NPs application. Moreover, the application of $\mathrm{ZnO}$ NPs could contribute to reduced Zn environmental pollution [284]. ZnO NPs used as a DIS increased Zn digestibility, serum GH levels, and carbonic anhydrase activity and enhanced the immune response of weanling piglets [285].

$\mathrm{Cr}$ (III) belongs to essential elements in the nutrition of both animals and humans, and in many animal species its deficiency results in reduced feed intake, lower weight gains, reproductive disorders, and increased lipid levels, and a moderate $\mathrm{Cr}$ deficiency represents a risk factor of ischemic heart disease with myocardial infarction and coronary artery disease. Cr improves lean body mass in animals, increases growth rate and feed conversion, and improves feed intake and energy efficiency, and the dietary $\mathrm{Cr}$ requirement of an animal body is probably $300 \mu \mathrm{g} \mathrm{Cr} / \mathrm{kg}$ d.w. of feed. A pronouncedly increased $\mathrm{Cr}$ content in the blood, longissimus muscle, heart, liver, kidneys, jejunum, and ileum was observed in pigs receiving dietary $\mathrm{Cr}$ nanocomposite supplementation [286]. Dietary CrPic NPs supplementation at $400 \mathrm{ppb}$ increased feed intake in finisher gilts during mid-summer and was able to improve some of the adverse effects of heat stress in pigs, through decreasing circulating cortisol levels [287]. Pigs with initial body weight of $66.10 \pm 1.01 \mathrm{~kg}$ receiving basal diet supplemented with 200 or $400 \mu \mathrm{g} / \mathrm{kg}$ of Cr from Cr-loaded CS NPs (Cr-CS NPs) for $35 \mathrm{~d}$ showed increased carcass lean ratio and longissimus muscle area, decreased carcass fat ratio and backfat thickness as well as increased serum free fatty acids, lipase activity, and serum insulin-like growth factor I, while a decreased level of serum insulin was estimated. Moreover, decreased activities of fatty acid synthase and malate dehydrogenase and increased activity of hormone-sensitive lipase in subcutaneous adipose tissue were observed in treated pigs. These results indicate a favorable impact of $\mathrm{Cr}$ in the form of the Cr-CS NPs on growth, carcass characteristics, pork quality, and lipid catabolism in finishing pigs [288]. The control diet supplemented with $200 \mu \mathrm{g} \mathrm{Cr}$ from $\mathrm{Cr}$ nanocomposite pronouncedly reduced serum levels of glucose, urea nitrogen, triglyceride, cholesterol, and nonesterified fatty acid, increased total protein, HDL, and lipase activity in finishing pigs with initial weight $64.8 \pm 0.83 \mathrm{~kg}$ fed for $35 \mathrm{~d}$, and considerably increased serum insulin-like growth factor I, while reducing serum insulin and cortisol levels. Moreover, it affected immune status in finishing pigs, which was reflected in notable increments of IgM and IgG contents in plasma [289].

\subsection{Other Pets}

Dried matrices of CS Cu chelate gels designed as a multimicronutrient feed additive for cattle were loaded with vitamin riboflavin. Following restricted rehydration in simulated rumen fluid, they exhibited sustained release of riboflavin without releasing $\mathrm{Cu}$ in these neutral conditions for up to $24 \mathrm{~h}$, demonstrating $\mathrm{Cu}$ rumen bypass. A sustained release of the mineral was observed in abomasal conditions of $\mathrm{pH} 2$ over a $3 \mathrm{~h}$ period suggesting that this formulation could supply nutritionally relevant levels of the free mineral in these conditions, as required for effective supplementation in cattle [290].

A decreasing trend in serum Fe concentration was observed in Lori-Bakhtiary sheep, which orally received SeNPs and $\mathrm{Na}_{2} \mathrm{SO}_{3}(1 \mathrm{mg} / \mathrm{kg})$ for 10 consecutive days, particularly during the early and middle stages of supplementation ( $0-20$ days) in contrast to the increasing levels of total iron binding capacity, suggesting that the expression of transferrin and its receptor genes was considerably increased. However, after this period, the expression of the transferrin and transferrin binding receptor genes showed a notable decrease, especially in $\mathrm{SeO}_{3}{ }^{2-}$ treated animals [291].

Improved rumen fermentation and feed utilization, stimulation of rumen microbial activity, digestive microorganisms, and enzyme activity by supplementation of SeNPs in basal diet of sheep with optimum dose approx. $3.0 \mathrm{~g} / \mathrm{kg}$ dietary dry mater was reported by Shi et al. [292]. Using the rumen simulation technique, it was observed that nanoemulsified soyabean oil modulated the PUFAs proportions in ruminal cultures, which was reflected in markedly increased proportions of oleic acid, $\alpha$-LLA, and $\alpha$-LNA in the fermentation fluid without any negative effect on rumen fermentation parameters [293]. 
Nano-copper as a new growth promoter in the diet of growing New Zealand white rabbits was reported by Refaie et al. [294]. Similarly, the male five-week-old New Zealand white rabbits fed with the basal diet supplemented with 60 and $30 \mathrm{mg} \mathrm{ZnO}$ NPs / kg diet had higher body weight, daily weight gain, daily feed intake, serum total protein, globulin, IgG, and SOD compared to control animals and rabbits fed with a diet supplemented with bulk $\mathrm{ZnO}(60 \mathrm{mg} / \mathrm{kg}$ diet), suggesting that traditional zinc sources in rabbit diets could be replaced by $30 \mathrm{mg} \mathrm{ZnO} \mathrm{NP} / \mathrm{kg}$ diet [295]. On the other hand, Ismail and El-Araby [296] recommended the combined use of bulk and nanosized $\mathrm{ZnO}$ at ratio 1:1 in the dietary system of rabbit's farms ensuring dietary supplementation with $\mathrm{Zn}$ as an essential element but reducing adverse effects such as lipid peroxidation and oxidant stress induced by the whole dose of ZnO NPs. A complete overview of the used nanoscale veterinary dietary supplements is shown in Figure 3.

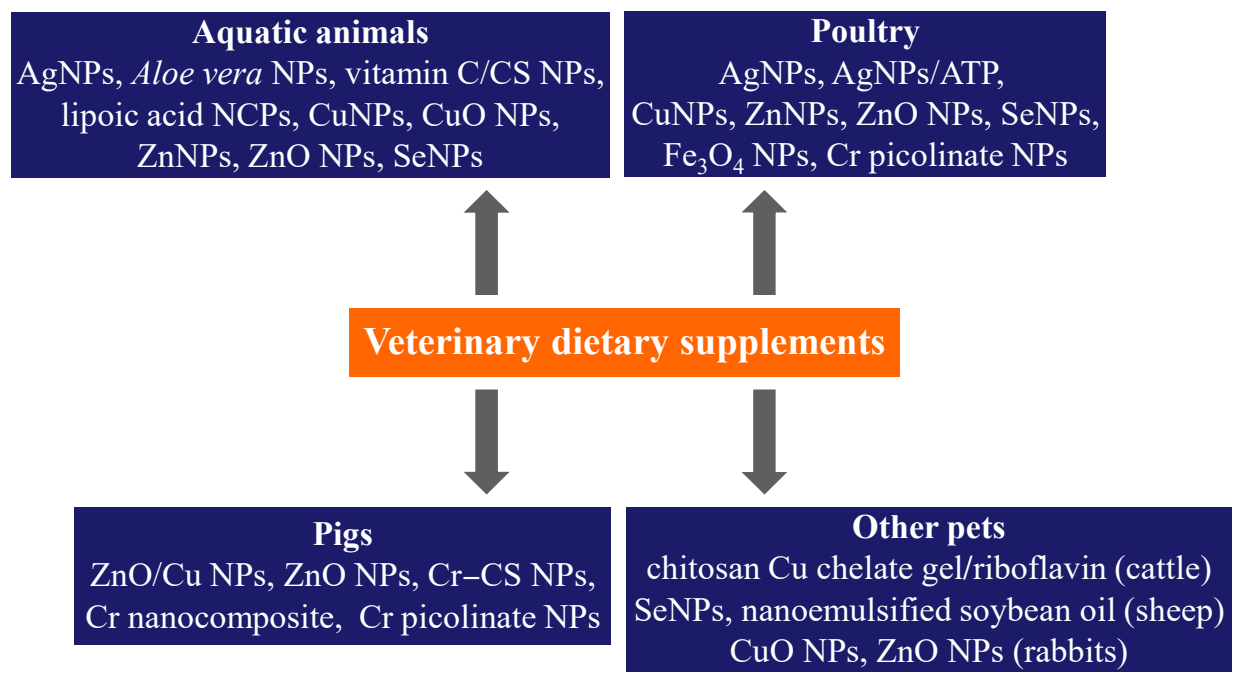

Figure 3. Summary of most frequently used veterinary dietary nanosupplements.

\section{Conclusions}

The importance of balanced nutrition containing important nutrients, for example, vitamins or antioxidants, in sufficient amount needed for health of humans and animals is indisputable. Moreover, recently, physicians attribute an increasing significance to the consumption of food products containing special effective ingredients to prevent and improve the health of people suffering from certain diseases (e.g., cancer, diabetes, hyperlipidemia, mental disorders, osteoporosis, various malabsorption, etc.). The fortification of food products with such dietary supplements/nutraceuticals can be easily used in practice when an appropriate stability of the active ingredient in the formulation could be guaranteed at least until the date of consumption (expiration date). For these purposes, nanoformulations of active compounds prepared using biodegradable nature- or semisynthetic-based nanocarriers, such as polymeric matrices, micelles, liposomes, nanoemulsions, solid lipid NPs, nanostructured lipid carriers, or appropriate inorganic matrices are especially favorable, securing not only enhanced stability but also frequently controlled release of nutrients. Definitely, based on previous thorough experiments, for supplementation of food products (e.g., bread, butter, yogurt, cake, biscuit) or beverages (e.g., milk, juice) with individual healthy ingredients, the most convenient nanoformulation could be selected and used. Unlike nutraceuticals that are available for sale in pharmacy and could be overused by some careless consumers resulting in possible harmful side effects, at fortification of food products with dietary supplements/nutraceuticals, the excessive consumption of these compounds is excluded. However, even though nanoformulations enhance the bioavailability and increase the stability of individual active ingredients, all nanoscale materials applied in food industry should be used advisedly and only after in-depth investigation of cytotoxicity due to possible increased nanosize-based toxicity effects (e.g., surface reactivity of NPs), which could result 
in unspecified toxic effects also in humans or animals. Therefore, an increased attention should be paid to the influence of risk factors associated with their applications and possible adverse/hazardous effects to humans and animals, observing the relevant guidelines, regulations, and directives issued by the European Commission and the EFSA.

Author Contributions: J.J., J.K. and K.K. composition and writing.

Funding: This study was supported by the Slovak Research and Development Agency (projects APVV-17-0373 and APVV-14-0547), and by the Ministry of Education of the Czech Republic (LO1305).

Conflicts of Interest: The authors declare no conflicts of interest.

\section{Abbreviations}

AChE (acetylcholinesterase); Alb (albumin); AST (astaxanthin); ATP (adenosine triphosphate); $\alpha$-Lalb $(\alpha$-lactalbumin); $\alpha$-LLA ( $\alpha$-linoleic acid); $\alpha$-LNA ( $\alpha$-linolenic acid); BAP (bioactive association platform); BMD (bone mineral densities); $\beta$-Car ( $\beta$-carotene); $\beta$-Lglb ( $\beta$-lactoglobulin); CDs (cyclodextrins); CPE (Citrus reticulata Blanco cv. unshiu peel extract); CrPic (chromium picolinate); CS (chitosan); CUR (curcumin); CVD (cardiovascular disease); CVPs (Catathelasma ventricosum polysaccharides); DESs (delivery systems); DHA (docosahexaenoic acid); DISs (dietary supplements); EE (encapsulation efficiency); EFSA (European Food Safety Authority); EGCG (epigallocatechin gallate); FA (folic acid); FDA (U.S. Food and Drug Administration); FSMPs (foods for special medical purposes); GH (growth hormone); GI (gastrointestinal); Glb (globulin); GPx (glutathione peroxidase); GSH (glutathione); HDL (high-density lipoprotein); LCT (long-chain triglycerides); LDHs (layered double hydroxides); LDL (low-density lipoprotein); MCT (medium chain triglycerides); MDA (malondialdehyde); Met (methionine); MPs (microparticles); MSPs (mesoporous particles); NE (nanoemulsion); NLCs (nanostructured lipid carriers); NPs (nanoparticles); NPES (nanopowdered eggshell); NRC (National Research Council); OVX (ovariectomized); PC (phosphatidylcholine); PGA (polyglutamic acid); PUFAs (polyunsaturated fatty acids); Q (quercetin); r-CMs (re-assembled casein micelles); RES (resveratrol); SCas (sodium caseinate); SOD (superoxide dismutase); SPI sesame protein isolate); STZ (streptozotocin); TBFs (tartary buckwheat rich in flavonoids); ZLNPs (zein NPs encapsulating lutein).

\section{References}

1. Dwyer, J.T.; Wiemer, K.L.; Dary, O.; Keen, C.L.; King, J.C.; Miller, K.B.; Philbert, M.A.; Tarasuk, V.; Taylor, C.L.; Gaine, P.C.; et al. Fortification and health: Challenges and opportunities. Adv. Nutr. 2015, 6, 124-131. [CrossRef] [PubMed]

2. Rao, P.J.; Naidu, M.M. Nanoencapsulation of Bioactive Compounds for Nutraceutical Food. In Nanoscience in Food and Agriculture 2. Sustainable Agriculture Reviews; Ranjan, S., Dasgupta, N., Lichtfouse, E., Eds.; Springer: Cham, Germany, 2016; Volume 21, pp. 129-156.

3. National Institutes of Health. Dietary Supplements: Background Information. Available online: https: / / ods.od.nih.gov/factsheets/DietarySupplements-HealthProfessional/ (accessed on 20 November 2018).

4. European Commission. Food Supplements. Available online: https://ec.europa.eu/food/safety/labelling nutrition/supplements_en (accessed on 20 November 2018).

5. U.S. Food and Drug Administration. Dietary Supplements Guidance Documents \& Regulatory Information. Available online: https:/ /www.fda.gov/Food/GuidanceRegulation/GuidanceDocumentsRegulatoryInformation/ DietarySupplements/default.htm (accessed on 20 November 2018).

6. European Commission-Health Claims. Available online: https://ec.europa.eu/food/safety/labelling nutrition/claims/health_claims_en (accessed on 20 November 2018).

7. Kuhnert, P. Foods, 3. Food Additives. In Ullmann's Encyclopedia of Industrial Chemistry; Wiley-VCH: Weinheim, Germany, 2016; Available online: 10.1002/14356007.a11_561.pub2 (accessed on 20 November 2018).

8. EFSA. Foods for Special Medical Purposes. Available online: https://www.efsa.europa.eu/en/press/news / 151126 (accessed on 20 November 2018).

9. European Commission-Foods for Specific Groups. Available online: https:/ / ec.europa.eu/food/safety / labelling_nutrition/special_groups_food_en (accessed on 20 November 2018).

10. FDA. Medical Foods Guidance Documents \& Regulatory Information. Available online: https: / www.fda.gov / Food/GuidanceRegulation/GuidanceDocumentsRegulatoryInformation/ MedicalFoods/default.htm (accessed on 20 November 2018).

11. Corradini, C.; Lantano, C.; Cavazza, A. Innovative analytical tools to characterize prebiotic carbohydrates of functional food interest. Anal. Bioanal. Chem. 2013, 405, 4591-4605. [CrossRef] [PubMed] 
12. Shahidi, F. Nutraceuticals, functional foods and dietary supplements in health and disease. J. Food Drug Anal. 2012, 20, 226-230.

13. National Nanotechnology Initiative. Big Things from a Tiny World; National Nanotechnology Initiative: Arlington, VA, USA, 2008.

14. European Commission. Definition of a Nanomaterial. Available online: http://ec.europa.eu/environment/ chemicals/nanotech/faq/definition_en.htm (accessed on 3 December 2018).

15. Mody, V.V.; Siwale, R.; Singh, A.; Mody, H.R. Introduction to metallic nanoparticles. J. Pharm. Bioallied Sci. 2010, 2, 282-289. [CrossRef]

16. Couvreur, P. Nanoparticles in drug delivery: Past, present and future. Adv. Drug Deliv. Rev. 2013, 65, 21-23. [CrossRef] [PubMed]

17. Kateb, B.; Heiss, J.D. The Textbook of Nanoneuroscience and Nanoneurosurgery; CRC Press, Taylor \& Francis Group: Boca Raton, FL, USA, 2014.

18. Vaculikova, E.; Placha, D.; Jampilek, J. Toxicology of drug nanocarriers. Chem. Listy 2015, 109, 346-352.

19. Jampilek, J.; Kralova, K. Application of nanobioformulations for controlled release and targeted biodistribution of drugs. In Nanobiomaterials: Applications in Drug Delivery; Sharma, A.K., Keservani, R.K., Kesharwani, R.K., Eds.; CRC Press: Warentown, NJ, USA, 2018; pp. 131-208.

20. Jampilek, J.; Kralova, K. Nanotechnology based formulations for drug targeting to central nervous system. In Nanoparticulate Drug Delivery Systems; Keservani, R.K., Sharma, A.K., Eds.; Apple Academic Press \& CRC Press: Warentown, NJ, USA, 2019; pp. 151-220.

21. Bhushan, B.; Luo, D.; Schricker, S.R.; Sigmund, W.; Zauscher, S. Handbook of Nanomaterials Properties; Springer: Berlin/Heidelberg, Germany, 2014.

22. Singh, O.V. Bio-Nanoparticles: Biosynthesis and Sustainable Biotechnological Implications; Wiley-Blackwell: Hoboken, NJ, USA, 2015.

23. Shukla, A.; Iravani, S. Green Synthesis, Characterization and Applications of Nanoparticles; Elsevier: Amsterdam, The Netherlands, 2018.

24. Jampilek, J.; Kralova, K. Nano-antimicrobials: Activity, benefits and weaknesses. In Nanostructures for Antimicrobial Therapy; Ficai, A., Grumezescu, A.M., Eds.; Elsevier: Amsterdam, The Netherlands, 2017; pp. 23-54.

25. Jampilek, J.; Kralova, K. Nanomaterials for delivery of nutrients and growth-promoting compounds to Plants. In Nanotechnology: An Agricultural Paradigm; Prasad, R., Kumar, M., Kumar, V., Eds.; Springer: Singapore, 2017; pp. 177-226.

26. Brayner, R.; Fievet, F.; Coradin, T. Nanomaterials: A Danger or a Promise? A Chemical and Biological Perspective; Springer: London, UK, 2013.

27. Acosta, E. Bioavailability of nanoparticles in nutrient and nutraceutical delivery. Curr. Opin. Colloid Interface Sci. 2009, 14, 3-15. [CrossRef]

28. Bamrungsap, S.; Zhao, Z.; Chen, T.; Wang, L.; Li, C.; Fu, T.; Tan, W. Nanotechnology in therapeutics: A focus on nanoparticles as a drug delivery system. Nanomedicine 2012, 7, 1253-1271. [CrossRef] [PubMed]

29. Nekkanti, V.; Vabalaboina, V.; Pillai, R. Drug nanoparticles-An overview. In The Delivery of Nanoparticles; Hashim, A.A., Ed.; InTech: Rieka, Croatia, 2012; pp. 111-132.

30. Frohlich, E. Cellular targets and mechanisms in the cytotoxic action of non-biodegradable engineered nanoparticles. Curr. Drug Metab. 2013, 14, 976-988. [CrossRef] [PubMed]

31. Dolez, P.I. Nanoengineering: Global Approaches to Health and Safety Issues; Elsevier: Amterdam, The Netherlands, 2015.

32. Busquets, R. Emerging Nanotechnologies in Food Science; Elsevier: Amterdam, The Netherlands, 2018.

33. Jampilek, J.; Kralova, K. Nanomaterials applicable in food protection. In Nanotechnology Applications in Food Industry; Rai, R.V., Bai, J.A., Eds.; Taylor \& Francis Group: Boca Raton, FL, USA, 2018; pp. 75-96.

34. Vaculikova, E.; Grunwaldova, V.; Kral, V.; Dohnal, J.; Jampilek, J. Preparation of candesartan and atorvastatin nanoparticles by solvent evaporation. Molecules 2012, 17, 13221-13234. [CrossRef]

35. Jampilek, J.; Zaruba, K.; Oravec, M.; Kunes, M.; Babula, P.; Ulbrich, P.; Brezaniova, I.; Triska, J.; Suchy, P. Preparation of silica nanoparticles loaded with nootropics and their in vivo permeation through blood-brain barrier. Biomed. Res. Int. 2015, 2015, 812673. [CrossRef] [PubMed]

36. Vaculikova, E.; Cernikova, A.; Placha, D.; Pisarcik, M.; Dedkova, K.; Peikertova, P.; Devinsky, F.; Jampilek, J. Cimetidine nanoparticles for permeability enhancement. J. Nanosci. Nanotechnol. 2016, 16, 7840-7843. [CrossRef] 
37. Vaculikova, E.; Cernikova, A.; Placha, D.; Pisarcik, M.; Peikertova, P.; Dedkova, K.; Devinsky, F.; Jampilek, J. Preparation of hydrochlorothiazide nanoparticles for solubility enhancement. Molecules 2016, $21,1005$. [CrossRef] [PubMed]

38. Pentak, D.; Kozik, V.; Bak, A.; Dybal, P.; Sochanik, A.; Jampilek, J. Methotrexate and cytarabine-Loaded nanocarriers for multidrug cancer therapy. Spectroscopic study. Molecules 2016, 21, 1689. [CrossRef] [PubMed]

39. Pisarcik, M.; Jampilek, J.; Lukac, M.; Horakova, R.; Devinsky, F.; Bukovsky, M.; Kalina, M.; Tkacz, J.; Opravil, T. Silver nanoparticles stabilised by cationic gemini surfactants with variable spacer length. Molecules 2017, 22, 1794. [CrossRef]

40. Pisarcik, M.; Lukac, M.; Jampilek, J.; Bilka, F.; Bilkova, A.; Paskova, L.; Devinsky, F.; Horakova, R.; Opravil, T. Silver nanoparticles stabilised with cationic single-chain surfactants. Structure-physical properties-biological activity relationship study. J. Mol. Liq. 2018, 272, 60-72. [CrossRef]

41. Vaculikova, E.; Pokorna, A.; Placha, D.; Pisarcik, M.; Dedková, K.; Peikertova, P.; Devinsky, F.; Jampilek, J. Improvement of glibenclamide water solubility by nanoparticle preparation. J. Nanosci. Nanotechnol. 2019, 19, 3031-3034. [CrossRef]

42. Kozik, V.; Bak, A.; Pentak, D.; Hachula, B.; Pytlakowska, K.; Rojkiewicz, M.; Jampilek, J.; Sieron, K.; Jazowiecka-Rakus, J.; Sochanik, A. Derivatives of graphene oxide as potential drug carriers. J. Nanosci. Nanotechnol. 2019, 19, 2489-2492. [CrossRef]

43. Oehlke, K.; Adamiuk, M.; Behsnilian, D.; Graef, V.; Mayer-Miebach, E.; Walz, E.; Greiner, R. Potential bioavailability enhancement of bioactive compounds using food-grade engineered nanomaterials: A review of the existing evidence. Food Funct. 2014, 5, 1341-1359. [CrossRef]

44. Akhavan, S.; Assadpour, E.; Katouzian, I.; Jafari, S.M. Lipid nano scale cargos for the protection and delivery of food bioactive ingredients and nutraceuticals. Trends Food Sci. Technol. 2018, 74, 132-146. [CrossRef]

45. Kumar, D.H.L.; Sarkar, P. Encapsulation of bioactive compounds using nanoemulsions. Environ. Chem. Lett. 2018, 16, 59-70. [CrossRef]

46. Babazadeh, A.; Ghanbarzadeh, B.; Hamishehkar, H. Formulation of food grade nanostructured lipid carrier (NLC) for potential applications in medicinal-functional foods. J. Drug Deliv. Sci. Technol. 2017, 39, 50-58. [CrossRef]

47. Simoes, L.D.S.; Madalena, D.A.; Pinheiro, A.C.; Teixeira, J.A.; Vicente, A.A.; Ramos, O.L. Micro- and nano bio-based delivery systems for food applications: In vitro behavior. Adv. Colloid Interface Sci. 2017, 243, $23-45$. [CrossRef] [PubMed]

48. Goncalves, R.F.S.; Martins, J.T.; Duarte, C.M.M.; Vicente, A.A.; Pinheiro, A.C. Advances in nutraceutical delivery systems: From formulation design for bioavailability enhancement to efficacy and safety evaluation. Trends Food Sci. Technol. 2018, 78, 270-291. [CrossRef]

49. Arora, D.; Jaglan, S. Nanocarriers based delivery of nutraceuticals for cancer prevention and treatment: A review of recent research developments. Trends Food Sci. Technol. 2016, 54, 114-126. [CrossRef]

50. Katouzian, I.; Jafari, S.M. Nano-encapsulation as a promising approach for targeted delivery and controlled release of vitamins. Trends Food Sci. Technol. 2016, 53, 34-48. [CrossRef]

51. Chai, J.J.; Jiang, P.; Wang, P.J.; Jiang, Y.M.; Li, D.; Bao, W.E.; Liu, B.X.; Liu, B.; Zhao, L.Y.; Norde, W.; et al. The intelligent delivery systems for bioactive compounds in foods: Physicochemical and physiological conditions, absorption mechanisms, obstacles and responsive strategies. Trends Food Sci. Technol. 2018, 78, 144-154. [CrossRef]

52. Gleeson, J.P.; Ryan, S.M.; Brayden, D.J. Oral delivery strategies for nutraceuticals: Delivery vehicles and absorption enhancers. Trends Food Sci. Technol. 2016, 53, 90-101. [CrossRef]

53. Jafari, S.M.; Assaidpoor, E.; Bhandari, B.; He, Y.H. Nano-particle encapsulation of fish oil by spray drying. Food Res. Int. 2008, 41, 172-183. [CrossRef]

54. Li, Q.; Li, T.; Liu, C.M.; Dai, T.T.; Zhang, R.J.; Zhang, Z.P.; McClements, D.J. Enhancement of carotenoid bioaccessibility from tomatoes using excipient emulsions: Influence of particle size. Food Biophys. 2017, 12, 172-185. [CrossRef]

55. Bioinicia, Valencia, Spain. Available online: https://bioinicia.com/electrospinning-electrosprayingtechnology (accessed on 13 February 2019).

56. Lagaron, J.M. Multifunctional and Nanoreinforced Polymers for Food Packaging; Woodhead Publishing: Cambridge, UK, 2011. 
57. Bhushani, J.A.; Anandharamakrishnan, C. Electrospinning and electrospraying techniques: Potential food based applications. Trends Food Sci. Technol. 2014, 38, 21-33. [CrossRef]

58. Torres-Giner, S.; Martinez-Abad, A.; Ocio, M.J.; Lagaron, J.M. Stabilization of a nutraceutical omega-3 fatty acid by encapsulation in ultrathin electrosprayed zein prolamine. J. Food. Sci. 2010, 75, N69-N79. [CrossRef] [PubMed]

59. Perez-Masia, R.; Lopez-Nicolas, R.; Periago, M.J.; Ros, G.; Lagaron, J.M.; Lopez-Rubio, A. Encapsulation of folic acid in food hydrocolloids through nanospray drying and electrospraying for nutraceutical applications. Food Chem. 2015, 168, 124-133. [CrossRef]

60. Nagarajan, S.; Soussan, L.; Bechelany, M.; Teyssier, C.; Cavailles, V.; Pochat-Bohatier, C.; Miele, P.; Kalkura, N.; Janota, J.M.; Balme, S. Novel biocompatible electrospun gelatin fiber mats with antibiotic drug delivery properties. J. Mater. Chem. B 2016, 4, 1134-1141. [CrossRef]

61. Khorasani, S.; Danaei, M.; Mozafari, M.R. Nanoliposome technology for the food and nutraceutical industries. Trends Food Sci. Technol. 2018, 79, 106-115. [CrossRef]

62. Ghanbarzadeh, B.; Babazadeh, A.; Hamishehkar, H. Nano-phytosome as a potential food-grade delivery system. Food Biosci. 2016, 15, 126-135. [CrossRef]

63. Babazadeh, A.; Ghanbarzadeh, B.; Hamishehkar, H. Phosphatidylcholine-rutin complex as a potential nanocarrier for food applications. J. Funct. Foods 2017, 33, 134-141. [CrossRef]

64. Bochicchio, S.; Barba, A.A.; Grassi, G.; Lamberti, G. Vitamin delivery: Carriers based on nanoliposomes produced via ultrasonic irradiation. LWT Food Sci. Technol. 2016, 69, 9-16. [CrossRef]

65. Azzi, J.; Jraij, A.; Auezova, L.; Fourmentin, S.; Greige-Gerges, H. Novel findings for quercetin encapsulation and preservation with cyclodextrins, liposomes, and drug-in-cyclodextrin-in-liposomes. Food Hydrocoll. 2018, 81, 328-340. [CrossRef]

66. Li, Z.L.; Peng, S.F.; Chen, X.; Zhu, Y.Q.; Zou, L.Q.; Liu, W.; Liu, C.M. Pluronics modified liposomes for curcumin encapsulation: Sustained release, stability and bioaccessibility. Food Res. Int. 2018, 108, $246-253$. [CrossRef]

67. Semenova, M.G.; Antipova, A.S.; Zelikina, D.V.; Martirosova, E.I.; Plashchina, I.G.; Palmina, N.P.; Binyukov, V.I.; Bogdanova, N.G.; Kasparov, V.V.; Shumilina, E.A. Biopolymer nanovehicles for essential polyunsaturated fatty acids: Structure-functionality relationships. Food Res. Int. 2016, 88, 70-78. [CrossRef] [PubMed]

68. Dey, T.K.; Banerjee, P.; Chatterjee, R.; Dhar, P. Designing of $\omega-3$ PUFA enriched biocompatible nanoemulsion with sesame protein isolate as a natural surfactant: Focus on enhanced shelf-life stability and biocompatibility. Colloids Surf. A Physicochem. Eng. Asp. 2018, 538, 36-44. [CrossRef]

69. Hategekimana, J.; Chamba, M.V.M.; Shoemaker, C.F.; Majeed, H.; Zhong, F. Vitamin E nanoemulsions by emulsion phase inversion: Effect of environmental stress and long-term storage on stability and degradation in different carrier oil types. Colloids Surf. A Physicochem. Eng. Asp. 2015, 483, 70-80. [CrossRef]

70. Guttoff, M.; Saberi, A.H.; McClements, D.J. Formation of vitamin D nanoemulsion-based delivery systems by spontaneous emulsification: Factors affecting particle size and stability. Food Chem. 2015, 171, 117-122. [CrossRef] [PubMed]

71. Salvia-Trujillo, L.; McClements, D.J. Improvement of $\beta$-carotene bioaccessibility from dietary supplements using excipient nanoemulsions. J. Agric. Food Chem. 2016, 64, 4639-4647. [CrossRef] [PubMed]

72. Liu, X.J.; Zhang, R.J.; McClements, D.J.; Li, F.; Liu, H.; Cao, Y.; Xiao, H. Nanoemulsion-based delivery systems for nutraceuticals: Influence of long-chain triglyceride (LCT) type on in vitro digestion and astaxanthin bioaccessibility. Food Biophys. 2018, 13, 412-421. [CrossRef]

73. Saxena, V.; Hasan, A.; Sharma, S.; Pandey, L.M. Edible oil nanoemulsion: An organic nanoantibiotic as a potential biomolecule delivery vehicle. Int. J. Polym. Mater. 2018, 67, 410-419. [CrossRef]

74. Parthasarathi, S.; Muthukumar, S.P.; Anandharamakrishnan, C. The influence of droplet size on the stability, in vivo digestion, and oral bioavailability of vitamin E emulsions. Food Funct. 2016, 7, 2294-2302. [CrossRef]

75. Ozturk, B.; Argin, S.; Ozilgen, M.; McClements, D.J. Formation and stabilization of nanoemulsion-based vitamin E delivery systems using natural surfactants: Quillaja saponin and lecithin. J. Food Eng. 2014, 142, 57-63. [CrossRef]

76. Peng, S.F.; Li, Z.L.; Zou, L.Q.; Liu, W.; Liu, C.M.; McClements, D.J. Improving curcumin solubility and bioavailability by encapsulation in saponin-coated curcumin nanoparticles prepared using a simple pH-driven loading method. Food Funct. 2018, 9, 1829-1839. [CrossRef] 
77. Zheng, B.J.; Peng, S.F.; Zhang, X.Y.; McClements, D.J. Impact of delivery system type on curcumin bioaccessibility: Comparison of curcumin-loaded nanoemulsions with commercial curcumin supplements. J. Agric. Food Chem. 2018, 66, 10816-10826. [CrossRef] [PubMed]

78. Braithwaite, M.C.; Choonara, Y.E.; Kumar, P.; Tomar, L.K.; Du Toit, L.C.; Pillay, V. A novel bile salts-lipase polymeric film-infused minitablet system for enhanced oral delivery of cholecalciferol. Pharm. Dev. Technol. 2016, 21, 832-846. [CrossRef] [PubMed]

79. Liu, F.G.; Ma, C.C.; Zhang, R.J.; Gao, Y.X.; McClements, D.J. Controlling the potential gastrointestinal fate of $\beta$-carotene emulsions using interfacial engineering: Impact of coating lipid droplets with polyphenol-protein-carbohydrate conjugate. Food Chem. 2017, 221, 395-403. [CrossRef] [PubMed]

80. Liu, X.; Bi, J.F.; Xiao, H.; McClements, D.J. Enhancement of nutraceutical bioavailability using excipient nanoemulsions: Role of lipid digestion products on bioaccessibility of carotenoids and phenolics from mangoes. J. Food Sci. 2016, 81, N754-N761. [CrossRef] [PubMed]

81. Sharifi, F.; Jahangiri, M. Investigation if the stability of vitamin D in emulsion-based delivery systems. Chem. Ind. Chem. Eng. 2018, 24, 157-167. [CrossRef]

82. Esfanjani, A.F.; Assadpour, E.; Jafari, S.M. Improving the bioavailability of phenolic compounds by loading them within lipid-based nanocarriers. Trends Food Sci. Technol. 2018, 76, 56-66. [CrossRef]

83. Gonzalez-Reza, R.M.; Quintanar-Guerrero, D.; Del Real-Lopez, A.; Pinon-Segundo, E.; Zambrano-Zaragoza, M.L. Effect of sucrose concentration and $\mathrm{pH}$ onto the physical stability of $\beta$-carotene nanocapsules. LWT-Food Sci. Technol. 2018, 90, 354-361. [CrossRef]

84. Dan, N. Compound release from nanostructured lipid carriers (NLCs). J. Food Eng. 2016, 171, $37-43$. [CrossRef]

85. Kong, R.; Xia, Q.; Liu, G.Y. Preparation and characterization of vitamin A palmitate-loaded nanostructured lipid carriers as delivery systems for food products. Adv. Mater. Res. 2011, 236-238, 1818-1823. [CrossRef]

86. Paucar, O.C.; Tulini, F.L.; Thomazini, M.; Balieiro, J.C.C.; Pallone, E.M.J.A.; Favaro-Trindade, C.S. Production by spray chilling and characterization of solid lipid microparticles loaded with vitamin $\mathrm{D}_{3}$. Food Bioprod. Process. 2016, 100, 344-350. [CrossRef]

87. Ramalingam, P.; Yoo, S.W.; Ko, Y.T. Nanodelivery systems based on mucoadhesive polymer coated solid lipid nanoparticles to improve the oral intake of food curcumin. Food Res. Int. 2016, 84, 113-119. [CrossRef]

88. Nunes, S.; Madureira, A.R.; Campos, D.; Sarmento, B.; Gomes, A.M.; Pintado, M.; Reis, F. Solid lipid nanoparticles as oral delivery systems of phenolic compounds: Overcoming pharmacokinetic limitations for nutraceutical applications. Crit. Rev. Food Sci. Nutr. 2017, 57, 1863-1873. [CrossRef] [PubMed]

89. Sampathkumar, K.; Loo, S.C.J. Targeted gastrointestinal delivery of nutraceuticals with polysaccharide-based coatings. Macromol. Biosci. 2018, 18, 1700363. [CrossRef] [PubMed]

90. Hasanvand, E.; Fathi, M.; Bassiri, A. Production and characterization of vitamin $\mathrm{D}_{3}$ loaded starch nanoparticles: Effect of amylose to amylopectin ratio and sonication parameters. J. Food Sci. Tech. Mys. 2018, 55, 1314-1324. [CrossRef] [PubMed]

91. Hategekirnana, J.; Masamba, K.G.; Ma, J.G.; Zhong, F. Encapsulation of vitamin E: Effect of physicochemical properties of wall material on retention and stability. Carbohydr. Polym. 2015, 124, 172-179. [CrossRef] [PubMed]

92. Khan, A.; Wen, Y.B.; Huq, T.; Ni, Y.H. Cellulosic nanomaterials in food and nutraceutical applications: A review. J. Agric. Food Chem. 2018, 66, 8-19. [CrossRef]

93. Huq, T.; Fraschini, C.; Khan, A.; Riedl, B.; Bouchard, J.; Lacroix, M. Alginate based nanocomposite for microencapsulation of probiotic: Effect of cellulose nanocrystal (CNC) and lecithin. Carbohydr. Polym. 2017, 168, 61-69. [CrossRef]

94. Guo, C.J.; Yin, J.G.; Chen, D.Q. Co-encapsulation of curcumin and resveratrol into novel nutraceutical hyalurosomes nano-food delivery system based on oligo-hyaluronic acid-curcumin polymer. Carbohydr. Polym. 2018, 181, 1033-1037. [CrossRef]

95. Xia, S.Q.; Tan, C.; Xue, J.; Lou, X.W.; Zhang, X.M.; Feng, B.A. Chitosan/tripolyphosphate-nanoliposomes core-shell nanocomplexes as vitamin E carriers: Shelf-life and thermal properties. Int. J. Food Sci. Technol. 2014, 49, 1367-1374. [CrossRef]

96. Ge, J.; Yue, P.X.; Chi, J.P.; Liang, J.; Gao, X.L. Formation and stability of anthocyanins-loaded nanocomplexes prepared with chitosan hydrochloride and carboxymethyl chitosan. Food Hydrocoll. 2018, 74, $23-31$. [CrossRef] 
97. Acevedo-Fani, A.; Soliva-Fortuny, R.; Martin-Belloso, O. Photo-protection and controlled release of folic acid using edible alginate/chitosan nanolaminates. J. Food Eng. 2018, 229, 72-82. [CrossRef]

98. Sun, Q.C.; Zhang, Z.P.; Zhang, R.J.; Gao, R.C.; McClements, D.J. Development of functional or medical foods for oral administration of insulin for diabetes treatment: Gastroprotective edible microgels. J. Agric. Food Chem. 2018, 66, 4820-4826. [CrossRef] [PubMed]

99. Papagiannopoulos, A.; Vlassi, E. Stimuli-responsive nanoparticles by thermal treatment of bovine serum albumin inside its complexes with chondroitin sulfate. Food Hydrocoll. 2019, 87, 602-610. [CrossRef]

100. Dai, L.; Wei, Y.; Sun, C.X.; Mao, L.K.; McClements, D.J.; Gao, Y.X. Development of protein-polysaccharide-surfactant ternary complex particles as delivery vehicles for curcumin. Food Hydrocoll. 2018, 85, 75-85. [CrossRef]

101. Fathi, M.; Donsi, F.; McClements, D.J. Protein-based delivery systems for the nanoencapsulation of food ingredients. Compr. Rev. Food Sci. 2018, 17, 920-936. [CrossRef]

102. Ramos, O.L.; Pereira, R.N.; Martins, A.; Rodrigues, R.; Fucinos, C.; Teixeira, J.A.; Pastrana, L.; Malcata, F.X.; Vicente, A.A. Design of whey protein nanostructures for incorporation and release of nutraceutical compounds in food. Crit. Rev. Food Sci. Nutr. 2017, 57, 1377-1393. [CrossRef] [PubMed]

103. Parthasarathi, S.; Anandharamakrishnan, C. Enhancement of oral bioavailability of vitamin $\mathrm{E}$ by spray-freeze drying of whey protein microcapsules. Food Bioprod. Process. 2016, 100, 469-476.

104. Cheng, C.J.; Ferruzzi, M.; Jones, O.G. Fate of lutein-containing zein nanoparticles following simulated gastric and intestinal digestion. Food Hydrocoll. 2019, 87, 229-236. [CrossRef]

105. Arzeni, C.; Perez, O.E.; LeBlanc, J.G.; Pilosof, A.M.R. Egg albumin-folic acid nanocomplexes: Performance as a functional ingredient and biological activity. J. Funct. Foods 2015, 18, 379-386. [CrossRef]

106. Zema, P.; Pilosof, A.M.R. On the binding of folic acid to food proteins performing as vitamin micro/nanocarriers. Food Hydrocoll. 2018, 79, 509-517. [CrossRef]

107. Madalena, D.A.; Ramos, O.L.; Pereira, R.N.; Bourbon, A.I.; Pinheiro, A.C.; Malcata, F.X.; Teixeira, J.A.; Vicente, A.A. In vitro digestion and stability assessment of $\beta$-lactoglobulin/riboflavin nanostructures. Food Hydrocoll. 2016, 58, 89-97. [CrossRef]

108. Ochnio, M.E.; Martinez, J.H.; Allievi, M.C.; Palavecino, M.; Martinez, K.D.; Perez, O.E. Proteins as nano-carriers for bioactive compounds. The case of 7S and 11S soy globulins and folic acid complexation. Polymers 2018, 10, 149. [CrossRef]

109. Rubio, A.P.D.; Martinez, J.H.; Casillas, D.C.M.; Leskow, F.C.; Piuri, M.; Perez, O.E. Lactobacillus casei BL23 produces microvesicles carrying proteins that have been associated with its probiotic effect. Front. Microbiol. 2017, 8, 1783. [CrossRef] [PubMed]

110. Peng, S.F.; Li, Z.L.; Zou, L.Q.; Liu, W.; Liu, C.M.; McClements, D.J. Enhancement of curcumin bioavailability by encapsulation in sophorolipid-coated nanoparticles: An in vitro and in vivo study. J. Agric. Food Chem. 2018, 66, 1488-1497. [CrossRef]

111. Liu, G.Y.; Huang, W.J.; Babii, O.; Gong, X.Y.; Tian, Z.G.; Yang, J.Q.; Wang, Y.X.; Jacobs, R.L.; Donna, V.; Lavasanifar, A.; et al. Novel protein-lipid composite nanoparticles with an inner aqueous compartment as delivery systems of hydrophilic nutraceutical compounds. Nanoscale 2018, 10, 10629-10640. [CrossRef]

112. Lin, Y.; Wang, Y.H.; Yang, X.Q.; Guo, J.; Wang, J.M. Corn protein hydrolysate as a novel nano-vehicle: Enhanced physicochemical stability and in vitro bioaccessibility of vitamin $\mathrm{D}_{3}$. LWT Food Sci. Technol. 2016, 72, 510-517. [CrossRef]

113. David, S.; Livney, Y.D. Potato protein based nanovehicles for health promoting hydrophobic bioactives in clear beverages. Food Hydrocoll. 2016, 57, 229-235. [CrossRef]

114. Cohen, Y.; Levi, M.; Lesmes, U.; Margier, M.; Reboul, E.; Livney, Y.D. Re-assembled casein micelles improve in vitro bioavailability of vitamin D in a Caco-2 cell model. Food Funct. 2017, 8, 2133-2141. [CrossRef]

115. Ghayour, N.; Hosseini, S.M.H.; Eskandari, M.H.; Esteghlal, S.; Nekoei, A.R.; Gahruie, H.H.; Tatar, M.; Naghibalhossaini, F. Nanoencapsulation of quercetin and curcumin in casein-based delivery systems. Food Hydrocoll. 2019, 87, 394-403. [CrossRef]

116. Yerramilli, M.; Longmore, N.; Ghosh, S. Stability and bioavailability of curcumin in mixed sodium caseinate and pea protein isolate nanoemulsions. J. Am. Oil Chem. Soc. 2018, 95, 1013-1026. [CrossRef]

117. Moeller, H.; Martin, D.; Schrader, K.; Hoffmann, W.; Lorenzen, P.C. Spray- or freeze-drying of casein micelles loaded with vitamin D2: Studies on storage stability and in vitro digestibility. LWT-Food Sci. Technol. 2018, 97, 87-93. [CrossRef] 
118. Penalva, R.; Esparza, I.; Agueeros, M.; Gonzalez-Navarro, C.J.; Gonzalez-Ferrero, C.; Irache, J.M. Casein nanoparticles as carriers for the oral delivery of folic acid. Food Hydrocoll. 2015, 44, 399-406. [CrossRef]

119. Trofimov, A.D.; Ivanova, A.A.; Zyuzin, M.V.; Timin, A.S. Porous inorganic carriers based on silica, calcium carbonate and calcium phosphate for controlled/modulated drug delivery: Fresh outlook and future perspectives. Pharmaceutics 2018, 10, 167. [CrossRef] [PubMed]

120. Sayed, E.; Haj-Ahmad, R.; Ruparelia, K.; Arshad, M.S.; Chang, M.W.; Ahmad, Z. Porous inorganic drug delivery systems-A review. AAPS PharmSciTech 2017, 18, 1507-1525. [CrossRef] [PubMed]

121. Mishra, G.; Dash, B.; Pandey, S. Layered double hydroxides: A brief review from fundamentals to application as evolving biomaterials. Appl. Clay Sci. 2018, 153, 172-186. [CrossRef]

122. Perez-Esteve, E.; Ruiz-Rico, M.; de la Torre, C.; Villaescusa, L.A.; Sancenon, F.; Marcos, M.D.; Amoros, P.; Martinez-Manez, R.; Barat, J.M. Encapsulation of folic acid in different silica porous supports: A comparative study. Food Chem. 2016, 196, 66-75. [CrossRef] [PubMed]

123. Perez-Esteve, E.; Fuentes, A.; Coll, C.; Acosta, C.; Bernardos, A.; Amoros, P.; Marcos, M.D.; Sancenon, F.; Martinez-Manez, R.; Barat, J.M. Modulation of folic acid bioaccessibility by encapsulation in $\mathrm{pH}$-responsive gated mesoporous silica particles. Micropor. Mesopor. Mater. 2015, 202, 124-132. [CrossRef]

124. Perez-Esteve, E.; Ruiz-Rico, M.; Fuentes, A.; Marcos, M.D.; Sancenon, F.; Martinez-Manez, R.; Barat, J.M. Enrichment of stirred yogurts with folic acid encapsulated in $\mathrm{pH}$-responsive mesoporous silica particles: Bioaccessibility modulation and physico-chemical characterization. LWT Food Sci. Technol. 2016, 72, 351-360. [CrossRef]

125. Ruiz-Rico, M.; Perez-Esteve, E.; Lerma-Garcia, M.J.; Marcos, M.D.; Martinez-Manez, R.; Barat, J.M. Protection of folic acid through encapsulation in mesoporous silica particles included in fruit juices. Food Chem. 2017, 218, 471-478. [CrossRef]

126. Juere, E.; Florek, J.; Bouchoucha, M.; Jambhrunkar, S.; Wong, K.Y.; Popat, A.; Kleitz, F. In vitro dissolution, cellular membrane permeability, and anti-inflammatory response of resveratrol-encapsulated mesoporous silica nanoparticles. Mol. Pharm. 2017, 14, 4431-4441. [CrossRef]

127. Summerlin, N.; Qu, Z.; Pujara, N.; Sheng, Y.; Jambhrunkar, S.; McGuckin, M.; Popat, A. Colloidal mesoporous silica nanoparticles enhance the biological activity of resveratrol. Colloids Surf. B Biointerfaces 2016, 144, 1-7. [CrossRef]

128. Singh, S.; Rathi, N.; Angal, A.; Parida, P.; Rautaray, D. Biofortification of food with minerals and vitamins encapsulated in silica. In Nanoscience in Food and Agriculture 2. Sustainable Agriculture Reviews; Ranjan, S., Dasgupta, N., Lichtfouse, E., Eds.; Springer: Cham, Germany, 2016; Volume 21, pp. 157-206.

129. Pagano, C.; Tiralti, M.C.; Perioli, L. Nanostructured hybrids for the improvement of folic acid biopharmaceutical properties. J. Pharm. Pharmacol. 2016, 68, 1384-1395. [CrossRef] [PubMed]

130. Constantinescu-Aruxandei, D.; Frincu, R.M.; Capra, L.; Oancea, F. Selenium analysis and speciation in dietary supplements based on next-generation selenium ingredients. Nutrients 2018, 10, 1466. [CrossRef] [PubMed]

131. De Villiers, M.M. Antioxidants. In A Practical Guide to Contemporary Pharmacy Practice, 3rd ed.; Thompson, J.E., Ed.; Lippincott Williams \& Wilkins: Baltiomor, MD, USA, 2009; pp. 216-223.

132. Aditya, N.P.; Espinosa, Y.G.; Norton, I.T. Encapsulation systems for the delivery of hydrophilic nutraceuticals: Food application. Biotechnol. Adv. 2017, 35, 450-457. [CrossRef]

133. Pisoschi, A.M.; Pop, A.; Cimpeanu, C.; Turcus, V.; Predoi, G.; Iordache, F. Nanoencapsulation techniques for compounds and products with antioxidant and antimicrobial activity-A critical view. Eur. J. Med. Chem. 2018, 157, 1326-1345. [CrossRef]

134. Hou, M.N.; Li, Q.; Liu, X.X.; Lu, C.; Li, S.; Wang, Z.Z.; Dang, L.P. Substantial enhancement of the antioxidant capacity of an $\alpha$-linolenic acid loaded microemulsion: Chemical manipulation of the oil-water interface by carbon dots and its potential application. J. Agric. Food Chem. 2018, 66, 6917-6925. [CrossRef]

135. Kaur, K.; Kaur, J.; Kumar, R.; Mehta, S.K. Formulation and physiochemical study of $\alpha$-tocopherol based oil in water nanoemulsion stabilized with non toxic, biodegradable surfactant: Sodium stearoyl lactate. Ultrason. Sonochem. 2017, 38, 570-578. [CrossRef] [PubMed]

136. Tamjidi, F.; Shahedi, M.; Varshosaz, J.; Nasirpour, A. Stability of astaxanthin-loaded nanostructured lipid carriers in beverage systems. J. Sci. Food Agric. 2018, 98, 511-518. [CrossRef] 
137. Liu, F.G.; Ma, D.; Luo, X.; Zhang, Z.Y.; He, L.L.; Gao, Y.X.; McClements, D.J. Fabrication and characterization of protein-phenolic conjugate nanoparticles for co-delivery of curcumin and resveratrol. Food Hydrocoll. 2018, 79, 450-461. [CrossRef]

138. Tapia-Hernandez, J.A.; Rodriguez-Felix, F.; Juarez-Onofre, J.E.; Ruiz-Cruz, S.; Robles-Garcia, M.A.; Borboa-Flores, J.; Wong-Corral, F.J.; Cinco-Moroyoqui, F.J.; Castro-Enriquez, D.D.; Del-Toro-Sanchez, C.L. Zein-polysaccharide nanoparticles as matrices for antioxidant compounds: A strategy for prevention of chronic degenerative diseases. Food Res. Int. 2018, 111, 451-471. [CrossRef]

139. Paulo, F.; Santos, L. Inclusion of hydroxytyrosol in ethyl cellulose microparticles: In vitro release studies under digestion conditions. Food Hydrocoll. 2018, 84, 104-116. [CrossRef]

140. Hu, Y.; Zhang, W.; Ke, Z.; Li, Y.; Zhou, Z. In vitro release and antioxidant activity of Satsuma mandarin (Citrus reticulata Blanco cv. unshiu) peel flavonoids encapsulated by pectin nanoparticles. Int. J. Food Sci. Technol. 2017, 52, 2362-2373. [CrossRef]

141. Huang, X.X.; Huang, X.L.; Gong, Y.S.; Xiao, H.; McClements, D.J.; Hu, K. Enhancement of curcumin water dispersibility and antioxidant activity using core-shell protein-polysaccharide nanoparticles. Food Res. Int. 2016, 87, 1-9. [CrossRef] [PubMed]

142. Jiao, Z.; Wang, X.D.; Yin, Y.T.; Xia, J.X.; Mei, Y.N. Preparation and evaluation of a chitosan-coated antioxidant liposome containing vitamin C and folic acid. J. Microencapsul. 2018, 35, 272-280. [CrossRef] [PubMed]

143. Silva, H.D.; Poejo, J.; Pinheiro, A.C.; Donsi, F.; Serra, A.T.; Duarte, C.M.M.; Ferrari, G.; Cerqueira, M.A.; Vicente, A.A. Evaluating the behaviour of curcumin nanoemulsions and multilayer nanoemulsions during dynamic in vitro digestion. J. Funct. Foods 2018, 48, 605-613. [CrossRef]

144. Kunwar, A.; Priyadarsini, K.I. Free radicals, oxidative stress and importance of antioxidants in human health. J. Med. Allied. Sci. 2011, 1, 53-60.

145. Pizzino, G.; Irrera, N.; Cucinotta, M.; Pallio, G.; Mannino, F.; Arcoraci, V.; Squadrito, F.; Altavilla, D.; Bitto, A. Oxidative stress: Harms and benefits for human health. Oxid. Med. Cell. Longev. 2017, 2017, 8416763. [CrossRef]

146. Galati, G.; Sabzevari, O.; Wilson, J.X.; O’Brien, P.J. Prooxidant activity and cellular effects of the phenoxyl radicals of dietary flavonoids and other polyphenolics. Toxicology 2002, 177, 91-104. [CrossRef]

147. Herbert, V. The antioxidant supplement myth. Am. J. Clin. Nutr. 1994, 60, 157-168. [CrossRef]

148. Chan, T.S.; Galati, G.; Pannala, A.S.; Rice-Evans, C.; O’Brien, P.J. Simultaneous detection of the antioxidant and pro-oxidant activity of dietary polyphenolics in a peroxidase system. Free Radic Res. 2003, 37, 787-794. [CrossRef]

149. Rezaei, A.; Fathi, M.; Jafari, S.M. Nanoencapsulation of hydrophobic and low-soluble food bioactive compounds within different nanocarriers. Food Hydrocoll. 2019, 88, 146-162. [CrossRef]

150. Aadinath, W.; Bhushani, A.; Anandharamakrishnan, C. Synergistic radical scavenging potency of curcumin-in- $\beta$-cyclodextrin-in-nanomagnetoliposomes. Mater. Sci. Eng. C Mater. Biol. Appl. 2016, 64, 293-302. [CrossRef] [PubMed]

151. Yi, J.; Li, Y.; Zhong, F.; Yokoyama, W. The physicochemical stability and in vitro bioaccessibility of $\beta$-carotene in oil-in-water sodium caseinate emulsions. Food Hydrocoll. 2014, 35, 19-27. [CrossRef]

152. Mao, L.K.; Wang, D.; Liu, F.G.; Gao, Y.X. Emulsion design for the delivery of beta-carotene in complex food systems. Crit. Rev. Food Sci. Nutr. 2018, 58, 770-784. [CrossRef] [PubMed]

153. Brito-Oliveira, T.C.; Molina, C.V.; Netto, F.M.; Pinho, S.C. Encapsulation of $\beta$-carotene in lipid microparticles stabilized with hydrolyzed soy protein isolate: Production parameters, $\alpha$-tocopherol coencapsulation and stability under stress conditions. J. Food Sci. 2017, 82, 659-669. [CrossRef] [PubMed]

154. Wang, W.Y.; Sun, C.X.; Mao, L.K.; Ma, P.H.; Liu, F.G.; Yang, J.; Gao, Y.X. The biological activities, chemical stability, metabolism and delivery systems of quercetin: A review. Trends Food Sci. Technol. 2016, 56, 21-38. [CrossRef]

155. Zhang, J.M.; Wang, D.; Wu, Y.H.; Li, W.; Hu, Y.; Zhao, G.; Fu, C.M.; Fu, S.; Zou, L. Lipid-polymer hybrid nanoparticles for oral delivery of tartary buckwheat flavonoids. J. Agric. Food Chem. 2018, 66, 4923-4932. [CrossRef]

156. Tavakoli, H.; Hosseini, O.; Jafari, S.M.; Katouzian, I. Evaluation of physicochemical and antioxidant properties of yogurt enriched by olive leaf phenolics within nanoliposomes. J. Agric. Food Chem. 2018, 66, 9231-9240. [CrossRef] 
157. Huang, X.L.; Dai, Y.Q.; Cai, J.X.; Zhong, N.J.; Xiao, H.; McClements, D.J.; Hu, K. Resveratrol encapsulation in core-shell biopolymer nanoparticles: Impact on antioxidant and anticancer activities. Food Hydrocoll. 2017, 64, 157-165. [CrossRef]

158. Liu, Y.X.; Fan, Y.T.; Gao, L.Y.; Zhang, Y.Z.; Yi, J. Enhanced pH and thermal stability, solubility and antioxidant activity of resveratrol by nanocomplexation with $\alpha$-lactalbumin. Food Funct. 2018, 9, 4781-4790. [CrossRef]

159. Alarcon-Alarcon, C.; Inostroza-Riquelme, M.; Torres-Gallegos, C.; Araya, C.; Miranda, M.; Sanchez-Caamano, J.C.; Moreno-Villoslada, I.; Oyarzun-Ampuero, F.A. Protection of astaxanthin from photodegradation by its inclusion in hierarchically assembled nano and microstructures with potential as food. Food Hydrocoll. 2018, 83, 36-44. [CrossRef]

160. Tamjidi, F.; Shahedi, M.; Varshosaz, J.; Nasirpour, A. Stability of astaxanthin-loaded nanostructured lipid carriers as affected by $\mathrm{pH}$, ionic strength, heat treatment, simulated gastric juice and freeze-thawing. J. Food Sci. Tech. Mysore 2017, 54, 3132-3141. [CrossRef] [PubMed]

161. Khader, M.; Eckl, P.M. Thymoquinone: An emerging natural drug with a wide range of medical applications. Iran. J. Basic. Med. Sci. 2014, 17, 950-957. [PubMed]

162. El-Far, A.H.; Al Jaouni, S.K.; Li, W.K.; Mousa, S.A. Protective roles of thymoquinone nanoformulations: Potential nanonutraceuticals in human diseases. Nutrients 2018, 10, 1369. [CrossRef] [PubMed]

163. De Farias, S.S.; Siqueira, S.M.C.; Cunha, A.P.; de Souza, C.A.G.; Fontenelle, R.O.D.; de Araujo, T.G.; de Amorim, A.F.V.; de Menezes, J.E.S.A.; de Morais, S.M.; Ricardo, N.M.P.S. Microencapsulation of riboflavin with galactomannan biopolymer and F127: Physico-chemical characterization, antifungal activity and controlled release. Ind. Crops Prod. 2018, 118, 271-281. [CrossRef]

164. Cheong, A.M.; Tan, K.W.; Tan, C.P.; Nyam, K.L. Kenaf (Hibiscus cannabinus L.) seed oil-in-water pickering nanoemulsions stabilised by mixture of sodium caseinate, Tween 20 and $\beta$-cyclodextrin. Food Hydrocolloids 2016, 52, 934-941. [CrossRef]

165. Pandey, K.R.; Naik, S.R.; Vakil, B.V. Probiotics, prebiotics and synbiotics-A review. J. Food Sci. Technol. 2015, 52, 7577-7587. [CrossRef] [PubMed]

166. Markowiak, P.; Slizewska, K. Effects of probiotics, prebiotics, and synbiotics on human health. Nutrients 2017, 9, 1021. [CrossRef] [PubMed]

167. Kerry, R.G.; Patra, J.K.; Gouda, S.; Park, Y.; Shin, H.S.; Das, G. Benefaction of probiotics for human health: A review. J. Food Drug Anal. 2018, 26, 927-939. [CrossRef]

168. Gbassi, G.K.; Vandamme, T. Probiotic encapsulation technology: From microencapsulation to release into the gut. Pharmaceutics 2012, 4, 149-163. [CrossRef]

169. Sathyabama, S.; Kumar, M.R.; Devi, P.B.; Vijayabharathi, R.; Priyadharisini, V.B. Co-encapsulation of probiotics with prebiotics on alginate matrix and its effect on viability in simulated gastric environment. Food Sci. Technol. 2014, 57, 419-425. [CrossRef]

170. Kuo, S.M.; Merhige, P.M.; Hagey, L.R. The effect of dietary prebiotics and probiotics on body weight, large intestine indices, and fecal bile acid profile in wild type and IL10-/- mice. PLOS ONE 2013, 8, 60270. [CrossRef] [PubMed]

171. Yao, M.F.; Li, B.; Ye, H.W.; Huang, W.H.; Luo, Q.X.; Xiao, H.; McClements, D.J.; Li, L.J. Enhanced viability of probiotics (Pediococcus pentosaceus Li05) by encapsulation in microgels doped with inorganic nanoparticles. Food Hydrocoll. 2018, 83, 246-252. [CrossRef]

172. Atia, A.; Gomaa, A.; Fliss, I.; Beyssac, E.; Garrait, G.; Subirade, M. A prebiotic matrix for encapsulation of probiotics: Physicochemical and microbiological study. J. Microencapsul. 2016, 33, 89-101. [CrossRef] [PubMed]

173. Peredo, A.G.; Beristain, C.I.; Pascual, L.A.; Azuara, E.; Jimenez, M. The effect of prebiotics on the viability of encapsulated probiotic bacteria. Food Sci. Technol. 2016, 73, 191-196. [CrossRef]

174. Mishra, S.S.; Behera, P.K.; Kar, B.; Ray, R.C. Advances in probiotics, prebiotics and nutraceuticals. In Innovations in Technologies for Fermented Food and Beverage Industries; Panda, S., Shetty, P., Eds.; Springer: Cham, Germany, 2018; pp. 121-141.

175. Salami, A.; Seydi, E.; Pourahmad, J. Use of nutraceuticals for prevention and treatment of cancer. Iran. J. Pharm. Res. 2013, 12, 219-220. [PubMed]

176. Lefranc, F.; Tabanca, N.; Kiss, R. Assessing the anticancer effects associated with food products and/or nutraceuticals using in vitro and in vivo preclinical development-related pharmacological tests. Sem. Cancer Biol. 2017, 46, 14-32. [CrossRef] [PubMed] 
177. Fritz, H.; Seely, D.; Flower, G.; Skidmore, B.; Fernandes, R.; Vadeboncoeur, S.; Kennedy, D.; Cooley, K.; Wong, R.; Sagar, S.; et al. Soy, red clover, and isoflavones and breast cancer: A systematic review. PLoS ONE 2013, 8, e81968. [CrossRef]

178. Lotha, R.; Sivasubramanian, A. Flavonoids nutraceuticals in prevention and treatment of cancer: A review. Asian J. Pharm. Clin. Res. 2018, 11, 42-47. [CrossRef]

179. Chikwere, P. Functional foods and nutraceuticals, wonders in cancer risks-A review. World Sci. News 2017, 64, 18-33.

180. Wargovich, M.J.; Morris, J.; Brown, V.; Ellis, J.; Logothetis, B.; Weber, R. Nutraceutical use in late-stage cancer. Cancer Metastasis Rev. 2010, 29, 503-510. [CrossRef] [PubMed]

181. McClements, D.J.; Xiao, H. Designing food structure and composition to enhance nutraceutical bioactivity to support cancer inhibition. Semin. Cancer Biol. 2017, 46, 215-226. [CrossRef] [PubMed]

182. Liu, L.; Gao, Y.X.; McClements, D.J.; Decker, E.A. Role of continuous phase protein, (-)-epigallocatechin-3-gallate and carrier oil on beta-carotene degradation in oil-in-water emulsions. Food Chem. 2016, 210, 242-248. [CrossRef]

183. Granja, A.; Frias, I.; Neves, A.R.; Pinheiro, M.; Reis, S. Therapeutic potential of epigallocatechin gallate nanodelivery systems. Biomed. Res. Int. 2017, 2017, 5813793. [CrossRef]

184. Hu, K.; Huang, X.X.; Gao, Y.Q.; Huang, X.L.; Xiao, H.; McClements, D.J. Core-shell biopolymer nanoparticle delivery systems: Synthesis and characterization of curcumin fortified zein-pectin nanoparticles. Food Chem. 2015, 182, 275-281. [CrossRef] [PubMed]

185. Quagliariello, V.; Vecchione, R.; Coppola, C.; Di Cicco, C.; De Capua, A.; Piscopo, G.; Paciello, R.; Narciso, V.; Formisano, C.; Taglialatela-Scafati, O.; et al. Cardioprotective effects of nanoemulsions loaded with anti-inflammatory nutraceuticals against doxorubicin-induced cardiotoxicity. Nutrients 2018, 10, 1304. [CrossRef] [PubMed]

186. Meghani, N.; Patel, P.; Kansara, K.; Ranjan, S.; Dasgupta, N.; Ramalingam, C.; Kumar, A. Formulation of vitamin D encapsulated cinnamon oil nanoemulsion: Its potential anti-cancerous activity in human alveolar carcinoma cells. Colloids Surf. B Biointerfaces 2018, 166, 349-357. [CrossRef] [PubMed]

187. Alaarg, A.; Jordan, N.Y.; Verhoef, J.J.F.; Metselaar, J.M.; Storm, G.; Kok, R.J. Docosahexaenoic acid liposomes for targeting chronic inflammatory diseases and cancer: An in vitro assessment. Int. J. Nanomed. 2016, 11, 5027-5040. [CrossRef] [PubMed]

188. Skibinski, C.G.; Das, A.; Chen, K.M.; Liao, J.; Manni, A.; Kester, M.; El-Bayoumy, K. A novel biologically active acid stable liposomal formulation of docosahexaenoic acid in human breast cancer cell lines. Chem. Biol. Interact. 2016, 252, 1-8. [CrossRef]

189. Gokmen, V.; Mogol, B.A.; Lumaga, R.B.; Fogliano, V.; Kaplun, Z.; Shimoni, E. Development of functional bread containing nanoencapsulated $\omega-3$ fatty acids. J. Food Eng. 2011, 105, 585-591. [CrossRef]

190. Bhatt, P.C.; Pathak, S.; Kumar, V.; Panda, B.P. Attenuation of neurobehavioral and neurochemical abnormalities in animal model of cognitive deficits of Alzheimer's disease by fermented soybean nanonutraceutical. Inflammopharmacology 2018, 26, 105-118. [CrossRef]

191. Zempleni, J.; Aguilar-Lozano, A.; Sadri, M.; Sukreet, S.; Manca, S.; Wu, D.; Zhou, F.; Mutai, E. Biological activities of extracellular vesicles and their cargos from bovine and human milk in humans and implications for infants. J. Nutr. 2017, 147, 3-10. [CrossRef] [PubMed]

192. Rigacci, S.; Stefani, M. Nutraceuticals and amyloid neurodegenerative diseases: A focus on natural phenols. Expert Rev. Neurother. 2015, 1, 41-52. [CrossRef] [PubMed]

193. Aalinkeel, R.; Kutscher, H.L.; Singh, A.; Cwiklinski, K.; Khechen, N.; Schwartz, S.A.; Prasad, P.N.; Mahajan, S.D. Neuroprotective effects of a biodegradable poly(lactic-co-glycolic acid)-ginsenoside Rg3 nanoformulation: A potential nanotherapy for Alzheimer's disease? J. Drug Target. 2018, 26, 182-193. [CrossRef] [PubMed]

194. Kumar, S.A.; Brown, L. Alginates in metabolic syndrome. In Aginates and Theirbiomedical Applications; Rehm, B.H.A., Moradali, M.F., Eds.; Springer: Singapore, 2018; Volume 11, pp. 223-235.

195. Kar, S.K.; Jansman, A.J.M.; Boeren, S.; Kruijt, L.; Smits, M.A. Protein, peptide, amino acid composition, and potential functional properties of existing and novel dietary protein sources for monogastrics. J. Anim. Sci. 2016, 94, 30-39. [CrossRef] 
196. Pham, T.M.; Ekwaru, J.P.; Mastroeni, S.S.; Mastroeni, M.F.; Loehr, S.A.; Veugelers, P.J. The effect of serum 25-hydroxyvitamin D on elevated homocysteine concentrations in participants of a preventive health program. PLoS ONE 2016, 11, 0161368. [CrossRef] [PubMed]

197. Xie, C.L.; Lee, S.S.; Choung, S.Y.; Kang, S.S.; Choi, Y.J. Preparation and optimisation of liposome-in-alginate beads containing oyster hydrolysate for sustained release. Int. J. Food Sci. Technol. 2016, 51, 2209-2216. [CrossRef]

198. Feng, T.; Wang, K.; Liu, F.F.; Ye, R.; Zhu, X.; Zhuang, H.N.; Xue, Z.M. Structural characterization and bioavailability of ternary nanoparticles consisting of amylose, $\alpha$-linoleic acid and $\beta$-lactoglobulin complexed with naringin. Int. J. Biol. Macromol. 2017, 99, 365-374. [CrossRef]

199. Mahmoud, M.H.; Badr, G.; El Shinnawy, N.A. Camel whey protein improves lymphocyte function and protects against diabetes in the offspring of diabetic mouse dams. Int. J. Immunopathol. Pharmacol. 2016, 29, 632-646. [CrossRef]

200. Paul, D.; Dey, T.K.; Mukherjee, S.; Ghosh, M.; Dhar, P. Comparative prophylactic effects of alpha-eleostearic acid rich nano and conventional emulsions in induced diabetic rats. J. Food Sci. Tech. Mysore 2014, 51, 1724-1736. [CrossRef]

201. Tarighat-Esfanjani, A.; Fallahnejad, H.; Omidi, H.; Jafarabadi, M.A.; Abbasi, M.M.; Khorram, S. The effects of natural nano-sized clinoptilolite and metformin on the levels of serum glucose, lipid profile, and minerals in rats with type 2 diabetes mellitus. Iran. Red Crescent Med. J. 2018, 20, 74365. [CrossRef]

202. Nia, B.H.; Khorram, S.; Rezazadeh, H.; Safaiyan, A.; Tarighat-Esfanjani, A. The effects of natural clinoptilolite and nano-sized clinoptilolite supplementation on glucose levels and oxidative stress in rats with type 1 diabetes. Can. J. Diabetes. 2018, 42, 31-35.

203. Hossein-Nia, B.; Khorram, S.; Rezazadeh, H.; Safaiyan, A.; Ghiasi, R.; Tarighat-Esfanjani, A. The effects of natural clinoptilolite and nano-sized clinoptilolite supplementation on lipid profile, food intakes and body weight in rats with streptozotocin-induced diabetes. Adv. Pharm. Bull. 2018, 8, 211-216. [CrossRef] [PubMed]

204. Perurnal, V.; Manickam, T.; Bang, K.S.; Velmurugan, P.; Oh, B.T. Antidiabetic potential of bioactive molecules coated chitosan nanoparticles in experimental rats. Int. J. Biol. Macromol. 2016, 92, 63-69. [CrossRef] [PubMed]

205. Liu, Y.T.; Zeng, S.G.; Liu, Y.X.; Wu, W.J.; Shen, Y.B.; Zhang, L.; Li, C.; Chen, H.; Liu, A.P.; Shen, L. Synthesis and antidiabetic activity of selenium nanoparticles in the presence of polysaccharides from Catathelasma ventricosum. Int. J. Biol. Macromol. 2018, 114, 632-639. [CrossRef]

206. Sechi, M.; Syed, D.N.; Pala, N.; Mariani, A.; Marceddu, S.; Brunetti, A.; Mukhtar, H.; Sanna, V. Nanoencapsulation of dietary flavonoid fisetin: Formulation and in vitro antioxidant and $\alpha$-glucosidase inhibition activities. Mater. Sci. Eng. C Mater. Biol. Appl. 2016, 68, 594-602. [CrossRef]

207. Bagherpour, S.; Alizadeh, A.; Ghanbarzadeh, S.; Mohammadi, M.; Hamishehkar, H. Preparation and characterization of Betasitosterol-loaded nanostructured lipid carriers for butter enrichment. Food Biosci. 2017, 20, 51-55. [CrossRef]

208. Nakada, H.; Sakae, T.; Watanabe, T.; Takahashi, T.; Fujita, K.; Tanimoto, Y.; Teranishi, M.; Kato, T.; Kawai, Y. A new osteoporosis prevention supplements-diet improve bone mineral density in ovariectomized rats on micro-CT. J. Hard Tissue Biol. 2014, 23, 1-8. [CrossRef]

209. Khashayar, P.; Keshtkar, A.; Ebrahimi, M.; Larijani, B. Nano calcium supplements: Friends or foes? J. Bone Biol. Osteoporosis 2015, 1, 32-33.

210. Park, H.S.; Jeon, B.J.; Ahn, J.; Kwak, H.S. Effects of nanocalcium supplemented milk on bone calcium metabolism in ovariectomized rats. Asian-Aust. J. Anim. Sci. 2007, 20, 1266-1271. [CrossRef]

211. Choi, H.S.; Han, J.H.; Chung, S.; Hong, Y.H.; Suh, H.J. Nano-calcium ameliorates ovariectomy-induced bone loss in female rats. Korean J. Food Sci. Anim. Res. 2013, 33, 515-521. [CrossRef]

212. Huang, S.; Chen, J.C.; Hsu, C.W.; Chang, W.H. Effects of nano calcium carbonate and nano calcium citrate on toxicity in ICR mice and on bone mineral density in an ovariectomized mice model. Nanotechnology 2009, 20, 375102. [CrossRef] [PubMed]

213. Erfanian, A.; Mirhosseini, H.; Abd Manap, M.Y.; Rasti, B.; Hair-Bejo, M. Influence of nano-size reduction on absorption and bioavailability of calcium from fortified milk powder in rats. Food Res. Int. 2014, 66, 1-11. [CrossRef] 
214. Erfanian, A.; Mirhosseini, H.; Rasti, B.; Hair-Bejo, M.; Bin Mustafa, S.; Abd Manap, M.Y. Absorption and bioavailability of nano-size reduced calcium citrate fortified milk powder in ovariectomized and ovariectomized-osteoporosis rats. J. Agric. Food Chem. 2015, 63, 5795-57804. [CrossRef]

215. Erfanian, A.; Rasti, B.; Manap, Y. Comparing the calcium bioavailability from two types of nano-sized enriched milk using in-vivo assay. Food Chem. 2017, 214, 606-613. [CrossRef] [PubMed]

216. Guo, H.H.; Hong, Z.A.; Yi, R.Z. Core-shell collagen peptide chelated calcium/calcium alginate nanoparticles from fish scales for calcium supplementation. J. Food Sci. 2015, 80, N1595-N1601. [CrossRef] [PubMed]

217. Cai, X.X.; Zhao, L.N.; Wang, S.Y.; Rao, P.F. Fabrication and characterization of the nano-composite of whey protein hydrolysate chelated with calcium. Food Funct. 2015, 6, 816-823.

218. Noor, Z. Nanohydroxyapatite application to osteoporosis management. J. Osteoporosis 2013, $2013,679025$. [CrossRef]

219. Zhang, X.; Zhu, L.; Lv, H.; Cao, Y.; Liu, Y.; Xu, Y.; Ye, W.; Wang, J. Repair of rabbit femoral condyle bone defects with injectable nanohydroxyapatite/chitosan composites. J. Mater. Sci. Mater. Med. 2012, 23, 1941-1949. [CrossRef]

220. Severin, A.V.; Mazina, S.E.; Melikhov, I.V. Physicochemical aspects of the antiseptic action of nanohydroxyapatite. Biophysics 2009, 54, 701-705. [CrossRef]

221. Chakraborty, A.P. Chicken eggshell as calcium supplement tablet. Int. J. Sci. Eng. Manag. 2016, 1, 45-49.

222. Ray, S.; Barman, A.K.; Roy, P.K.; Singh, B.K. Chicken eggshell powder as dietary calcium source in chocolate cakes. Pharma Innov. J. 2017, 6, 1-4.

223. Mijan, M.A.; Lee, Y.K.; Kwak, H.S. Effects of nanopowdered eggshell on postmenopausal osteoporosis: A rat study. Food Sci. Biotechnol. 2014, 23, 1667-1676. [CrossRef]

224. El-Shibiny, S.; Abd El-Gawad, M.A.M.; Assem, F.M.; El-Sayed, S.M. The use of nano-sized eggshell powder for calcium fortification of cow's and buffalo's milk yogurts. Acta Sci. Pol. Technol. Aliment. 2018, 17, 37-49. [PubMed]

225. Zanella, D.; Bossi, E.; Gornati, R.; Bastos, C.; Faria, N.; Bernardini, G. Iron oxide nanoparticles can cross plasma membranes. Sci. Rep. 2017, 7, 11413. [CrossRef] [PubMed]

226. Hosny, K.M.; Banjar, Z.M.; Hariri, A.H.; Hassan, A.H. Solid lipid nanoparticles loaded with iron to overcome barriers for treatment of iron deficiency anemia. Drug Des. Dev. Ther. 2015, 9, 313-320. [CrossRef] [PubMed]

227. Gornati, R.; Pedretti, E.; Rossi, F.; Cappellini, F.; Zanella, M.; Olivato, I.; Sabbioni, E.; Bernardini, G. Zerovalent $\mathrm{Fe}, \mathrm{Co}$ and Ni nanoparticle toxicity evaluated on SKOV-3 and U87 cell lines. J. Appl. Toxicol. 2016, 36, 385-393. [CrossRef]

228. Lonnerdal, B.; Bryant, A.; Liu, X.; Theil, E.C. Iron absorption from soybean ferritin in nonanemic women. Am. J. Clin. Nutr. 2006, 83, 103-107. [CrossRef]

229. Powell, J.J.; Bruggraber, S.F.A.; Faria, N.; Poots, L.K.; Hondow, N.; Pennycook, T.J.; Latunde-Dada, G.O.; Simpson, R.J.; Brown, A.P.; Pereira, D.I.A. A nano-disperse ferritin-core mimetic that efficiently corrects anemia without luminal iron redox activity. Nanomedicine 2014, 10, 1529-1538. [CrossRef]

230. Pereira, D.I.A.; Bruggraber, S.F.A.; Faria, N.; Poots, L.K.; Tagmount, M.A.; Aslam, M.F.; Frazer, D.M.; Vulpe, C.D.; Anderson, G.J.; Powell, J.J. Nanoparticulate iron(III) oxo-hydroxide delivers safe iron that is well absorbed and utilised in humans. Nanomedicine 2014, 10, 1877-1886. [CrossRef]

231. Pereira, D.I.A.; Mohammed, N.I.; Ofordile, O.; Camara, F.; Baldeh, B.; Mendy, T.; Sanyang, C.; Jallow, A.T.; Hossain, I.; Wason, J.; et al. A novel nano-iron supplement to safely combat iron deficiency and anaemia in young children: The IHAT-GUT double-blind, randomised, placebo-controlled trial protocol. Gates Open Res. 2018, 2, 48. [CrossRef] [PubMed]

232. Hilty, F.M.; Arnold, M.; Hilbe, M.; Teleki, A.; Knijnenburg, J.T.; Ehrensperger, F.; Hurrell, R.F.; Pratsinis, S.E.; Langhans, W.; Zimmermann, M.B. Iron from nanocompounds containing iron and zinc is highly bioavailable in rats without tissue accumulation. Nat. Nanotechnol. 2010, 5, 374-380. [CrossRef] [PubMed]

233. Srinivasu, B.Y.; Mitra, G.; Muralidharan, M.; Srivastava, D.; Pinto, J.; Thankachan, P.; Suresh, S.; Shet, A.; Rao, S.; Ravikumar, G.; et al. Beneficiary effect of nanosizing ferric pyrophosphate as food fortificant in iron deficiency anemia: Evaluation of bioavailability, toxicity and plasma biomarker. RSC Adv. 2015, 5, 61678-61687. [CrossRef]

234. Salaheldin, T.A.; Regheb, E.M. In-Vivo nutritional and toxicological evaluation of nano iron fortified biscuits as food supplement for iron deficient anemia. J. Nanomed. Res. 2016, 3, 00049. [CrossRef] 
235. Center for Veterinary Medicine Nanotechnology Programs. Available online: https://www.fda.gov/ ScienceResearch/SpecialTopics/Nanotechnology/ucm309682.htm (accessed on 1 December 2018).

236. Animal \& Veterinary. Available online: https://www.fda.gov/AnimalVeterinary/UCM2005229 (accessed on 1 December 2018).

237. Robinson, N.G. Nutraceuticals and Dietary Supplements. MSD Veterinary Manual. 2018. Available online: https://www.msdvetmanual.com/management-and-nutrition/complementary-andalternative-veterinary-medicine/nutraceuticals-and-dietary-supplements (accessed on 1 December 2018).

238. Valpotic, H.; Gracner, D.; Turk, R.; Duricic, D.; Vince, S.; Folnozic, I.; Lojkic, M.; Zaja, I.Z.; Bedrica, L.; Macesic, N.; et al. Zeolite clinoptilolite nanoporous feed additive for animals of veterinary importance: Potentials and limitations. Period. Biol. 2017, 119, 159-172. [CrossRef]

239. Swain, P.S.; Rao, S.B.N.; Rajendran, D.; Dominic, G.; Selvaraju, S. Nano zinc, an alternative to conventional zinc as animal feed supplement: A review. Anim. Nutr. 2016, 2, 134-141. [CrossRef] [PubMed]

240. Yan, R.; Zhang, L.; Yang, X.; Wen, C.; Zhou, Y. Bioavailability evaluation of zinc-bearing palygorskite as a zinc source for broiler chickens. Appl. Clay Sci. 2016, 119, 155-160. [CrossRef]

241. Tsai, Y.H.; Mao, S.Y.; Li, M.Z.; Huang, J.T.; Lien, T.F. Effects of nanosize zinc oxide on zinc retention, eggshell quality, immune response and serum parameters of aged laying hens. Anim. Feed Sci. Technol. 2016, 213, 99-107. [CrossRef]

242. Chrastinova, L.; Cobanova, K.; Chrenkova, M.; Polacikova, M.; Foemelova, Z.; Laukova, L.; Ondruska, A.; Pogany, S.M.; Strompfova, V.; Mlynekova, Z.; et al. Effect of dietary zinc supplementation on nutrients digestibility and fermentation characteristics of caecal content in physiological experiment with young rabbits. Slovak J. Anim. Sci. 2016, 49, 23-31.

243. Swain, P.S.; Rajendran, D.; Rao, S.B.; Dominic, G. Preparation and effects of nano mineral particle feeding in livestock: A review. Vet. World. 2015, 8, 888-891. [CrossRef]

244. Debski, B. Supplementation of pigs diet with zinc and copper as alternative to conventional antimicrobials. Pol. J. Vet. Sci. 2016, 19, 917-924. [CrossRef]

245. Yin, J.; Li, X.; Li, D.; Yue, T.; Fang, Q.; Ni, J.; Zhou, X.; Wu, G. Dietary supplementation with zinc oxide stimulates ghrelin secretion from stomach of young pigs. J. Nutr. Biochem. 2009, 20, 783-790. [CrossRef] [PubMed]

246. Li, X.; Yin, J.; Li, D.; Chen, X.; Zang, J.; Zhou, X. Dietary supplementation with zinc oxide increases Igf-I and Igf-I receptor gene expression in the small intestine of weanling piglets. J. Nutr. 2006, 136, 1786-1791. [CrossRef] [PubMed]

247. Zhou, W.; Kornegay, E.T.; Lindermann, M.D.; Swinkels, J.W.; Welten, M.K.; Wong, E.A. Stimulation of growth by intravenous injection of copper in weanling pigs. J. Anim. Sci. 2014, 72, 2395-2403. [CrossRef]

248. Jacela, J.Y.; De Rouchey, J.M.; Tokach, M.D.; Goodband, R.D.; Nelssen, J.L.; Renter, D.G.; Dritz, S.S. Feed additives for swine: Fact sheets-high dietary levels of copper and zinc for young pigs, and phytase. J. Swine Health Prod. 2010, 18, 87-92. [CrossRef]

249. Saha, U.; Fayiga, A.; Hancock, D.; Sonon, L. Selenium in animal nutrition: Deficiencies in soils and forages, requirements, supplementation and toxicity. Int. J. Appl. Agric. Sci. 2016, 2, 112-125. [CrossRef]

250. Hosnedlova, B.; Kepinska, M.; Skalickova, S.; Fernandez, C.; Ruttkay-Nedecky, B.; Peng, Q.M.; Baron, M.; Melcova, M.; Opatrilova, R.; Zidkova, J.; et al. Nano-selenium and its nanomedicine applications: A critical review. Int. J. Nanomed. 2018, 13, 2107-2128. [CrossRef] [PubMed]

251. Bai, D.P.; Lin, X.Y.; Huang, Y.F.; Zhang, X.F. Theranostics aspects of various nanoparticles in veterinary medicine. Int. J. Mol. Sci. 2018, 19, 3299. [CrossRef]

252. Hill, E.K.; Li, J. Current and future prospects for nanotechnology in animal production. J. Anim. Sci. Biotechnol. 2017, 8, 26. [CrossRef]

253. Nikonov, I.N.; Folmanis, Y.G.; Folmanis, G.E.; Kovalenko, L.V.; Laptev, G.Y.; Egorov, I.A.; Fisinin, V.I.; Tananaev, I.G. Iron nanoparticles as a food additive for poultry. Dokl. Biol. Sci. 2011, 440, 328-331. [CrossRef]

254. Izquierdo, M.S.; Ghrab, W.; Roo, J.; Hamre, K.; Hernandez-Cruz, C.M.; Bernardini, G.; Terova, G.; Saleh, R. Organic, inorganic and nanoparticles of Se, $\mathrm{Zn}$ and $\mathrm{Mn}$ in early weaning diets for gilthead seabream (Sparus aurata; Linnaeus, 1758). Aqua. Res. 2017, 48, 2852-2867. [CrossRef]

255. Chris, O.U.; Singh, N.B.; Agarwal, A. Nanoparticles as feed supplement on growth behaviour of cultured catfish (Clarias gariepinus) fingerlings. Appl. Mater. Today 2018, 5, 9076-9081. [CrossRef] 
256. Zadmajid, V.; Mohammadi, C. Dietary thyme essential oil (Thymus vulgaris) changes serum stress markers, enzyme activity, and hematological parameters in gibel carp (Carassius auratus gibelio) exposed to silver nanoparticles. Iran. J. Fish. Sci. 2017, 16, 1063-1084.

257. Rohani, S.M.; Haghighi, M.; Moghaddam, B.S. Study on nanoparticles of Aloe vera extract on growth performance, survival rate and body composition in Siberian sturgeon (Acipenser baerii). Iran. J. Fish. Sci. 2017, 16, 457-468.

258. Alishahi, A.; Mirvaghefi, A.; Tehrani, M.R.; Farahmand, H.; Koshio, S.; Dorkoosh, F.A.; Elsabee, M.Z. Chitosan nanoparticle to carry vitamin $\mathrm{C}$ through the gastrointestinal tract and induce the non-specific immunity system of rainbow trout (Oncorhynchus mykiss). Carbohydr. Polym. 2011, 86, 142-146. [CrossRef]

259. Martins, A.C.D.; Flores, J.A.; Porto, C.; Romano, L.A.; Wasielesky, J.W.; Caldas, S.S.; Primel, E.G.; Kulkamp-Guerreiro, I.; Monserrat, J.M. Antioxidant effects of nanoencapsulated lipoic acid in tissues and on the immune condition in haemolymph of Pacific white shrimp Litopenaeus vannamei (Boone, 1931). Aquac. Nutr. 2018, 24, 1255-1262. [CrossRef]

260. El Basuini, M.F.; El-Hais, A.M.; Dawood, M.A.O.; Abou-Zeid, A.E.S.; EL-Damrawy, S.Z.; Khalafalla, M.M.E.S.; Koshio, S.; Ishikawa, M.; Dossou, S. Effects of dietary copper nanoparticles and vitamin C supplementations on growth performance, immune response and stress resistance of red sea bream, Pagrus major. Aquac. Nutr. 2017, 23, 1329-1340. [CrossRef]

261. Wang, H.; Zhu, H.Y.; Wang, X.D.; Li, E.C.; Du, Z.Y.; Qin, J.G.; Chen, L.Q. Comparison of copper bioavailability in copper-methionine, nano-copper oxide and copper sulfate additives in the diet of Russian sturgeon Acipenser gueldenstaedtii. Aquaculture 2018, 482, 146-154. [CrossRef]

262. Kumar, N.; Krishnani, K.K.; Gupta, S.K.; Sharma, R.; Baitha, R.; Singh, D.K.; Singh, N.P. Immuno-protective role of biologically synthesized dietary selenium nanoparticles against multiple stressors in Pangasinodon hypophthalrnus. Fish. Shellfish Immunol. 2018, 78, 289-298.

263. Anjugam, M.; Vaseeharan, B.; Iswarya, A.; Gobi, N.; Divya, M.; Thangaraj, M.P.; Elumalai, P. Effect of $\beta-1,3$ glucan binding protein based zinc oxide nanoparticles supplemented diet on immune response and disease resistance in Oreochromis mossambicus against Aeromonas hydrophila. Fish. Shellfish Immunol. 2018, 76, 247-259. [CrossRef] [PubMed]

264. Shaphar, Z.; Johari, S.A. Effects of dietary organic, inorganic, and nanoparticulate zinc on rainbow trout, Oncorhynchus mykiss larvae. Biol. Trace Elem. Res. 2018, in press. [CrossRef]

265. Saffari, S.; Keyvanshokooh, S.; Zakeri, M.; Johari, S.A.; Pasha-Zanoosi, H.; Mozanzadeh, M.T. Effects of dietary organic, inorganic, and nanoparticulate selenium sources on growth, hemato-immunological, and serum biochemical parameters of common carp (Cyprinus carpio). Fish. Physiol. Biochem. 2018, 44, 1087-1097. [CrossRef] [PubMed]

266. Zhou, X.X.; Wang, Y.B.; Gu, Q.; Li, W.F. Effects of different dietary selenium sources (selenium nanoparticle and selenomethionine) on growth performance, muscle composition and glutathione peroxidase enzyme activity of crucian carp (Carassius auratus gibelio). Aquaculture 2009, 291, 78-81. [CrossRef]

267. Khan, K.U.; Zuberi, A.; Nazir, S.; Fernandes, J.B.K.; Jamil, Z.; Sarwar, H. Effects of dietary selenium nanoparticles on physiological and biochemical aspects of juvenile Tor putitora. Turk. J. Zool. 2016, 40, 704-712. [CrossRef]

268. Qin, F.J.; Shi, M.M.; Yuan, H.X.; Yuan, L.X.; Lu, W.H.; Zhang, J.; Tong, J.; Song, X.H. Dietary nano-selenium relieves hypoxia stress and, improves immunity and disease resistance in the Chinese mitten crab (Eriocheir sinensis). Fish. Shellfish Immunol. 2016, 54, 481-488. [CrossRef] [PubMed]

269. Naderi, M.; Keyvanshokooh, S.; Salati, A.P.; Ghaedi, A. Combined or individual effects of dietary vitamin $\mathrm{E}$ and selenium nanoparticles on humoral immune status and serum parameters of rainbow trout (Oncorhynchus mykiss) under high stocking density. Aquaculture 2017, 474, 40-47. [CrossRef]

270. Kumar, N.; Krishnani, K.K.; Singh, N.P. Effect of dietary zinc-nanoparticles on growth performance, anti-oxidative and immunological status of fish reared under multiple stressors. Biol. Trace Elem. Res. 2018, 186, 267-278. [CrossRef]

271. Gangadoo, S.; Stanley, D.; Hughes, R.J.; Moore, R.J.; Chapman, J. Nanoparticles in feed: Progress and prospects in poultry research. Trends Food Sci. Technol. 2016, 58, 115-126. [CrossRef]

272. Song, Z.G.; Lv, J.D.; Sheikhahmadi, A.; Uerlings, J.; Everaert, N. Attenuating effect of zinc and vitamin E on the intestinal oxidative stress induced by silver nanoparticles in broiler chickens. Biol. Trace Elem. Res. 2017, 180, 306-313. [CrossRef] 
273. Sawosz, F.; Pineda, L.; Hotowy, A.; Jaworski, S.; Prasek, M.; Sawosz, E.; Chwalibog, A. Nano-nutrition of chicken embryos. The effect of silver nanoparticles and ATP on expression of chosen genes involved in myogenesis. Arch. Anim. Nutr. 2013, 67, 347-355. [CrossRef]

274. Scott, A.; Vadalasetty, K.P.; Lukasiewicz, M.; Jaworski, S.; Wierzbicki, M.; Chwalibog, A.; Sawosz, E. Effect of different levels of copper nanoparticles and copper sulphate on performance, metabolism and blood biochemical profiles in broiler chicken. J. Anim. Physiol. Anim. Nutr. (Berl.) 2018, 102, E364-E373. [CrossRef] [PubMed]

275. Ognik, K.; Sembratowicz, I.; Cholewinska, E.; Jankowski, J.; Kozlowski, K.; Juskiewicz, J.; Zdunczyk, Z. The effect of administration of copper nanoparticles to chickens in their drinking water on the immune and antioxidant status of the blood. Anim. Sci. J. 2018, 89, 579-588. [CrossRef] [PubMed]

276. Joshua, P.P.; Valli, C.; Balakrishnan, V. Effect of in ovo supplementation of nano forms of zinc, copper, and selenium on post-hatch performance of broiler chicken. Vet. World 2016, 9, 287-294. [CrossRef] [PubMed]

277. Abedini, M.; Shariatmadari, F.; Torshizi, M.A.K.; Ahmadi, H. Effects of zinc oxide nanoparticles on the egg quality, immune response, zinc retention, and blood parameters of laying hens in the late phase of production. J. Anim. Physiol. Anim. Nutr. (Berl.) 2018, 102, 736-745. [CrossRef] [PubMed]

278. Mao, S.Y.; Lien, T.F. Effects of nanosized zinc oxide and -polyglutamic acid on eggshell quality and serum parameters of aged laying hens. Arch. Anim. Nutr. 2017, 71, 373. [CrossRef] [PubMed]

279. Cai, S.J.; Wu, C.X.; Gong, L.M.; Song, T.; Wu, H.; Zhang, L.Y. Effects of nano-selenium on performance, meat quality, immune function, oxidation resistance, and tissue selenium content in broilers. Poultry Sci. 2012, 91, 2532-2539. [CrossRef] [PubMed]

280. Boostani, A.; Sadeghi, A.A.; Mousavi, S.N.; Chamani, M.; Kashan, N. The effects of organic, inorganic, and nano-selenium on blood attributes in broiler chickens exposed to oxidative stress. Acta Sci. Vet. 2015, 43, 1264 .

281. Ahmadi, M.; Ahmadian, A.; Seidavi, A.R. Effect of different levels of nano-selenium on performance, blood parameters, immunity and carcass characteristics of broiler chickens. Poult. Sci. J. 2018, 6, 99-108.

282. Rahmatollah, D.; Farzinpour, A.; Vaziry, A.; Sadeghi, G. Effect of replacing dietary $\mathrm{FeSO}_{4}$ with cysteine-coated $\mathrm{Fe}_{3} \mathrm{O}_{4}$ nanoparticles on quails. Ital. J. Anim. Sci. 2018, 17, 121-127. [CrossRef]

283. Lin, Y.C.; Huang, J.T.; Li, M.Z.; Cheng, C.Y.; Lien, T.F. Effects of supplemental nanoparticle trivalent chromium on the nutrient utilization, growth performance and serum traits of broilers. J. Anim. Physiol. Anim. Nutr. (Berl.) 2015, 99, 59-65. [CrossRef]

284. Xia, T.; Lai, W.Q.; Han, M.M.; Han, M.; Ma, X.; Zhang, L.Y. Dietary ZnO nanoparticles alters intestinal microbiota and inflammation response in weaned piglets. Oncotarget 2017, 8, 64878-64891. [CrossRef] [PubMed]

285. Li, M.Z.; Huang, J.T.; Tsai, Y.H.; Mao, S.Y.; Fu, C.M.; Lien, T.F. Nanosize of zinc oxide and the effects on zinc digestibility, growth performances, immune response and serum parameters of weanling piglets. Anim. Sci. J. 2016, 87, 1379-1385. [CrossRef] [PubMed]

286. Kosla, T.; Lasocka, I.; Skibniewska, E.M.; Kolnierzak, M.; Skibniewski, M. Trivalent chromium (Cr III) as a trace element essential for animals and humans. Med. Weter. 2018, 74, 560-567.

287. Hung, A.T.; Leury, B.J.; Sabin, M.A.; Collins, C.L.; Dunshea, F.R. Dietary nano-chromium tripicolinate increases feed intake and decreases plasma cortisol in finisher gilts during summer. Trop. Anim. Health Prod. 2014, 46, 1483-1489. [CrossRef] [PubMed]

288. Wang, M.Q.; Wang, C.; Du, Y.J.; Li, H.; Tao, W.J.; Ye, S.S.; He, Y.D.; Chen, S.Y. Effects of chromium-loaded chitosan nanoparticles on growth, carcass characteristics, pork quality, and lipid metabolism in finishing pigs. Livest. Sci. 2014, 161, 123-129. [CrossRef]

289. Wang, M.Q.; Xu, Z.R.; Zha, L.Y.; Lindemann, M.D. Effects of chromium nanocomposite supplementation on blood metabolites, endocrine parameters and immune traits in finishing pigs. Anim. Feed Sci. Technol. 2007, 139, 69-80. [CrossRef]

290. Duffy, C.; O'Riordan, D.; O'Sullivan, M.; Jacquier, J.C. In vitro evaluation of chitosan copper chelate gels as a multimicronutrient feed additive for cattle. J. Sci. Food Agric. 2018, 98, 4177-4183. [CrossRef]

291. Kojouri, G.A.; Jahanabadi, S.; Shakibaie, M.; Ahadi, A.M.; Shahverdi, A.R. Effect of selenium supplementation with sodium selenite and selenium nanoparticles on iron homeostasis and transferrin gene expression in sheep: A preliminary study. Res. Vet. Sci. 2012, 93, 275-278. [CrossRef] 
292. Shi, L.G.; Xun, W.J.; Yue, W.B.; Zhang, C.X.; Ren, Y.S.; Liu, Q.A.; Wang, Q.A.; Shi, L. Effect of elemental nano-selenium on feed digestibility, rumen fermentation, and purine derivatives in sheep. Anim. Feed Sci. Technol. 2011, 163, 136-142. [CrossRef]

293. EI-Sherbiny, M.; Cieslak, A.; Szczechowiak, J.; Kolodziejski, P.; Szulc, P.; Szumacher-Strabel, M. Effect of nanoemulsified oils addition on rumen fermentation and fatty acid proportion in a rumen simulation technique. J. Anim. Feed Sci. 2016, 25, 116-124. [CrossRef]

294. Refaie, A.M.; Ghazal, M.N.; Easa, F.M.; Barakat, S.A.; Morsy, W.A.; Younan, G.E.; Eisa, W.H. Nano-copper as a new growth promoter in the diet of growing New Zealand white rabbits. Egypt. J. Rabbit Sci. 2015, 25, 39-57.

295. Hassan, F.A.M.; Mahmoud, R.; El-Araby, I.E. Growth performance, serum biochemical, economic evaluation and IL6 gene expression in growing rabbits fed diets supplemented with zinc nanoparticles. Zagazig Vet. J. 2017, 45, 238-249. [CrossRef]

296. Ismail, H.T.H.; El-Araby, I.E. Effect of dietary zinc oxide nanoparticles supplementation on biochemical, hematological and genotoxucity parameters in rabbits. Int. J. Curr. Adv. Res. 2017, 6, 2108-2115.

(C) 2019 by the authors. Licensee MDPI, Basel, Switzerland. This article is an open access article distributed under the terms and conditions of the Creative Commons Attribution (CC BY) license (http://creativecommons.org/licenses/by/4.0/). 